San Jose State University

SJSU ScholarWorks

Master's Theses

Master's Theses and Graduate Research

2000

\title{
Estimation of chlorophyll, detritus and dissolved substances from optical measurments
}

Elena Mauri

San Jose State University

Follow this and additional works at: https://scholarworks.sjsu.edu/etd_theses

\section{Recommended Citation}

Mauri, Elena, "Estimation of chlorophyll, detritus and dissolved substances from optical measurments" (2000). Master's Theses. 2102.

DOI: https://doi.org/10.31979/etd.m5mj-w2es

https://scholarworks.sjsu.edu/etd_theses/2102

This Thesis is brought to you for free and open access by the Master's Theses and Graduate Research at SJSU ScholarWorks. It has been accepted for inclusion in Master's Theses by an authorized administrator of SJSU ScholarWorks. For more information, please contact scholarworks@sjsu.edu. 


\section{INFORMATION TO USERS}

This manuscript has been reproduced from the microfilm master. UMI films the text directly from the original or copy submitted. Thus, some thesis and dissertation copies are in typewriter face, while others may be from any type of computer printer.

The quality of this reproduction is dependent upon the quality of the copy submitted. Broken or indistinct print, colored or poor quality illustrations and photographs, print bleedthrough, substandard margins, and improper alignment can adversely affect reproduction.

In the unlikely event that the author did not send UMI a complete manuscript and there are missing pages, these will be noted. Also, if unauthorized copyright material had to be removed, a note will indicate the deletion.

Oversize materials (e.g., maps, drawings, charts) are reproduced by sectioning the original, beginning at the upper left-hand comer and continuing from left to right in equal sections with small overlaps.

Photographs included in the original manuscript have been reproduced xerographically in this copy. Higher quality $6^{n} \times 9^{n}$ black and white photographic prints are available for any photographs or illustrations appearing in this copy for an additional charge. Contact UMI directly to order.

Bell \& Howell Information and Leaming 300 North Zeeb Road, Ann Arbor, MI 48106-1346 USA 800-521-0600






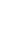




\title{
ESTIMATION OF CHLOROPHYLL, DETRITUS AND DISSOLVED
} SUBSTANCES FROM OPTICAL MEASUREMENTS

\author{
A thesis \\ Presented to the Faculty \\ of \\ San Jose State University \\ through \\ Moss Landing Marine Laboratories \\ In Partial Fulfillment \\ of the Requirements for the Degree \\ Master of Science in Marine Science
}

By

Elena Mauri

December 2000 
UMI Number: 1402526

\section{UMI}

UMI Microform 1402526

Copyright 2001 by Bell \& Howell Information and Learning Company.

All rights reserved. This microform edition is protected against unauthorized copying under Title 17, United States Code.

Bell \& Howell Information and Learning Company 300 North Zeeb Road

P.O. Box 1346

Ann Arbor, MI 48106-1346 
(C) 2000

Elena Mauri

ALL RIGHTS RESERVED 


\section{APPROVED FOR MOSS LANDING MARINE LABORATORIES}

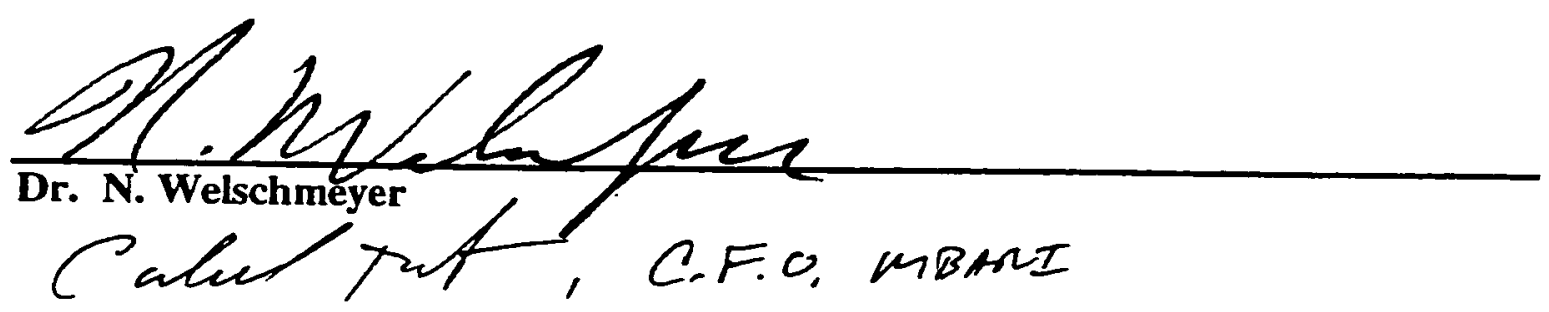

$$
\text { Aeting For DR. F. CAtruez }
$$

Dr. F. Chavez

(Monterey Bay Aquarium Institute)

$$
\text { Wilham Broaliow }
$$

Dr. W. Broenkow

\section{APPROVED FOQR THE CALIFORNIA STATE UNIVERSITY}

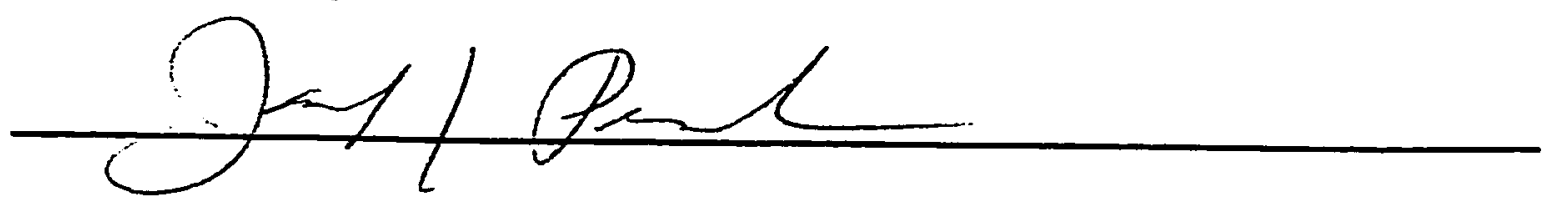




\title{
ABSTRACT \\ ESTIMATION OF CHLOROPHYLL, DETRITUS AND DISSOLVED SUBSTANCES FROM OPTICAL MEASUREMENTS
}

\author{
by Elena Mauri
}

Bio-Optical data from the global open ocean and Californian coastal waters are analyzed to assess the accuracy of empirical algorithms and semi-analytical models for estimating chlorophyll from remote sensing reflectance. The empirical algorithms generally yield high correlation between modeled and measured chlorophyll.

The semi-analytical model of Garver and Siegel (1997) predicts chlorophyll less accurately than the empirical models for the open ocean, whereas for the Pacific (between $10^{\circ} \mathrm{N}$ and $40^{\circ} \mathrm{S}$ ) and the coastal waters, it provides more accurate results. The model also provides information on other components responsible for remote sensing reflectance. It suggests that for coastal water dissolved material is more important than detrital mater, but in the open ocean the situation is reversed, except for the Indian Ocean. The semianalytical model was modified to consider a power law between the absorption coefficient of phytoplankton and the chlorophyll. The modified model provides a better one-to-one relationship between measured and modeled chlorophyll. 


\section{ACKNOWLEDGMENTS}

I would like to thank all the individuals who have helped and supported me to carry out this thesis work. In particular, I am grateful to my Committee members, Drs. Welschmeyer, Broenkow and Chavez, for their guidance.

I thank Dr. Chavez for providing me with the datasets, for supporting me financially and for allowing me to use the MBARI computing resources.

Thanks to all my friends in the Bio-ocean Group of MLML, at MBARI and at Hobi Labs. The discussions, meetings, social events, etc. contributed to make these last four years an interesting and enjoyable learning experience.

Last but not least, I would like to thank Pierre Poulain for his continuing support and patience. 
ACKNOWLEDGMENTS.

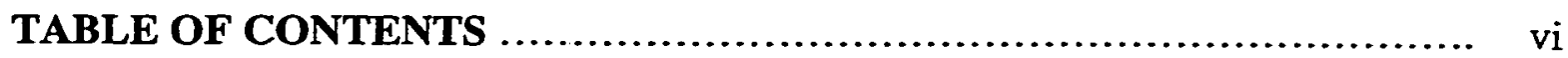

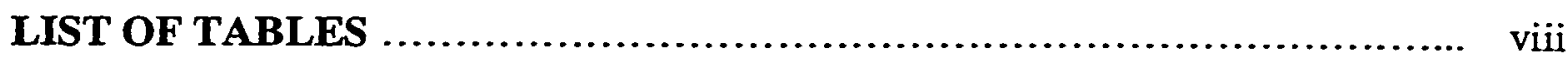



LIST OF ABBREVLATIONS ............................................... xiv

LIST OF SYMBOLS USED IN FIGURES................................. xiv

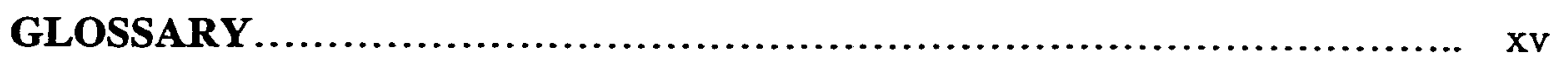

Chapter

1. INTRODUCTION .....................................................

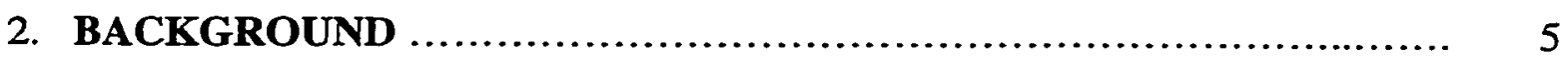

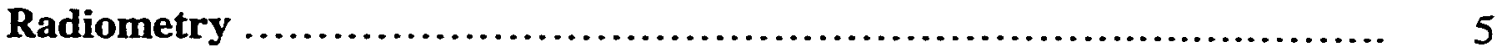

Measuring electromagnetic radiation ..................................... 7

Optical properties of water ............................................ 9

Inherent optical properties (IOP's) ................................... 9

Absorption ........................................................ 10

Scattering ......................................................... 17

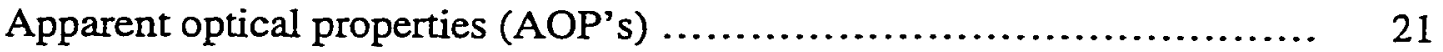

Attenuation coefficients ............................................ 21

Reflectance ..................................................... 22

3. MODELS TO ESTIMATE CHLOROPHYLL CONCENTRATION ...... 26

Empirical algorithms ................................................ 26

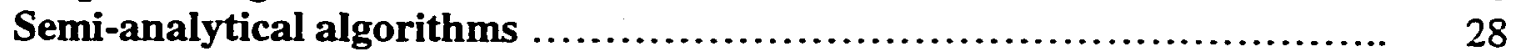

Model of Carder et al. (1999) ....................................... 28

Model of Garver and Siegel (1997) ................................. 30



Data ..................................................................... 36

General description .............................................. 36

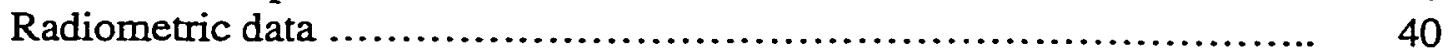

CTD/Rosette ........................................................ 42 
Methods ................................................................ 42

Radiometric data processing ............................................. 42

Processing with BBOP ........................................... 42

Special processing ............................................... 43

Estimation of chlorophyll-specific absorption coefficient $\quad \ldots \ldots \ldots \ldots \ldots \ldots . . . . . .44$

Data adjustments for the application of empirical models ................. 47

Implementation of the semi-Analytical inversion method of Garver and Siegel................................................................. 48

Modification of the semi-Analytical inversion method of Garver and Siegel.............................................................. 50



Variability with latitude ........................................... 51

Dependence of optical properties versus chlorophyll concentration ....... 54

Ratios of remote sensing reflectance .................................... 54

Absorption by phytoplankton ...................................... 55

Chlorophyll-specific absorption for phytoplankton..................... 59

Absorption by detritus............................................... $\quad 62$

Total particulate absorption ....................................... 67

Test of empirical models............................................. 67

Application of the semi-analytical model of Garver and Siegel ........... 73

Open ocean stations and sensitivity analysis .......................... $\quad 75$

Pacific Ocean stations ................................................. 85

California coastal stations ............................................ 88

Comparison between measured and modeled IOPs....................... 88

Application of the modified model of Garver and Siegel ................. 92

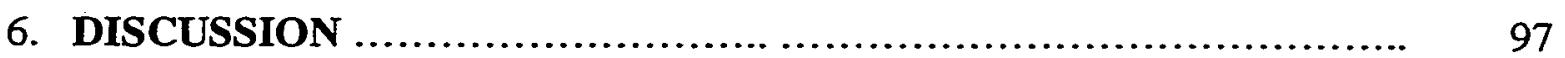

7. CONCLUSIONS.......................................................... 106

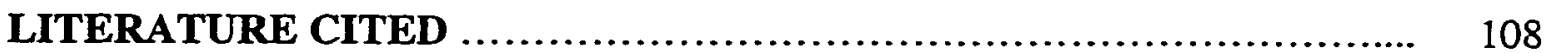




\section{LIST OF TABLES}

\section{Table}

3.1. Empirical models to retrieve chlorophyll concentration...........

4.1. Names of projects and cruises, geographical areas and time periods and number of stations for the data

4.2. Wavelength channels in which irradiances and radiances were measured by the instruments used.

4.3. Depths, volumes filtered and surface areas filtered for each project and cruise.

5.1. Values of the constants obtained when fitting the variations of $a_{p h}{ }^{*}$ versus $<c h l>$ to power laws of the form $a_{p h} *(\lambda)=A(\lambda)\langle c h l\rangle^{-B(\lambda)}$

5.2. Results of the linear regressions between modeled and measured chlorophyll concentrations

5.3. Same as in Table 5.2 but for 147 oligotrophic open ocean stations only.

5.4. Same as in Table 5.2 but for 47 South Pacific (north of $40^{\circ} \mathrm{S}$ ) open ocean stations only

5.5. Same as in Table 5.2 but for 72 coastal stations for which $\mathrm{a}^{*}$ measurements are available

5.6. Results of linear regressions between retrieved IOP's $\left(a_{p h}(443), a_{d m}(443)\right.$ and $\left.b_{b p}(443)\right)$ and measured bio-optical variables for sensitivity analysis varying $a_{d m} *$ spectra using open ocean data......................

5.7. Same as Table 5.6 but for sensitivity analysis varying $b_{b p} *(\lambda)$ spectra as $\left(\lambda / \lambda_{0}\right)^{-n}(n=0,1,2)$

5.8. Same as Table 5.6 but for sensitivity analysis varying $a_{p h} *(\lambda)$ spectra. 
5.9. Comparison between measured and modeled IOPs using the semi-analytical model of Garver and Siegel (1997) for



5.10 Results of the linear regressions between modeled and measured chlorophyll concentrations for the semi-analytical model of Garver and Siegel using all data

6.1. Relative difference between measured and modeled chlorophyll concentrations (in percent) for several empirical and semi-analytical models applied to the same number of common stations........................... 
Figure

\section{LIST OF FIGURES}

2.1. (a) Electromagnetic spectrum. (b) Visible portion of the electromagnetic spectrum showing various colors

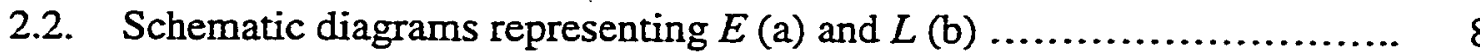

2.3. Geometry used to define inherent optical properties .................... 10

2.4. Total absorption spectrum of an idealized, productive ( $1 \mathrm{mg} \mathrm{chl} \mathrm{m} \mathrm{m}^{-3}$ ) oceanic water together with spectra of the individual absorbing components

2.5. Relative contribution of absorption by phytoplankton, $a_{p h}(\lambda)$, and by organic detritus, $a_{d}(\lambda)$, to the total particulate absorption, $a_{p}(\lambda)$, from Sargasso Sea waters at $20 \mathrm{~m}$ depth

2.6. Volume scattering functions for three natural waters and for pure water as a function of scattering angle

2.7. Schematic diagram illustrating the radiometric parameters and the bio-optical properties considered in this thesis

3.1. Known (or measured) and assumed spectral shapes composing the IOP inversion model of Garver and Siegel (1997)... ......

3.2. Flow diagram representing the inputs, the iterative nonlinear inversion and the outputs of the semi-analytical model of Garver and Siegel (1997)

4.1. Geographical location of the open ocean stations

4.2. (a) Geographical location of the stations off the coast of central California, (b) Stations in, and offshore of, Monterey Bay

4.3. Temporal distribution of the number of stations for the different months of the year in the vicinity of moorings M1 (between 1993 and 1998) and M2 (between 1995 and 1998).

4.4. Downward irradiance at $555 \mathrm{~nm}$ versus depth for a station in Monterey Bay with exponential fit to the points in depth range $5-12 \mathrm{~m}$ 
4.5. Absorption coefficients for phytoplankton, detritus and particles as a function of wavelength, after adjustment.

5.1. Latitudinal variation of optical properties at the open ocean stations....

5.2. Latitudinal and spectral dependence of the absorption coefficients for phytoplankton, $a_{p h}(\lambda)$, and detritus, $a_{d}(\lambda)$

5.3. Ratios of remote sensing reflectance versus chlorophyll concentration..

5.4. Absorption coefficients for phytoplankton, $a_{p h}(\lambda)$, for $\lambda=412,443$, 490 and $670 \mathrm{~nm}$ for all the stations

5.5. Same as in Fig. 5.5 but for $412,443,490,510,555$ and $670 \mathrm{~nm} . . . \ldots .$.

5.6. Chlorophyll-specific absorption coefficients for phytoplankton at 412 , $443,490,510,555$ and $670 \mathrm{~nm}$, versus chlorophyll concentration for all the stations

5.7. Chlorophyll-specific absorption coefficients for phytoplankton versus wavelength for all the stations

5.8. (a) Scatter diagram of $R_{r 5412} / R_{r 5443}$ versus $R_{r 5443} / R_{r 5555}$ for all stations.

(b) Chlorophyll-specific absorption for phytoplankton at $443 \mathrm{~nm}$ versus chlorophyll concentration.

5.9. Absorption coefficients for detritus, $a_{d}(\lambda)$, for $\lambda=412,443$ and $490 \mathrm{~nm}$ for all the stations versus chlorophyll concentration.

5.10. (a) Absorption coefficients for detritus, $a_{d}(\lambda)$, versus wavelength for all the stations. (b) Exponential decay constant, $S$, estimated from the $a_{d}(\lambda)$ curves shown in (a) and shown versus chlorophyll concentration

5.11. Particulate absorption coefficients, $a_{p}(443)$ (top panel) and its two components, $a_{p h}(443)$ (middle panel) and $a_{d}(443)$ (bottom panel), for all the stations

5.12. Variations of the ratio of non-algal absorption to total particulate

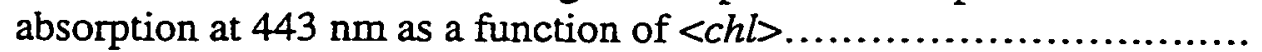

5.13. Test of empirical models for estimating chlorophyll concentration 
5.14. Results of the semi-analytical inversion model using an averaged $a_{p h}{ }^{*}$ estimated from all the data, $S=0.02 \mathrm{~nm}^{-1}$ and $b_{b p}-\lambda^{-1}$

5.15. The three IOPs, $a_{p h}(443), a_{d m}(443)$ and $b_{b p}(443)$, retrieved by the semianalytical model of Garver and Siegel (1997) at the open ocean stations for various values of $S\left(0.008,0.011,0.014\right.$ and $\left.0.02 \mathrm{~nm}^{-1}\right) \ldots \ldots$

5.16. Same as Figure 5.15 with $S=0.02 \mathrm{~nm}^{-1}$ and for different spectral shapes for the backscattering coefficient: $\lambda^{0}, \lambda^{-1}, \lambda^{-2}$

5.17. Same as Figure 5.15 with $S=0.02 \mathrm{~nm}^{-1}$ and with power law $\lambda^{-1}$ for backscattering but for the several $a_{p h} *$ spectral models.

5.18. Results of the optimized semi-analytical inversion model using an averaged $a_{p h}{ }^{*}$ from the open ocean stations, $S=0.02 \mathrm{~nm}^{-1}$ and $b_{b p} \sim \lambda^{-1}$..

5.19. Scatter diagrams of modeled versus measured variables for the optimized semi-analytical inversion model

5.20. Same as Fig. 5.18 but for the open ocean stations in the Pacific north of $40^{\circ} \mathrm{S}$ and using the following parameters: $a_{p h}{ }^{*}$ of Maritorena, $S=0.02 \mathrm{~nm}^{-1}$ and $b_{b p} \sim \lambda^{-1}$

5.21. Same as Fig. 5.19 but for the open ocean stations in the Pacific north of $40^{\circ} \mathrm{S}$

5.22. Same as Fig. 5.18 but for selected coastal stations (where $a^{*}$ measurements were available) and using the following parameters: $a_{p h} *$ estimated from coastal stations, $S=0.025 \mathrm{~nm}^{-1}$ and $b_{b p}-\lambda^{-1}$

5.23. Same as Fig. 5.19 but for Californian coastal stations

5.24. Same as Fig. 5.15 but using the modified model of Garver and Siegel (1997) with $A(\lambda)$ and $B(\lambda)$ obtained from the regression analysis with the data (Table 5.1), $S=0.02 \mathrm{~nm}^{-1}$ and $b_{b p} \sim \lambda^{-1}$

5.25. Same as Fig. 5.24 but with $B(\lambda)=0.25$

6.1. Linear $\left(a_{p h}{ }^{*}\right)$ and power law $\left(A<c h l>^{l-B}\right)$ models for $a_{p h}$ versus $<c h l>$ using coefficients similar to those estimated for the data at $490 \mathrm{~nm}$. 
6.2. Specific absorption of phytoplankton versus wavelength estimated from several subsets of the data: Indian (green), California coastal (black dashed), Atlantic (blue), South and Equatorial Pacific (purple and yellow) 


\section{LIST OF ABBREVIATIONS}

$\begin{array}{ll}\text { AOP } & \text { Apparent Optical Property } \\ \text { BBOP } & \text { Biological Bermuda Optical Program } \\ \text { CalCOFI } & \text { California Cooperative Oceanic Fisheries Investigation } \\ \text { CDOM } & \text { Colored Dissolved Organic Matter } \\ \text { CZCS } & \text { Coastal Zone Color Scanner } \\ \text { IOP } & \text { Inherent Optical Property } \\ \text { MBARI } & \text { Monterey Bay Aquarium Research Institute } \\ \text { MODIS } & \text { Moderate Resolution Imaging Spectrometer } \\ \text { OCTS } & \text { Ocean Color Temperature Sensor } \\ \text { PAR } & \text { Photosynthetic Active Radiation } \\ \text { PRR } & \text { Profiling Reflectance Radiometer } \\ \text { SeaWiFS } & \text { Sea-viewing Wide Field-of-view Sensor }\end{array}$

\section{LIST OF SYMBOLS USED IN FIGURE}

\footnotetext{
$\checkmark$ Monterey Bay 1993 (Shift up 93)

* Monterey Bay 1994 Time series

* Monterey Bay 1995 Time series

- California Current 1995 (CoOP95)

* Monterey Bay 1996 Time series

- California Current 1995 (COFE96)

* Monterey Bay 1997 Time series

+ SECRET1996 (S196)

+ SECRET1997 (S497) Monterey Bay 1998 Time series

+ SECRET1998 (S298)

+ SECRET1998 (S398)

O North Atlantic 1993

O South Pacific 1994

- Inidian Ocean 1995

O South Pacific 1996

O Equatorial Pacific 1996 Equatorial Pacific 1997
} 


\section{GLOSSARY}

$\lambda$ and $\lambda_{0}$ $\tau$

$a(\lambda)$

$a_{w}(\lambda)$

$a_{p h}(\lambda)$

$a_{p h}^{*}(\lambda)$

$a_{d}(\lambda)$

$a_{d}^{*}(\lambda)$

$a_{\text {CDOM }}(\lambda)$

$a_{d m}(\lambda)$

$b(\lambda)$

$b_{b}(\lambda)$

$b_{b w}(\lambda)$

$b_{b p}(\lambda)$

$c(\lambda)$

$n$

$r^{2}$

$r_{I}^{2}$

$t$

$A(\lambda)$

$B(\lambda)$

$D(\lambda)$

$E_{d}(\lambda)$

$E_{d}\left(0^{+}, \lambda\right)$

$F_{o}(\lambda)$

$K_{d}(\lambda)$

$K_{w}(\lambda)$

$K_{p h}(\lambda)$

$K_{\text {other }}(\lambda)$

$L_{u}$

$L_{\mathrm{u}}\left(0^{+}, \lambda\right)$ or $L_{w}(\lambda)$ water leaving radiance just above the surface $\left(\mathrm{W} \mathrm{m} \mathrm{m}^{-2} \mathrm{~nm}^{-1} \mathrm{sr}^{-1}\right)$

$L_{w n}$

$R(\lambda)$

$R_{r s}(\lambda)$

wavelength (nm) and reference value used in this study, 412 or $440 \mathrm{~nm}$ diffuse atmospheric transmittance absorption coefficient $\left(\mathrm{m}^{-1}\right)$

absorption coefficient for pure water $\left(\mathrm{m}^{-1}\right)$

absorption coefficient for phytoplankton $\left(\mathrm{m}^{-1}\right)$

chlorophyll-specific absorption coefficient of phytoplankton $\left(\mathrm{m}^{2} \mathrm{mg}^{-1}\right)$ absorption coefficient for detritus $\left(\mathrm{m}^{-1}\right)$

chlorophyll-specific absorption coefficient of detritus $\left(\mathrm{m}^{2} \mathrm{mg}^{-1}\right)$

absorption coefficient for colored dissolved organic matter $\left(\mathrm{m}^{-1}\right)$ absorption coefficient for dissolved/detrital substances $\left(\mathrm{m}^{-1}\right)$

scattering coefficient $\left(\mathrm{m}^{-1}\right)$

backscattering coefficient $\left(\mathrm{m}^{-1}\right)$

backscattering coefficient due to pure seawater $\left(\mathrm{m}^{-1}\right)$

backscattering coefficient for particles $\left(\mathrm{m}^{-1}\right)$

beam attenuation coefficient $\left(\mathrm{m}^{-1}\right)$

index of refraction from water to air

coefficient of determination (log-transformed values)

coefficient of determination (non log-transformed values)

air-sea transmittance

slope of hyperbolic function relating $a_{p h} *$ to $<c h l>$

power of hyperbolic function relating $a_{p h} *$ to $<c h l>$

absorbance or optical density

downwelling irradiance ( $\mathrm{W} \mathrm{m}^{-2} \mathrm{~nm}^{-1}$ )

irradiance just above the air-sea interface (W $\mathrm{m}^{-2} \mathrm{~nm}^{-1}$ )

mean extraterrestrial solar irradiance $\left(W \mathrm{~W} \mathrm{~m}^{-2} \mathrm{~nm}^{-1}\right)$

diffuse attenuation coefficients for downwelling irradiance $\left(\mathrm{m}^{-1}\right)$

diffuse attenuation coefficient for pure water $\left(\mathrm{m}^{-1}\right)$

diffuse attenuation coefficient for phytoplankton $\left(\mathrm{m}^{-1}\right)$

corresponds to the attenuation of nonalgal materials $\left(\mathrm{m}^{-1}\right)$

upwelling radiance $\left(\mathrm{W} \mathrm{m}^{-2} \mathrm{~nm}^{-1} \mathrm{sr}^{-1}\right)$

normalized water leaving radiance ( $\left.\mathrm{W} \mathrm{cm} \mathrm{cm}^{-2} \mathrm{nr}^{-1}\right)$

reflectance (sr)

remote sensing reflectance (sr) 


\section{CHAPTER 1}

\section{INTRODUCTION}

Since the pioneering work of Clarke et al. (1970), it has been known that the chlorophyli-a (or, more generally, pigments) contained in the phytoplankton in the nearsurface waters produced systematic variations in the color of the ocean, which could be observed from aircrafts and satellites. As a direct result of this work, NASA developed the Coastal Zone Color Scanner (CZCS) that was launched in October 1978 on board the Nimbus-7 satellite. This sensor was operational until 1986. After that, and for almost ten years, no ocean color sensors were operational. Starting in August 1996 the Japanese Ocean Color and Temperature Scanner (OCTS), was operated only for four months. It was followed in September 1997 by the Sea-viewing Wide Field-of-view Sensor (SeaWiFS) and, in December 1999, by the Moderate Resolution Imaging Spectrometer (MODIS), both of them operated by NASA. These new instruments started the new generation of ocean-viewing, visible/near-infrared satellite sensors. The improved SeaWiFS and MODIS sensors include more wavelength bands to better discriminate between the different effects acting on the electromagnetic signal measured.

The radiance received at the spacecraft altitudes consists of the solar radiation modified by scattering from and absorption by air molecules and particles (aerosols), absorption by ozone molecules, reflection at the air-sea interface, and finally by backscattering/absorption by water molecules, particles and dissolved substances in the ocean. All the above effects are wavelength-dependent. If the radiance measured by 
satellite sensors is corrected for all the atmospheric, surface and pure water effects it only comprises the backscattered energy from particulate and dissolved compounds and hence provides information about the seawater composition. The substances contributing to this backscattered energy are: (1) the living phytoplankton, (2) the associated "nonalgal" particles such as biogenious detritus and heterotrophic organisms and (3) the colored dissolved organic matter (CDOM) resulting from biological activities.

CDOM and degradation products such as phaeopigments, detritus and associated bacteria, absorbs more strongly in the $412 \mathrm{~nm}$ band than at the longer wavelengths (Bricaud et al., 1981, 1995; Kirk, 1994) while phytoplankton absorbs more strongly at $443 \mathrm{~nm}$ than at $412 \mathrm{~nm}$ (Bricaud et al., 1995, Carder et al., 1999). Carder et al. (1991) proposed that these contrasting absorption trends can be used to distinguish between the different absorbing components and developed a model to estimate chlorophyll concentration in the presence of CDOM, phaeopigments, detritus and bacteria.

Since the CZCS era in the late 1970's, algorithms have been developed to calculate chlorophyll-a concentration from the radiances measured by satellite sensors (O'Reilly et al., 1998). Empirical equations (e.g., Gordon et al., 1983; Morel, 1988; Abbott and Letelier, 1997; Mitchell and Kahru, 1998; Evans and Gordon, 1994) were first derived from statistical linear regression of chlorophyll-a concentration (measured in-situ) versus various ratios of radiances or remote sensing reflectances (measured by satellites). The accuracy of these algorithms is rather good for case I waters $( \pm 40 \%$ for local best cases, Gordon et al., 1983). In contrast, the algorithms are generally very inaccurate for waters in which chlorophyll-a and other compounds do not covary (case II) 
(inaccuracies as high as 133\%; Carder et al., 1991, 1999). This division in different water types was originally introduced by Morel and Prieur (1977): Case I waters are those in which the optical properties are dominated by chlorophyll-a and associated, covarying detrital pigments. In case II waters, other substances, which do not covary with chlorophyll, also affect the optical properties. Such substances include dissolved and particulate organic material, sediments and bacteria.

Advances in theoretical studies and new parameterizations of some optical properties are at the origin for the development of semi-analytical ocean color models (Carder et al, 1999, Garver and Siegel, 1997). These models relate the remote sensing reflectances (eventually derived from satellite measurements) to the absorption coefficient of phytoplankton, the absorption coefficients of other optically active components such as detrital and dissolved substances, and to the backscattering coefficient. Parts of the radiative model are expressed by empirical relationships, e.g., the spectral shapes of the absorption and backscattering coefficients. The models are inverted to retrieve the chlorophyll-a concentration and the absorption coefficients of phytoplankton and detritaldissolved substances. Semi-analytical models generally yield results inferior to those from the empirical algorithms (O'Reilly et al., 1998) but they are potentially more useful because they allow the derivation of other optically active constituents such as detrital/dissolved substances.

The atmospheric correction of satellite-radiances and application of adequate chlorophyll concentration algorithms are paramount, because they provide the only practical means for monitoring the spatial and seasonal variation of near surface 
phytoplankton, which is essential for the study of oceanic primary production, global carbon and other biogeochemical cycles as well as for fisheries research. The aim of the present study is to explore the bio-optical characteristics of different water bodies and to assess the effectiveness of selected empirical and semi-analytical models for retrieving chlorophyll concentration from in-situ optical measurements.

First, background information on radiometric definitions and optical properties of sea water is provided (Chapter 2). Selected empirical and semi-analytical models to retrieve chlorophyll concentration are presented in Chapter 3. Optical data and biogeochemical observations were analyzed from a large number of stations in open ocean waters (most of the word's ocean basins) and for the California coastal waters. Specifics about the data sets and the analysis methods adopted can be found in Chapter 4 . The results are presented in Chapter 5, including details about the dependence of the optical properties with respect to chlorophyll concentration, and the tests of the empirical and semi-analytical models with the open ocean and coastal datasets. Discussion of the results and conclusions are presented in Chapters 6 and 7, respectively. 


\section{CHAPTER 2}

\section{BACKGROUND}

This chapter presents fundamental radiometric definitions, as well as some basics on the optical properties of seawater. The definitions and symbols (summarized in a glossary) used hereafter are compatible to widely-accepted modern treatments, including current NASA protocol, but might differ from those employed in some papers. The objective of this chapter is to provide a framework of self-consistent definitions and symbols that will be used in this thesis.

\section{Radiometry}

Electromagnetic energy occurs in indivisible units referred to as quanta or photons. Despite its particulate nature, it behaves in some circumstances, as though it has a wave nature. Each photon has a wavelength, $\lambda(\mathrm{m})$, and a frequency, $v\left(\mathrm{~Hz}\right.$ or $\left.\mathrm{s}^{-1}\right)$, which are related in accordance with

$$
\lambda=\frac{c}{v}
$$

where $c\left(\mathrm{~m} \mathrm{~s}^{-1}\right)$ is the speed of light. Since $c$ is constant in a given medium, the greater the wavelength, the lower the frequency. The energy, $\epsilon$, in a photon varies with the frequency, and therefore inversely with the wavelength, the relation being 


$$
\epsilon=h v=\frac{h c}{\lambda},
$$

where $h$ is Planck's constant $\left(6.63 \times 10^{-34} \mathrm{~J} \mathrm{~s}\right)$.

The entire electromagnetic spectrum is shown in Fig. 2.1a, while only the visible spectrum from $350 \mathrm{~nm}$ (violet) and $700 \mathrm{~nm}$ (red) is presented in Fig. 2.1b.

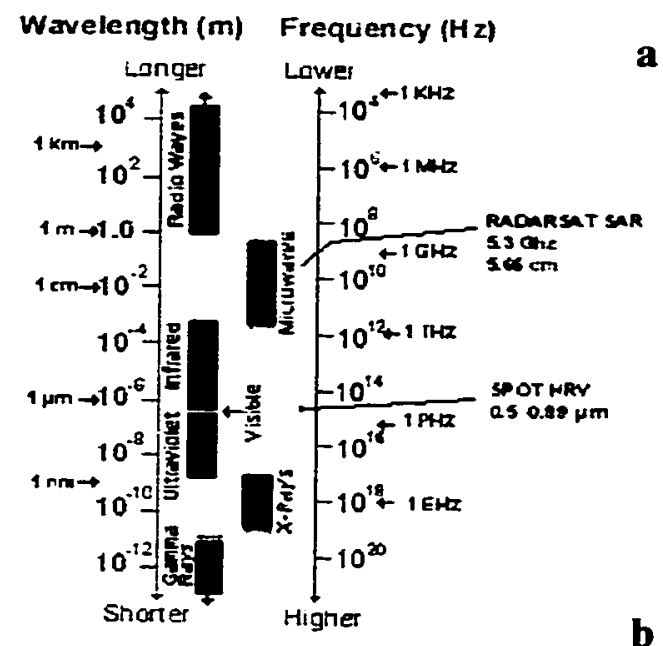

The Visible Spectrum
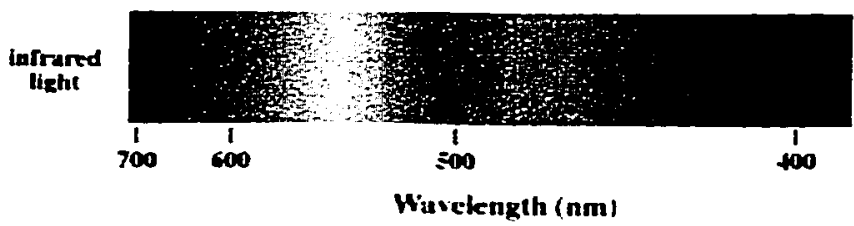

ulirevinket

Itint

Fig. 2.1. (a) Electromagnetic spectrum; (b) Visible portion of the electromagnetic spectrum showing various colors. 


\section{Measuring electromagnetic radiation}

The electromagnetic radiation flux is measured as the time rate of the flow of electromagnetic energy, or power $\Phi\left(\mathrm{J} \mathrm{s}^{-1}\right)$ expressed in watts $(\mathrm{W})$ in the System International (SI). There are two ways of quantifying the energy flux incident to a surface: the first considers the angle of the flux direction while the other is an integral quantity independent of the angle. The definitions are:

- The irradiance $E$ is the radiant flux $\Delta \Phi(W)$ impinging upon a surface $\Delta A\left(\mathrm{~m}^{-2}\right)$, per unit area, that is:

$$
E=\frac{\Delta \Phi}{\Delta A}\left(\mathrm{~W} \mathrm{~m}^{-2}\right)
$$

- The radiance $L$ is the radiant flux $\Delta \Phi(\mathrm{W})$ in a given direction per unit solid angle $\Delta \Omega$ (sr), per unit area $\Delta A\left(\mathrm{~m}^{2}\right)$ perpendicular to the direction of propagation:

$$
\mathrm{L}=\frac{\Delta \Phi}{(\Delta \Omega \Delta A \cos \theta)}\left(\mathrm{W} \mathrm{m}^{-2} \mathrm{sr}^{-1}\right)
$$

where $\theta$ is the angle between the direction of propagation and the perpendicular to the surface considered (Fig. 2.2). 

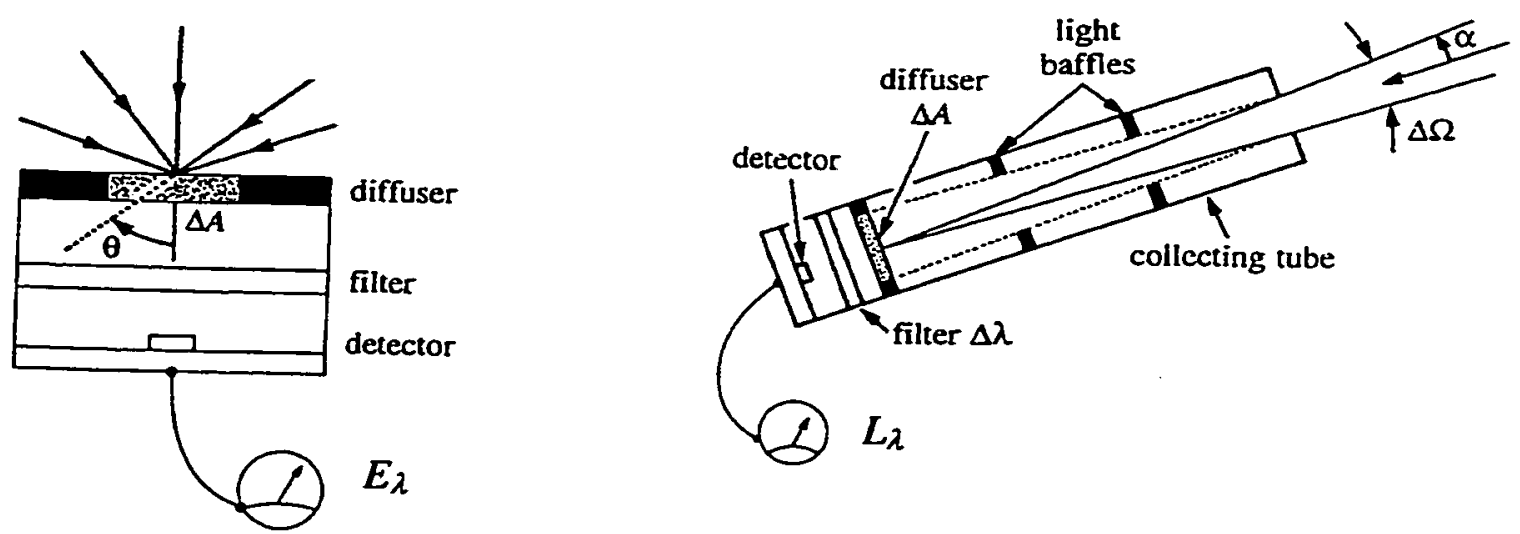

Fig. 2.2. Schematic diagrams representing $E_{\lambda}$ (a) and $L_{\lambda}$ (b) (adapted from Kirk, 1994).

When considering different wavelengths, the following related quantities characterize the radiance and irradiance over a given range of wavelengths $\Delta \lambda(\mathrm{nm})$, respectively:

$$
L_{\lambda}=\frac{L}{\Delta \lambda}\left(\mathrm{W} \mathrm{m}^{-2} \mathrm{sr}^{-1} \mathrm{~nm}^{-1}\right) \text { and } E_{\lambda}=\frac{E}{\Delta \lambda}\left(\mathrm{W} \mathrm{m}^{-2} \mathrm{~nm}^{-1}\right)
$$

In the water column, the following quantities are defined:

- The downwelling irradiance, $E_{d}$, that is the downwelling radiant flux impinging upon a horizontal surface, per unit area. $E_{d}$ includes all the electromagnetic energy coming from all the directions above the surface and impinging on the upper face of the surface.

- The upward radiance, $L_{u}$, on the lower face of a horizontal surface due to a given upwelling light stream in the vertical direction. 


\section{Optical properties of water}

The optical properties of water are conventionally divided into two different classes:

- The inherent optical properties (IOP's) are those properties that depend only upon the medium and therefore are independent of the ambient light field within the medium (Preisendorfer, 1961).

- The apparent optical properties (AOP's) are those properties that depend both on the medium (i.e., on the IOP's) and on the geometric (directional) structure of the radiance field.

\section{Inherent optical property (IOP's)}

Some inherent optical properties used in this thesis are defined and discussed hereafter.

Electromagnetic radiation is attenuated as it passes through a medium. The beam attenuation coefficient, $c$, expresses the fraction of electromagnetic radiation loss traveling through the medium per unit distance:

$$
c=-\frac{d \ln \Phi}{d r}=-\frac{1}{\Phi} \frac{d \Phi}{d r}\left(\mathrm{~m}^{-1}\right)
$$

where $r(\mathrm{~m})$ is distance and $\Phi(\mathrm{W})$ is the radiant flux. The beam attenuation coefficient measures the cumulative effects of the absorption coefficient, $a$, and scattering coefficient, $b$ :

$$
c(\lambda)=a(\lambda)+b(\lambda) \quad\left(\mathrm{m}^{-1}\right)
$$


The absorption coefficient and the scattering coefficient are respectively the fraction of the incident flux, which is absorbed and scattered out of the beam direction divided by the thickness of the medium. They are defined as:

$$
a(\lambda)=\lim _{\Delta r \rightarrow 0} \frac{\Phi_{a}(\lambda)}{\Phi_{i}(\lambda) \Delta r} \text { and } b(\lambda)=\lim _{\Delta r \rightarrow 0} \frac{\Phi_{s}(\lambda)}{\Phi_{i}(\lambda) \Delta r}
$$

where $\Phi_{i}, \Phi_{a}, \Phi_{s}$ are the incident, absorbed and scattered powers (or radiant fluxes), respectively and $\Delta r$ is the medium thickness (see Fig. 2.3).

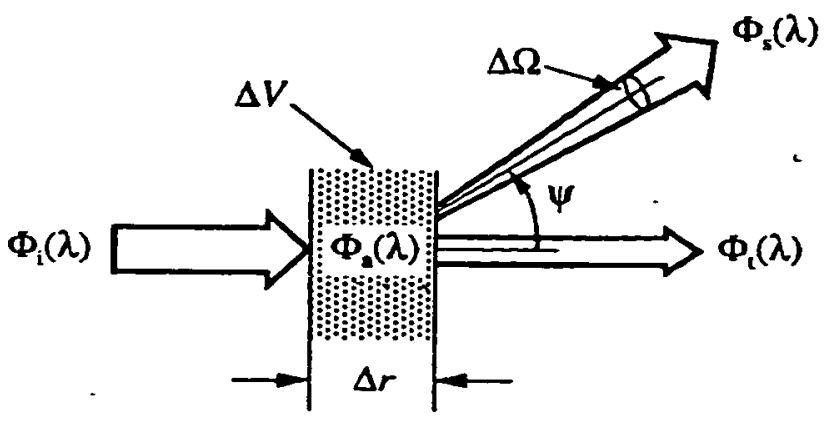

Fig. 2.3. Geometry used to define inherent optical properties (from Mobley, 1994).

\section{Absorption}

For cases of relative low absorption, the total absorption coefficient, $a$, can be approximated by the sum of the different components that affect the absorption, water $(w)$, phytoplankton $(p h)$, detritus (d), gelbstoff or gilvin, or colored dissolved organic matter (CDOM): 


$$
a(\lambda)=a_{w}(\lambda)+a_{p h}(\lambda)+a_{d}(\lambda)+a_{C D O M}(\lambda)\left(\mathrm{m}^{-1}\right)
$$

Absorption by phytoplankton and detritus can be combined under the particulate absorption coefficient, $a_{p}(\lambda)=a_{d}(\lambda)+a_{p h}(\lambda)$. The total absorption spectrum of an idealized productive ( $1 \mathrm{mg}$ chlorophyll-a $\mathrm{m}^{-3}$ ) oceanic water, together with spectra of the individual absorbing components, is depicted in Fig. 2.4. There is a significant wavelength dependence in the absorption for each of the contributing constituents. Water absorption is significant in the red portion $(600-700 \mathrm{~nm})$ of the spectrum, while the detritus and CDOM absorbs more at the blue wavelengths (400-450 nm). Phytoplankton cells have mainly two absorbing peaks: a main one in the blue ( $440 \mathrm{~nm})$ and another relatively smaller at red wavelengths $(-680 \mathrm{~nm})$ (see also Fig. 2.5$)$.

The total absorption coefficient, $a(\lambda)$, can, at least in principle, be measured in situ. The coefficient for pure seawater has been determined in laboratory experiments; some uncertainties, however, remain because of the extremely low absorption by water in particular in the blue part of the spectrum (Smith and Baker, 1981; Pope and Fry, 1997). At sea, absorption spectra of filtered particles can be measured (Trüper and Yentsch, 1967). Subsequent use of extractive or bleaching methods allow this coefficient to be partitioned into its two components $a_{p h}(\lambda)$ and $a_{d}(\lambda)$. Finally $a_{C D O M}(\lambda)$ can be measured from water samples previously filtered (0.2-0.4 $\mu \mathrm{m}$ pore size) using a spectrophotometer with $5 \mathrm{~cm}$ or $10 \mathrm{~cm}$ path length cells (Kirk, 1976). 


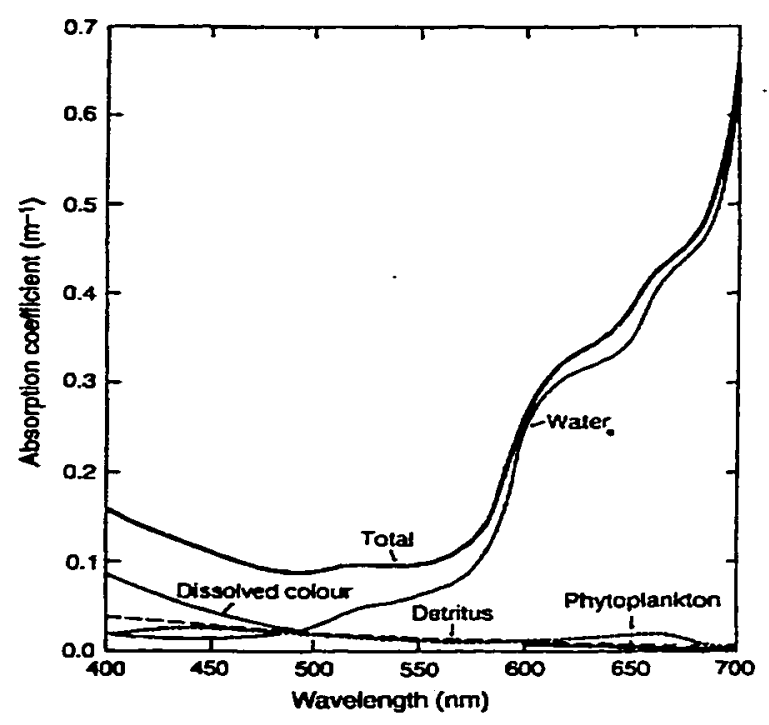

Fig. 2.4. Total absorption spectrum of an idealized, productive $(<c h l\rangle=1 \mathrm{mg} \mathrm{m}^{-3}$ ) oceanic water together with spectra of the individual absorbing components (from Kirk, 1994).

Absorption by phytoplankton occurs in various photosynthetic pigments, of which chlorophyll-a is the most important and is non-specific for all taxa, excluding prochlorophytes. An increasing chlorophyll-a concentration (denoted hereafter by <chl>) does not always lead to a proportional increase of absorption. The reasons for this anomaly can be due to two reasons: (1) An increase of packaging effect from oligotrophic to eutrophic waters (due to internal cellular change in pigment content resulting from photo-adaptation and nutrient stress), and (2) a possible inverse co-variation between the relative abundance of accessory pigments (chlorophyll-b, chlorophyll-c and carotenoids) and the chlorophyll-a concentration (Bricaud et al., 1995).

The packaging effect diminishes the effectiveness with which chlorophyll-a 
collects light and hence lowers specific absorption. This is due to the fact that the pigment molecules instead of being uniformly distributed are contained within discrete packages. The packaging effect is a major source of both inter- and intra-species variability in spectral absorption by phytoplankton, because the details of the pigment packaging within cells depend not only on species but also on the cell size and physiological state, which in turn depend on environmental factors such as ambient lighting and nutrient availability (Mobley, 1994).

Among the accessory pigments that increase phytoplankton absorption at wavelengths where chlorophyll-a absorption is important, there are non-photosynthetic carotenoids, e.g., diadinoxanthin, zeaxanthin (mainly photo-protective), chlorophyll-b and divinyl chlorophyll-b. For example, the absorption due to carotenoids is predominant in the blue part of the spectrum (400-530 nm, with maxima at $460-490 \mathrm{~nm}$, see Bidigare et al, 1990). The relative concentration of photo-protective carotenoid pigments varies inversely with $\langle c h l\rangle$, at least between the surface (where their concentration is maximum) and the deep chlorophyll maximum. In contrast, the ratio of chlorophyll-b (plus divinyl chlorophyll-b) to $<c h l>$ tends to increase from the surface down to the deep chlorophyll maximum. These pigments absorb at 400-500 and 630-670 nm, with maxima around 470 and $650 \mathrm{~nm}$. The relative effect of all the above-mentioned accessory pigments is on average higher in oligotrophic than in mesotrophic waters (Bricaud et al, 1995).

The absorption coefficient, $a$, is conventionally normalized with respect to the chlorophyll-a concentration, having the symbol $a^{*}(\lambda)$ and units $\mathrm{m}^{2}(\mathrm{mg} \mathrm{chl})^{-1}$. It has the 
dimension of an absorption cross section per unit amount of chlorophyll. Of particular interest is the chlorophyll-specific coefficient that is related exclusively to phytoplankton, $a_{p h} *(\lambda)$. The chlorophyll-specific absorption coefficient is related to the chlorophyll concentration $<$ chl $>$ through

$$
a_{p h}(\lambda)=a_{p h} *(\lambda)<c h l>
$$

Thus, if $a_{p h}{ }^{*}(\lambda)$ is known, the absorption by the phytoplankton in the water body can be predicted from the chlorophyll concentration. The chlorophyll-specific absorption coefficient by detritus $a_{d}^{*}(\lambda)$ is defined in a similar way.

Bricaud et al. (1995) have analyzed the variability of the chlorophyll-specific absorption coefficients of phytoplankton. Empirical relationships between $a_{p h} *(\lambda)$ and $<c h l>$ of the form:

$$
a_{p h}^{*}(\lambda)=A(\lambda)<c h l>^{-B(\lambda)},
$$

where derived, where $A(\lambda)$ and $B(\lambda)$ were determined by least squares fit. These can be used for refining estimates of the carbon fixation rate with primary production models based on physiological parameters, among which $a_{p h} *$ is an important one which can be retrieved from satellite measurements (through $<c h l>$ ).

The absorption spectrum shape of detritus is very similar to the CDOM one, but they have different compositions. Detritus is defined as the non-algal particles that include bacteria, viruses, fecal pellets and cell fragments. If the particles contain pigments at the time of their production, they can be rapidly photo-oxidized and loose the 
characteristic absorption spectrum of living phytoplankton, leaving significant absorption only a blue wavelengths (Mobley, 1994). CDOM is composed of dissolved organic compounds created during algal tissue decomposition. This complex group of compounds is loosely referred to as "humic substances". They are polymers consisting of aromatic rings, which are joined by long-chain alkyl structures to form a flexible network. Their molecular weights vary in size from a few hundred, to hundreds of thousands perhaps ranging up to the millions. This group also comprises the fulvic acid, a compound chemically very similar but which differs essentially by its lower molecular weight (Kirk, 1994).

The absorption spectrum shape (Figs. 2.5 and 2.6) of the detritus is usually modeled using a coefficient $S$, which describes the exponential decrease of the absorption with increasing wavelength. It can be calculated using the approximate relationship (Bricaud et al., 1981):

$$
a_{d}(\lambda)=a_{d}\left(\lambda_{0}\right) e^{-s\left(\lambda-\lambda_{0}\right)}
$$

where $\lambda_{0}$ is a reference wavelength.

It is interesting to compare the absorption by phytoplankton and by detritus at the shortest SeaWiFS wavelengths, i.e., 412, 443, 490 and $510 \mathrm{~nm}$ (Fig. 2.5). Since $a_{d}$ is maximum at $412 \mathrm{~nm}$ and $a_{p h}$ is maximum at $443 \mathrm{~nm}, a_{d}(412)$ and $a_{p h}(443)$ are used as indicator of the detritus and phytoplankton, respectively. Upwelling radiances or remote sensing reflectances at 443 and $490 \mathrm{~nm}$ normalized by their corresponding values at 550 $\mathrm{nm}$ (minimum in phytoplankton absorption) are related to the phytoplankton 
concentration, with the $443 / 550$ ratio being the most sensitive. The ratio $490 / 550$ is also used because there is less effect of detritus absorption at 490 than at $443 \mathrm{~nm}$. As for the estimation of detritus concentration, the ratios $410 / 488$ (or $412 / 490$ ) and $412 / 443$ are usually considered. The former ratio gives better results because organic detritus tend to covary with the phytoplankton concentration. For example, Garver and Siegel (1997) used the ratio $K_{d}(410) / K_{d}(488)$ and Carder et al. (1999) considered $R_{r s}(412) / R_{r s}(443$ (see symbol definitions below).



Fig. 2.5. Relative contribution of absorption by phytoplankton, $a_{p h}(\lambda)$, and by organic detritus, $a_{d e t}(\lambda)$ or $a_{d}(\lambda)$, to the total particulate absorption, $a_{p}(\lambda)$, from Sargasso Sea waters at $20 \mathrm{~m}$ depth (adapted from Iturriaga and Siegel, 1989).

Another parameter is used in absorption measurements. Commercially available spectrophotometers used for the measurement of light absorption, do so in terms of an optical parameter known as the absorbance or optical density $(D)$. Commonly $D$ is 
defined as the logarithm in base 10 of the ratio of the light radiant flux, $\Phi_{\mathrm{o}}$, incident on a physical system to the light radiant flux, $\Phi$, transmitted by the system

$$
D=\log _{10} \frac{\Phi_{0}}{\Phi}
$$

$D$ is related to the absorption coefficient $a$ defined in (9) through

$$
D=0.4343 a r,
$$

where $r$ is the path length through the system. The factor 0.4343 comes from the conversion from natural to base 10 logarithms.

\section{Scattering}

Most of the photons that enter the water are absorbed but many of these photons (the quantity depends of the water type) undergo scattering one or many times before they are absorbed. The scattering process does not remove light from the water body, it just increases the path length of the photons. Some of them are scattered back in the upward direction. Thus the effect of scattering is to intensify the vertical attenuation of light.

The scattering coefficient, $b$, contributing to the beam light attenuation (7) represents the total loss due to all the photons that are scattered out of the beam direction considered. The scattering efficiency depends generally on the angle between the incident 
photon and the scattered photon, referred to as the scattering angle $\psi$. The angular dependence is expressed through the volume scattering function $\beta(\psi, \lambda)$ which essentially represents the fraction of the incident radiant flux that is scattered in direction $\psi$ (see Fig. 2.3 for geometry). Mathematically it is defined as:

$$
\beta(\psi, \lambda)=\lim _{\Delta r \rightarrow 0} \lim _{\Delta \Omega \rightarrow 0} \frac{\Phi_{s}(\lambda)}{\Phi_{i}(\lambda) \Delta r \Delta \Omega},
$$

where $\Delta \Omega$ is a solid angle in direction $\psi$ and $\Delta r$ is the thickness of the medium considered. The scattering coefficient, $b$, the volume scattering function, $\beta$, and the scattering angle, $\Psi$, are related through (Mobley, 1994):

$$
b(\lambda)=2 \pi \int_{0}^{\pi} \beta(\psi, \lambda) \sin \psi d \psi .
$$

The above integration is often divided into forward $(0 \leq \psi \leq \pi / 2)$ and backward $(\pi / 2 \leq \psi \leq \pi)$ scattering. The corresponding forward and backward scattering coefficients are, respectively,

$$
\begin{aligned}
& b_{f}(\lambda)=2 \pi \int_{0}^{\pi / 2} \beta(\psi, \lambda) \sin \psi d \psi, \text { and } \\
& b_{b}(\lambda)=2 \pi \int_{\pi / 2}^{\pi} \beta(\psi, \lambda) \sin \psi d \psi .
\end{aligned}
$$

In seawater, two kinds of scattering must be considered: scattering by pure water 
(also called density fluctuation scattering by Kirk (1994)) and scattering by suspended organic and inorganic particles. Hence, the backscattering coefficient can be divided as

$$
b_{b}(\lambda)=b_{b w}(\lambda)+b_{b p}(\lambda)\left(m^{-1}\right)
$$

where $b_{b w}$ is the backscattering coefficient due to pure water and $b_{b p}$ is the backscattering coefficient due to particles.

The scattering by pure seawater has a spectral shape in $\lambda^{-4.32}$ similar to the Rayleigh scattering by air molecules. However, the scattering in liquids is not considered to be produced by small spherical particles (as assumed by Rayleigh for air) but it is due to small fluctuations in density of molecules. Thus to be accurate, scattering by pure liquids should be referred to as "fluctuation" or "Einstein-Smoluchowski" scattering. The values of $b_{b w}(\lambda)$ were measured by Smith and Baker (1981). The volume scattering function has a rather weak dependence on the scattering angle with maxima in both the forward and backward directions. The forward and backward scattering coefficients are therefore both equal to half the scattering coefficient $\left(b_{b w}=b_{f w}=0.5 b_{w}\right)$.

As soon as a slight amount of particulate matter is present in the water, the volume scattering coefficient becomes highly peaked in the forward direction and the scattering coefficient increases by a factor of ten (Mobley, 1994). The scattering characteristics depend obviously on the kind, size and amount of particles. Fig. 2.6 shows the volume scattering functions for three different natural waters and for pure seawater as a function of scattering angle. The strong $\lambda^{-4}$ wavelength dependence of scattering by pure water is not seen in natural waters. This is because scattering is dominated by 
diffraction from particles that are usually much larger than the wavelengths of visible light. Morel (1973) found that observations of scattering by turbid waters have a spectral dependence of the form $\lambda^{-i}$ where $i$ is $1.73-1.89$ for backscatter $\left(\Psi=150^{\circ}\right)$ and $i$ is 0.84 0.99 for forward scatter $\left(\Psi=30^{\circ}\right)$. Finally, several models exist to relate $b(\lambda)$ or $b_{p}(\lambda)$ to the chlorophyll concentration (Gordon and Morel, 1983; Morel, 1991). They are power laws in which the log-transformed scattering coefficients increase linearly with the logtransformed chlorophyll concentration.

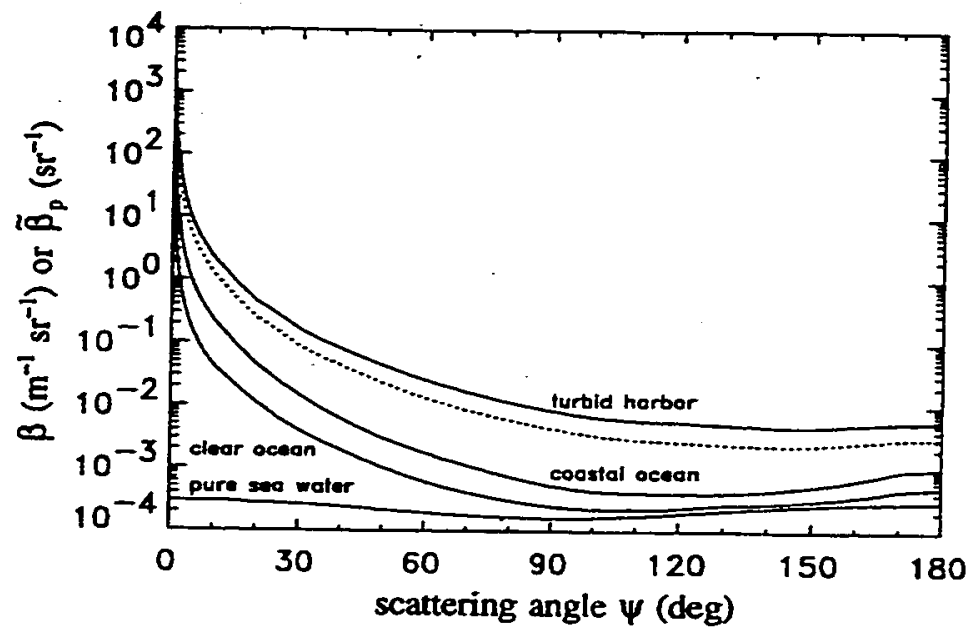

Fig. 2.6: Volume scattering functions for three natural waters and for pure water as a function of scattering angle (from Mobley, 1994)

Scattered light generally undergoes no change in wavelength. A small proportion of the scattered photons, however, lose/gain a small amount of energy corresponding to vibrational or rotational energy transition modes of the molecule, which result in wavelength shifts (Kirk, 1994). This process is known as Raman scattering. 


\section{Apparent optical properties (AOP's)}

\section{Attenuation coefficients}

The downwelling irradiance and the upwelling radiance diminish in value in an approximately exponential manner with depth (Kirk, 1994) and the decrease is wavelength dependent. It is therefore convenient to specify the rate of change of the logarithm of the value with depth, $z$, since it is approximately constant for all depths. In this way, the following diffuse attenuation coefficients, $K_{d}$, is defined as:

$$
K_{d}=-\frac{d \ln E_{d}}{d z}=-\frac{1}{E_{d}} \frac{d E_{d}}{d z}\left(\mathrm{~m}^{-1}\right)
$$

The distinction between the beam and diffuse attenuation coefficients is important. The beam attenuation coefficient, $c$, is defined in terms of the radiant power loss from a single, narrow, collimated beam of photons (see 6). The downwelling diffuse attenuation coefficient, $K_{d}$, is defined in terms of the decrease with depth of the ambient downwelling irradiance, $E_{d}$, which comprises photons heading in all downward direction (a diffuse, or uncollimated, light field, hence its classification as an apparent property).

The diffuse attenuation coefficient spectrum can be approximately partitioned into components which describe the effects of different attenuating materials, or:

$$
K_{d}(\lambda)=K_{w}(\lambda)+K_{p h}(\lambda)+K_{o t h e r}(\lambda)
$$

where $K_{w}(\lambda)$ is the attenuation due to pure water (Smith and Baker, 1981), $K_{p h}(\lambda)$ is the attenuation due to pigmented algal material (phytoplankton) and $K_{\text {other }}(\lambda)$ corresponds to 
the attenuation diue to nonalgal materials in the water column (Blizard, 1986; Smith et al., 1989). This partitioning assumes implicitly that $K_{d}$ is independent of the variation of the geometry of the in situ radiance distribution (Baker and Smith, 1979; Siegel and Dickey, 1987; Gordon, 1 989).

The dowenwelling attenuation coefficient, $K_{d}$, which is not an inherent optical property, is nevertheless dependent on two inherent optical properties, $a$ and $b$, the absorption and scattering coefficients. It is also a function of the angular structure of the light field. Kirk (1981) showed that at mid-point of the euphotic zone, for a wide range of $b / a$ values and high sun conditions that:

$$
K_{d}=\left(a^{2}+0.256 a b\right)
$$

The diffuse atten uation coefficient, $K_{d}$, sometimes is divided by the chlorophyll concentration and hence becomes the chlorophyll-specific diffuse coefficients often referred to $k_{c}$ (Morel, 1988). This $k_{c}$ differs from $a_{p h}{ }^{*}$ as it merges the contribution of living phytoplankton and of other associate particles to absorption and scattering and also the contribution of covarying dissolved matter to absorption.

\section{Reflectance}

The reflectance (or irradiance ratio) is also an AOP. It is defined as the ratio of spectral upwelling to downwelling plane irradiance (just below the air-water interface). Usually it is consindered at the surface: 


$$
R(\lambda)=\frac{E_{u}\left(0^{-}, \lambda\right)}{E_{d}\left(0^{-}, \lambda\right)} .
$$

The remote sensing reflectance, $R_{r s}$, is defined as:

$$
R_{r s}(\lambda)=\frac{L_{u}\left(0^{+}, \lambda\right)}{E_{d}\left(0^{+}, \lambda\right)}(\mathrm{sr})
$$

where $L_{\mathrm{u}}\left(0^{+}\right)$is the water leaving irradiance (eventually sensed by a satellite), also called the water leaving radiance $L_{w}(\lambda)$ (the upwelling radiance just above the surface), defined as:

$$
L_{w}(\lambda)=L_{u}\left(0^{+}, \lambda\right)=\left(\frac{t}{n^{2}}\right) L_{u}\left(0^{-}, \lambda\right)
$$

The factor $t / n^{2}$ accounts for the loss radiance at the sea surface from transmittance across the surface and from change of geometric spreading related to the index of refraction, $n$, from water to air. For a near zenith sun, a nadir viewing instrument, and calm sea, it is often approximated by 0.544 (Austin, 1974), considering $t \approx 0.98$ and $n \approx 1.341$.

The irradiance just above the air-sea interface, $E_{d}\left(0^{+}\right)$is related to the same quantity below the surface through:

$$
E_{d}\left(0^{+}, \lambda\right)=\frac{E_{d}\left(0^{-}, \lambda\right)}{t}
$$

where $t$ is the air-sea transmittance assuming a near zenith sun angle $(-0.96$; Smith and Baker, 1986). 
The water leaving radiance, $L_{w}(\lambda)$, is often normalized to account for effects of the atmosphere, solar zenith angle and earth-sun distance. The normalized water leaving radiance, $L_{w n}(\lambda)$, is defined as (Gordon et al., 1983):

$$
L_{w n}(\lambda)=\frac{L_{w}(\lambda)}{\tau(\theta) \cos (\theta)},
$$

where $\tau(\theta)$ is the diffuse transmittance of the atmosphere and $\theta$ is the sun zenith angle. It is the radiance leaving the sea surface if the sun were at the zenith and if the atmosphere were absent. The remote sensing reflectance, $R_{r s}$, defined in (23) is related to the normalized water leaving radiance through:

$$
L_{w n}=\frac{L_{w}(\lambda) F_{o}}{E_{d}\left(0^{+}, \lambda\right)}=R_{r s} F_{o}
$$

where $F_{o}$ is the mean extraterrestrial solar irradiance.

The radiometric parameters and the bio-optical properties considered in this thesis are summarized and illustrated in Fig. 2.7. 







\section{CHAPTER 3}

\section{MODELS TO ESTIMATE CHLOROPHYLL CONCENTRATION}

This chapter describes the various empirical and semi-analytical models relating chlorophyll concentration, and some inherent optical properties, to radiance measurements. These radiances can be estimated satellite-based radiometers after correction for atmospheric effects.

Since the 1970s, a variety of bio-optical models have been developed to estimate chlorophyll-a concentration from ocean radiance data, especially those measured by satellite sensors. Most of these consist of empirical equations derived from statistical regressions between measured radiance values and chlorophyll concentrations. Advances in theoretical studies and new parameterizations of some optical properties have provided new tools for modeling the marine light field. Semi-empirical ocean color algorithms largely results from these improvements in understanding the relationship between the remote sensing reflectance, $R_{r s}$, to the IOPs of the water column, and in particular to the ratio of backscattering to absorption.

\section{Empirical algorithms}

The empirical models essentially express the logarithm of the chlorophyll concentration as a polynomial function of the logarithm of a selected ratio of remote sensing reflectances or ratio of upwelling radiances, at generally two wavelengths. The empirical algorithms considered in this study are listed in Table 3.1. The coefficients 
(a(1), a(2), etc.) of the polynomial expressions were obtained through least squares fits. The second algorithm listed in Table 3.1 is an exception to the above rule. It is actually derived from the semi-analytical model of Morel (1988) that relates the difference between the total diffuse attenuation coefficient and the diffuse attenuation due to pure sea water, $K_{d}(\lambda)-K_{w}(\lambda)$, to the chlorophyll concentration. The model of Morel (1988) is based on the attenuation coefficient for downwelling irradiance, $K_{d}$, which is an AOP. In good approximation this coefficient can be related to the two IOP's, $a$ and $b$, though expression (22). The second algorithm of Table 3.1 is considered empirical because it is based simply on the relation of $\langle c h l\rangle$ to band ratios.

Table 3.1. Empirical models to retrieve chlorophyll concentration.

\begin{tabular}{|c|c|c|}
\hline Reference & Algorithms for $<C h l>$ calculation & Ratio R \\
\hline $\begin{array}{l}\text { SeaWIFS OC2v2 } \\
\text { (R. Kudela, Personal } \\
\text { Communication) }\end{array}$ & $\begin{array}{l}<c h l>=10^{\wedge}\left(\mathrm{a}(1)+\mathrm{a}(2) * \mathrm{R}+\mathrm{a}(3) * \mathrm{R}^{2}+\right. \\
\left.\left.\mathrm{a}(4)^{*} \mathrm{R}^{3}\right)+\mathrm{a}(5)\right) \\
\mathrm{a}=[0.2974,-2.2429,0.8358,-0.0077,- \\
0.0929]\end{array}$ & $\mathrm{R}=\log _{10}\left(R_{r 5490} / R_{r 5555}\right)$ \\
\hline Morel (1988) & $\begin{array}{l}<c h l>=\left(\left(K_{d 490}-K_{w 490}\right) / X\right)^{1 / c} \\
K_{d 490}=0.02+0.1 *(\mathrm{R})^{-1.29966}\end{array}$ & $\begin{array}{l}\mathrm{R}=R_{r 5443} / R_{r 5555} \\
K_{\mathrm{m} \times 90}=0.0217 \\
\mathrm{X}=0.069, \mathrm{e}=0.702\end{array}$ \\
\hline $\begin{array}{l}\text { Abbott and Letelier } \\
\text { (1997) }\end{array}$ & $\langle c h l\rangle=0.56353 *(R)^{-0.595}$ & $\mathrm{R}=L_{u 443} / L_{u 555}$ \\
\hline $\begin{array}{l}\text { CalCOFI } \\
\text { Mitchell and Kahru } \\
\text { (1998) }\end{array}$ & $\begin{array}{l}\left\langle c h l>=10^{\wedge}\left(\mathrm{a}(1)+\mathrm{a}(2) * \mathrm{R}+\mathrm{a}(3) * \mathrm{R}^{2}+\right.\right. \\
\left.\mathrm{a}(4) * \mathrm{R}^{3}\right) \\
\mathrm{a}=[0.450,-2.860,0.996,-0.3674]\end{array}$ & $\mathrm{R}=\log _{10}\left(R_{r 5490} / R_{r 5555}\right)$ \\
\hline $\begin{array}{l}\text { CZCS GPs } \\
\text { Gordon et al. (1983) }\end{array}$ & $\begin{array}{l}\mathrm{C}_{13}=10^{\wedge}\left(0.053+1.71^{*} \mathrm{R} 1\right) \\
\mathrm{C}_{23}=10^{\wedge}\left(0.522+2.44^{*} \mathrm{R} 2\right) \\
<c h l>+\mathrm{P}=\mathrm{C}_{13} ; \text { if } \mathrm{C}_{13}>1.5 \mathrm{mg} \mathrm{m}^{-3} \text { then } \\
<c h l>+\mathrm{P}=\mathrm{C}_{23}\end{array}$ & $\begin{array}{l}\mathbf{R}_{1}=\log _{10}\left(L_{\text {wnsso }} / L_{\text {nnf43 }}\right) \\
\mathbf{R}_{2}=\log _{10}\left(L_{\text {nnsso }} / L_{\text {nns }}\right) \\
\mathbf{P}=\text { phaeopigments } \\
(<c h l>+\mathrm{P})= \\
1.3404^{*}<c h l>^{0.983}\end{array}$ \\
\hline $\begin{array}{l}\text { OCTS-C } \\
\text { OCTS-C (1996) }\end{array}$ & $\begin{array}{l}<c h l>=10^{\wedge}(\mathrm{a}(1)+\mathrm{a}(2) * \mathrm{R}) \\
\mathrm{a}=[-0.55006,3.497]\end{array}$ & $\begin{array}{l}\mathrm{R}=\log _{10}\left(\left(L_{n \pi 520}+\right.\right. \\
\left.\left.L_{n \pi 565}\right) / L_{n \pi 490}\right)\end{array}$ \\
\hline
\end{tabular}




\section{Semi-analytical algorithms}

Semi-analytical (or semi-empirical) models use radiative transfer theory to relate upwelling radiances to the concentration of in-situ constituents in the water column, including phytoplankton, detritus and colored dissolved organic matter. Parts of the radiative model are expressed by empirical relationships. Constituent concentrations are then derived from irradiance and radiance values measured at several wavelengths by inversion of the system of equations. Two important semi-analytical algorithms are discussed below, the one developed by Carder et al. (1999) and the other by Garver and Siegel (1997). We have chosen to apply the latter to the data to retrieve the IOPs, and in particular the absorption by color dissolved organic matter, which was not measured. More details on the Garver and Siegel (1997) are therefore given.

\section{Model of Carder et al. (1999)}

Carder et al. (1999) developed algorithms to retrieve $<c h l>, a_{p h}$ and $a_{C D O M}$ from radiometric measurements in the MODIS spectral channels. They assume that the remote sensing reflectance is simply related to the absorption, $a(\lambda)$, and backscattering, $b_{b}(\lambda)$, coefficients through:

$$
R_{r s}(\lambda)=\text { const } \frac{b_{b}(\lambda)}{a(\lambda)}
$$

The model involves several parameters that are fixed or can be specified based on the region and season considered. These empirical parameters control the spectral shape of $a(\lambda)$ and $b_{b}(\lambda)$. Their systems of semi-analytical equations reduce to two equations that 
are inverted to solve for two free variables, $a_{p h}(650)$ and $a_{C D O M}(400)$ as a function of ratios of observed remote sensing reflectances. They also use an empirical relationship to relate $<c h l>$ to $a_{p h}(650)$ obtained through linear regression of $\log (<c h l>)$ versus $\log \left(a_{p h}(650)\right)($ similar to Bricaud et al, 1995). Carder et al. (1999) note that their semianalytical model is only valid for oligotrophic waters where $<c h l>$ does not exceed $2 \mathrm{mg} \mathrm{m}^{-3}$. For larger values of chlorophyll concentration, they use empirical algorithms similar to the ones shown in Table 3.1 .

Remote sensing reflectances at the visible MODIS wavelengths from two datasets (one subtropical, temperate-summer and the other global) were placed into the model, the model was inverted and values for $a_{p h}(650), a_{C D O M}(400)$ and the chlorophyll concentration were estimated. The absorption coefficients, $a$ and $a_{p h}$, were also retrieved at the MODIS wavelengths. The model was applied to three different bio-optical domains with different values for the empirical parameters involved in the model (the parameters were optimized separately for each domain). Domain 1 includes high photoprotective pigment to chlorophyll ratio and low self-shading (referred to as "unpackaged"). Domain 2 corresponds to low photoprotective pigment to chlorophyll ratio and high self-shading (designated "packaged"). Domain 3 is transitional or global-average type. Carder et al. (1999) claim that algorithms errors can be reduced from $45 \%$ to less than $30 \%$ if the data can be separated into the "unpackaged" and "packaged" domains, possibly identified from space through relationships between sea surface temperature and nitrate. The degree of nitrate/nutrient limitation can then be used to assess packaged and unpackaged domains. 


\section{Model of Garver and Siegel (1997)}

A nonlinear statistical method for the inversion of ocean color spectra is used to determine three IOPs, the absorption by phytoplankton and dissolved/detrital materials, and the backscattering due to particles. The model assumes that:

- The relationship between remote sensing reflectance and backscattering and absorption is known. A formulation slightly more complex than (29) is used, involving linear and quadratic terms:

$$
R_{r s}(\lambda)=\sum_{i=1}^{2} l_{i}\left[\frac{b_{b}(\lambda)}{b_{b}(\lambda)+a(\lambda)}\right]^{i}
$$

where $l_{l}=0.0949 \mathrm{sr}^{-1}$ and $l_{2}=0.0794 \mathrm{sr}^{-1}$ (Gordon et al., 1988). The linear term reduces to (29) since the backscattering coefficient is much smaller than the absorption coefficient. The quadratic term is important for high values of $\boldsymbol{R}_{r s}$.

- The optical coefficients for pure water, $a_{w}(\lambda)$ and $b_{b w}(\lambda)$ are known. The optical properties of pure seawater were estimated by Smith and Baker (1981). Values of the backscattering coefficient are assumed to be equal to half the total scattering coefficients for seawater. The optical coefficients are plotted versus visible wavelength in Fig. 3.1a. - The spectral shapes of the specific/normalized absorption coefficients for phytoplankton and for dissolved/detrital materials and the normalized backscattering coefficient for particulates are known (Fig. 3.1b,c,d).

The absorption and backscattering coefficients in (30) are defined in (9) and (19). Since $a_{d}(\lambda)$ and $a_{C D O M}(\lambda)$ have similar spectral shapes, Garver and Siegel (1997) 
combined them into the same parameter:

$$
a_{d m}(\lambda)=a_{d}(\lambda)+a_{C D O M}(\lambda)
$$

The spectral signature of $a_{d m}(\lambda)$ is modeled as an exponential shape similar to (12):

$$
a_{d m}(\lambda)=a_{d m}\left(\lambda_{0}\right) e^{-s\left(\lambda-\lambda_{0}\right)}
$$

where $a_{d m}\left(\lambda_{0}\right)$ is the absorption at a reference wavelength, $\lambda_{0}=440 \mathrm{~nm}$. The values for $S$, the exponential slope, were chosen to span values found in the literature $(S=0.006,0.014$ and $0.020 \mathrm{~nm}^{-1}$ ). The normalized absorption coefficient for dissolved/detrital substances, defined as $a_{d m}(\lambda) / a_{d m}(440)$, is plotted in Fig. 3.1b. The spectral shape of phytoplankton absorption results from the combination of the light-absorbing properties of chlorophyll-a and other pigments modified by packaging within the cell. Various models of $a_{p h} *(\lambda)$ versus wavelengths were considered (Prieur and Sathyendranath, 1981; Morel, 1988; Garver and Siegel, 1994; Bricaud et al., 1995). Some of these models are depicted in Fig. 3.1c.

Experimental data and theory indicate that under most conditions, $b_{b p}(\lambda)$ values decrease monotonically with increasing wavelengths (Morel, 1973). The following power law spectra are considered:

$$
b_{b p}(\lambda)=b_{b p}\left(\lambda_{0}\right)\left(\frac{\lambda}{\lambda_{0}}\right)^{i}
$$




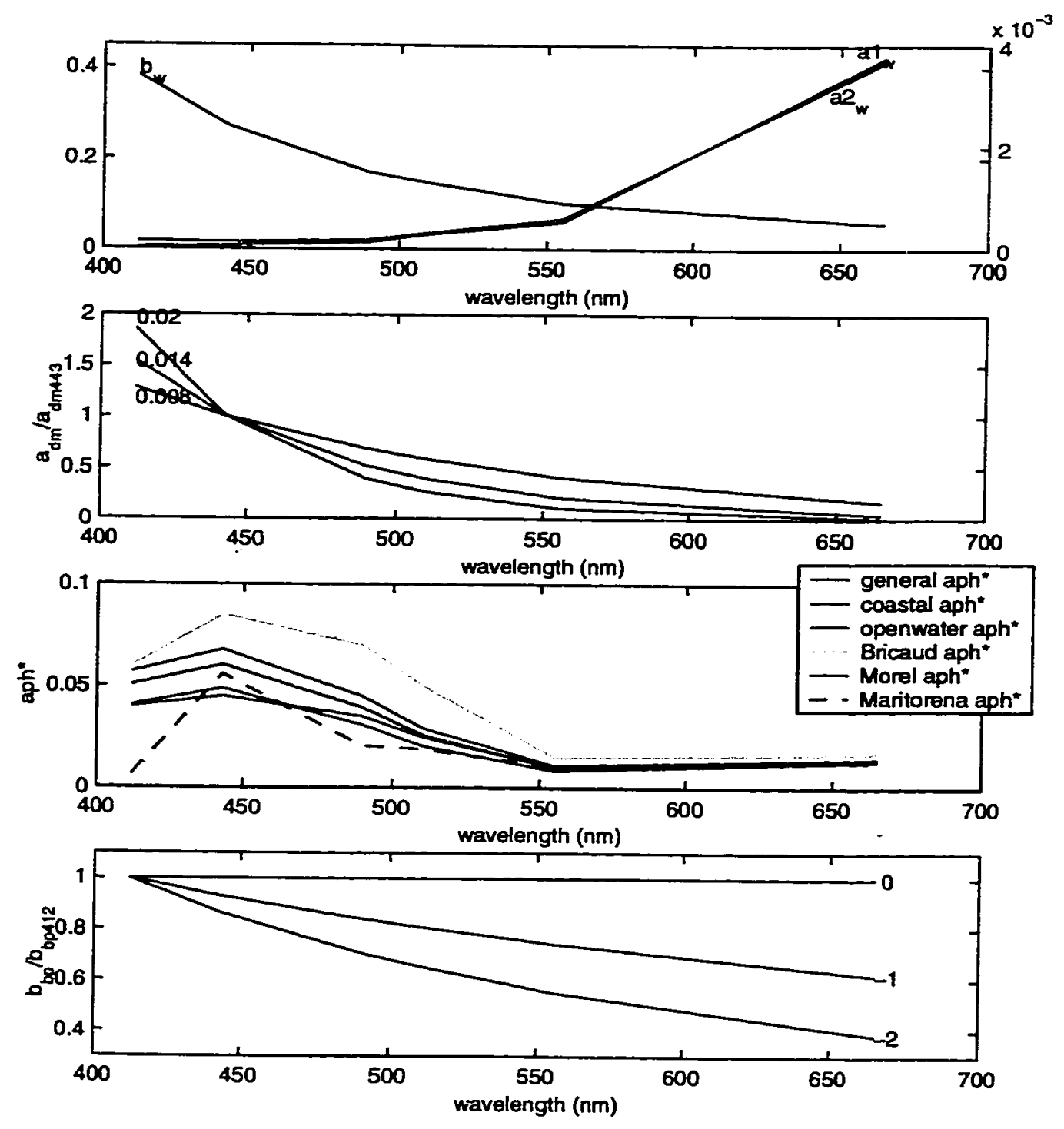

Fig. 3.1. Known (or measured) and assumed spectral shapes composing the IOP inversion model of Garver and Siegel (1997). (a) Absorption, $a_{w}$, and backscattering, $b_{w}$, by pure seawater $\left(a_{w 1}\right.$, Pope and Fry, 1997; $a_{w 2}$, Smith and Baker, 1981). Units are $\mathrm{m}^{-1}$ (left axis for $a_{w}$ and right axis for $b_{w}$ ). (b) Three models for the normalized absorption for dissolved/detrital substances with $S=0.008,0.014$ and $0.020 \mathrm{~nm}^{-1}$. (c) Various modeled spectra for the chlorophyll-specific absorption coefficient for phytoplankton, $a_{p h} *\left(\mathrm{~m}^{2} \mathrm{mg}^{-1}\right)$ : Morel (1988), Bricaud et al. (1995), Maritorena (Personal Communication, 2000), and the values estimated from the $\mathrm{a}^{*}$ method and averaged over all the stations (general) or over the coastal and open ocean stations. (d) Models for the normalized scattering coefficient, $b_{b p} / b_{b p}(412)$, with powers $0,-1$ and -2 . 
where $i=0,-1$ or -2 and $\lambda_{0}=412 \mathrm{~nm}$. The normalized backscattering coefficient, defined as $b_{b p}(\lambda) / b_{b p}(412)$, is displayed in Fig. 3.1d.

The remote sensing reflectance model (30) in which the absorption and backscattering coefficients are expressed using $(9,19,31,32,33)$ and using a given spectral model for $a_{p h}{ }^{*}$, is inverted to solve for the three unknown parameters, $b_{b p}(412)$, $a_{d m}(440)$, and $<c h l>$. By multiplying the retrieved magnitudes by the assumed spectral shapes, IOP estimates can be determined at all wavelengths. A nonlinear least squares fit method is used to invert the model (see Chapter 5 for details).

Garver and Siegel (1997) applied their semi-analytical model to in-situ optical (eight channels ranging from 410 to $665 \mathrm{~nm}$ ) and biogeochemical measurements of the Bermuda Atlantic Time Series (BATS). The data considered were collected with a biweekly to monthly interval in 1992 and 1993 at a single location in the nutrient-poor (blue) Sargasso Sea. The model was found to be most sensitive to changes in $S$, with some variability in model results obtained when varying the $a_{p h} *(\lambda)$ spectrum and minimal variations observed using $b_{b p}(\lambda)$ different spectra. Comparing the optical properties retrieved from the model to the BATS biogeochemical variables $(<c h l>$, $K_{d}(410) / K_{d}(488)$, POC, PON, nutrients, etc.) through linear regressions, they obtained the best fit with $S=0.02 \mathrm{~nm}^{-1}$, with the $a_{p h}{ }^{*}$ spectral shape of Bricaud et al. (1995) and with a $b_{b p}$ modeled as $\lambda^{-1}$. The IOP model was found to fit the in-situ $R_{r s}$ spectra better in winter (higher pigment and dissolved/detrital materials) than during the "blue" conditions of the summer months. This suggests that the knowledge of pure seawater optical properties may still be improved. 
The chlorophyll-a concentration retrieved from the IOP model showed an excellent correspondence with the BATS HPLC chlorophyll-a determinations $\left(r_{l}^{2}=\right.$ $81 \%)$. These results were also compared with chlorophyll estimates obtained from a CZCS-type empirical algorithm. The results of the two models are similar, with the CZCS estimates explaining $86 \%$ of the variance of the BATS HPLC chlorophyll-a data. When separated by season, the two models performed better in winter $\left(r_{l}^{2}=73-95 \%\right)$ when $\left\langle c h l>\right.$ is highest, than during the summer $\left(r_{l}{ }^{2}=1-15 \%\right)$. More importantly, the IOP model chlorophyll-a values have a better and clearer $1: 1$ relationship with the BATS HPLC data than the ones retrieved by the CZCS empirical algorithm. The latter algorithm underestimates the chlorophyll-a concentration, especially during winter-spring months when the in-situ values exceed $1 \mathrm{mg} \mathrm{m}^{-3}$. This is perhaps due to the ability of the semianalytical model to separate phytoplankton absorption from dissolved/detrital absorption.

A flow diagram of the semi-analytical inversion model of Garver and Siegel (1997) is presented in Fig. 3.2. The input parameters given to the model (the measured $R_{r s}(\lambda), a_{p h} *, S$ and $\left.i\right)$, the iterative nonlinear inversion method and the outputs obtained from the models (<chl> or $a_{p h}(443), a_{d}(443)$ and $b_{b p}(443)$ ) are clearly identified. 


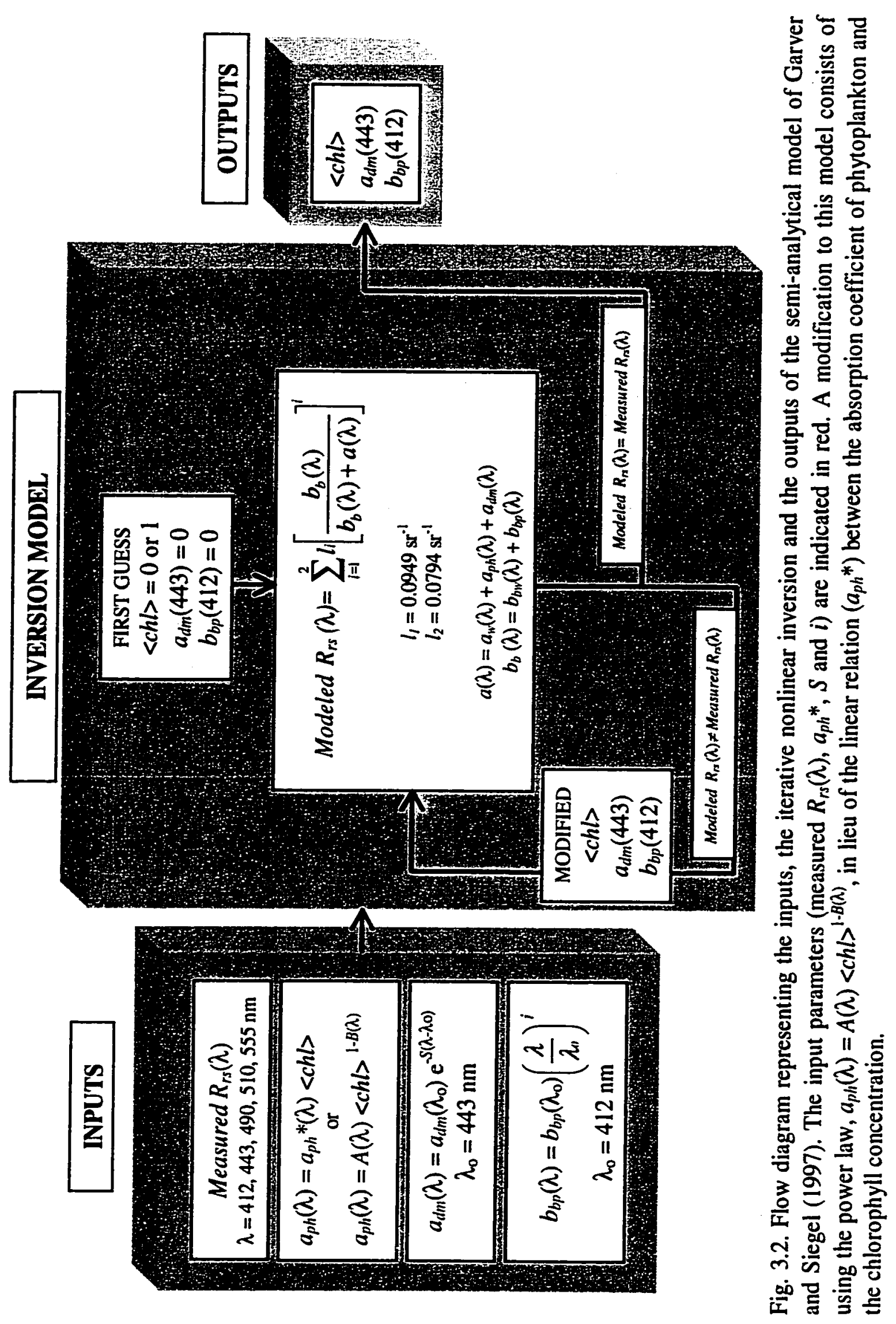




\section{CHAPTER 4}

\section{DATA AND METHODS}

\section{Data}

\section{General description}

Data for this study were collected during several oceanographic cruises during the period September 1993 to July 1998. The regions sampled included the North and equatorial Atlantic Ocean, the Indian Ocean and the South and equatorial Pacific Ocean, over a wide range of water types. The station locations for each cruise in the open ocean are shown in Fig. 4.1. A significant amount of data was also collected in coastal California (Fig. 4.2a) near Monterey Bay (Fig. 4.2b). Two sites in the vicinity of moorings M1 and M2 were heavily sampled at $~ 21$-day intervals. The number of stations per month over the entire period considered (1993-1998 for mooring M1 and 1995-1998 for mooring M2) is shown in Fig. 4.3.

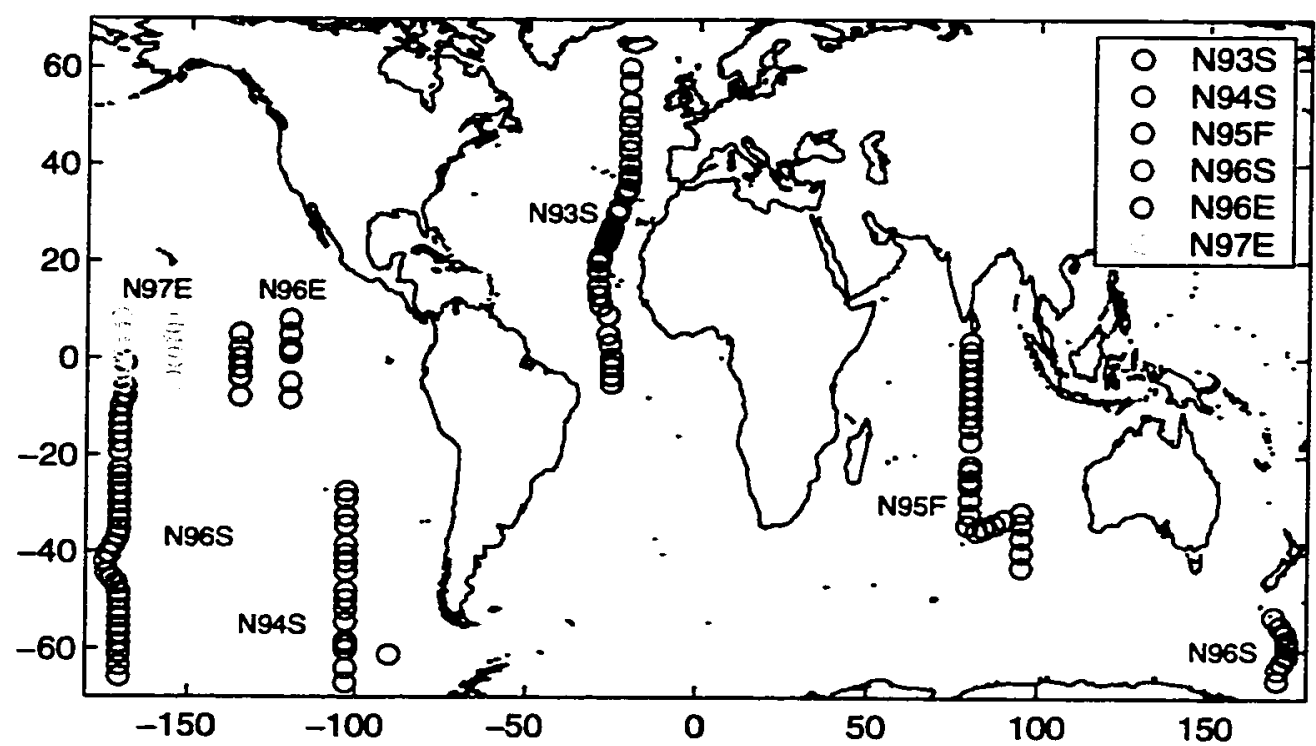

Fig. 4.1. Geographical location of the open ocean stations. The colors of the open circle symbols indicate the different cruises. 

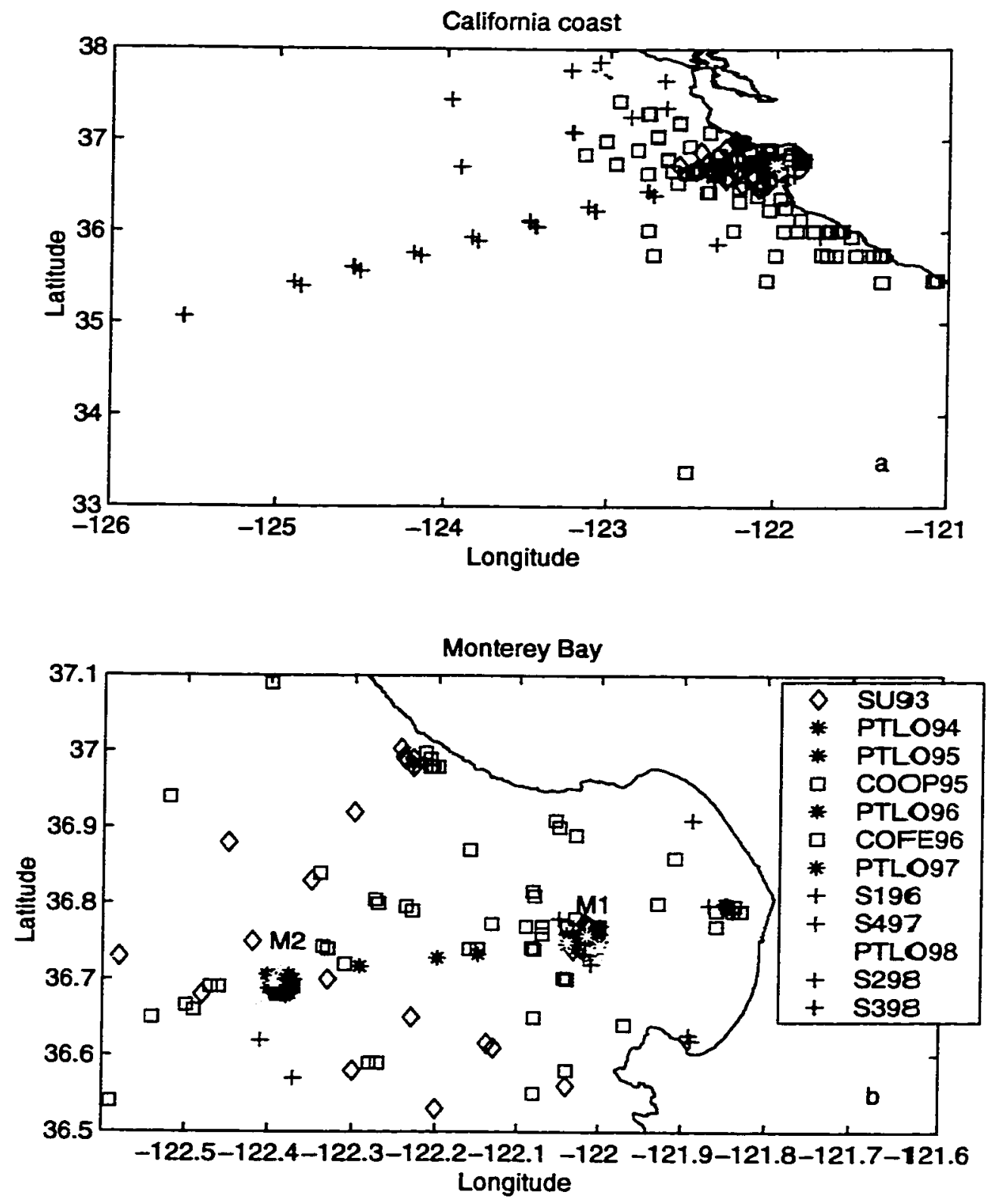

Fig. 4.2. (a) Geographical location of the stations off the coast of central California, including CalCOFI line 67 extending as far as $125^{\circ} \mathrm{W} 30^{\prime}$ in the California Current System. (b) Stations in, and offshore of, Monterey Bay. M1 and M2 are two oceanographic moorings maintained by MBARI, Moss Landing, California. The colors and symbols correspond to the different cruises. 

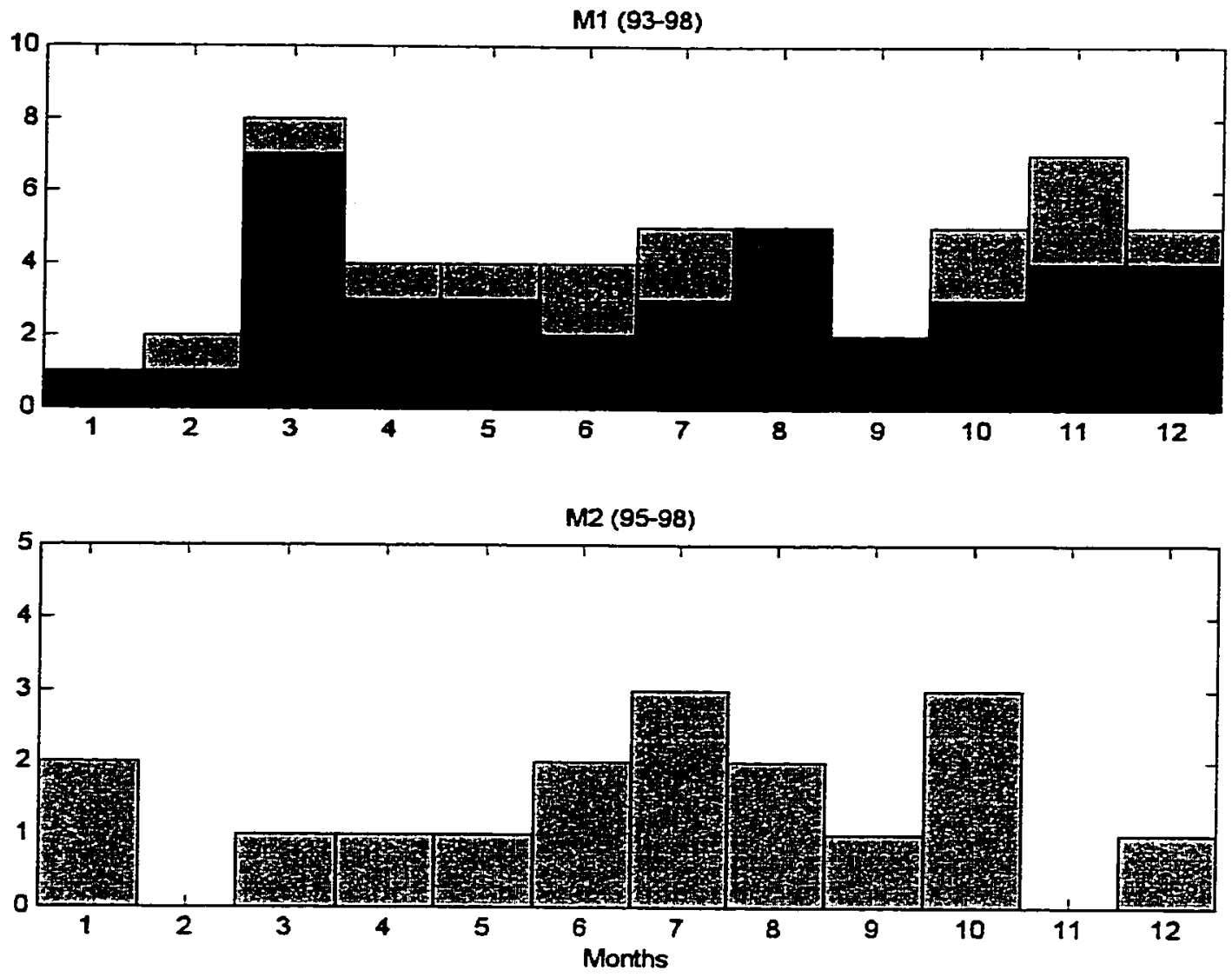

Fig. 4.3. Temporal distribution of the number of stations for the different months of the year in the vicinity of moorings M1 (between 1993 and 1998) and M2 (between 1995 and 1998). The number of stations where samples were taken for the $a^{*}$ analysis are shown in blue, whereas the number of PRR stations are depicted in light blue.

Three major types of data were used. The first type consists of optical radiances and irradiances measured in the water column using a Profiling Reflectance Radiometer (PRR). Water samples were taken at various depths with a CTD/Rosette. The second kind of data includes spectral absorption properties of the sampled seawater determined using a spectrophotometer ( $\mathrm{a}^{*}$ method, see details below). The third type comprises values of 
chlorophyll-a concentration derived from the water samples. Table 4.1 provides the location and time information for the cruises considered. The number of stations per cruise together with the quantity of the different types of data are also listed.

Table 4.1: Names of projects and cruises, geographical areas and time periods for the data considered in this study. Acronyms: CoOP (Coastal Ocean Processes), CoFe (Coastal Iron), SECRET (Studies of Ecological and Chemical Responses to Environmental Trends), NOAA (National Oceanic and Atmospheric Administration). The number of stations, of PRR profiles and of stations in which samples were taken for $\mathrm{a}^{*}$ analyses are also shown for each cruise. The number in parentheses indicate the total number of $a^{*}$ data at all depths.

\begin{tabular}{|l|l|l|l|l|l|l|}
\hline Project & Cruise & \multicolumn{1}{|c|}{ Area } & \multicolumn{2}{|c|}{ Time } & \multicolumn{3}{c|}{ Data } \\
\hline & & & & \# Sta & PRR & \multicolumn{1}{|c|}{ * $^{*}$} \\
\hline Shift up & SU93-3 & Monterey Bay & Sep. 11 - 16, 1993 & 26 & 7 & 20(20) \\
\hline $\begin{array}{l}\text { Timenterey Bay } \\
\text { Lories }\end{array}$ & Point & Monterey Bay & $\begin{array}{l}\text { Feb. 1994 - Jul. 1998 } \\
\text { (Bi-weekly) }\end{array}$ & 77 & 83 & $61(214)$ \\
\hline CoOP95 & CoOP95 & California Current & Apr. 21 - May 7, 1995 & 86 & 15 & $84(93)$ \\
\hline CoFe96 & CoFe96 & Monterey Bay & July 6 - 17, 1996 & 33 & 14 & $31(36)$ \\
\hline SECRET & S197 & California Current & Mar.3 - 7, 1997 & 7 & 7 & $21(21)$ \\
\hline SECRET & S497 & California Current & Sept. 6 - 14, 1997 & 7 & 7 & $9(12)$ \\
\hline SECRET & S198 & California Current & Jan. 21- 22, 1998 & 1 & 1 & - \\
\hline SECRET & S398 & California Current & Apr. 14 - 16, 1998 & 3 & 3 & - \\
\hline NOAA & N93S & Atlantic Ocean & Jul. 7 - Aug. 28, 1993 & 58 & 31 & $46(46)$ \\
\hline NOAA & N94S & South Pacific & Feb. 23 - Apr. 25, 1994 & 18 & 18 & - \\
\hline NOAA & N95F & Indian Ocean & Sep. 24 - Oct. 24, 1995 & 31 & 27 & $31(100)$ \\
\hline NOAA & N96S & South Pacific & Jan. 5 - Mar. 12, 1996 & 48 & 45 & $46(46)$ \\
\hline NOAA & N96E & Equatorial Pacific & Nov. 28 - Dec. 13, 1996 & 24 & 12 & $21(25)$ \\
\hline NOAA & N97E & Equatorial Pacific & May 10 - 25, 1997 & 15 & 15 & $17(17)$ \\
\hline & & Open Ocean & Jul. 1993 - May 1997 & 194 & 148 & $161(234)$ \\
\hline TOTAL & & Coastal Ocean & Sep. 1993 - Jul. 1998 & 240 & 137 & $226(396)$ \\
\hline & & Jul. 1993 - Jul. 1998 & 434 & 285 & $387(630)$ \\
\hline
\end{tabular}


All the data were collected under National Oceanic and Atmospheric Administration (NOAA) grants, with exception of the data in Monterey Bay and in the California Current, which were collected with Monterey Bay Aquarium Research Institute (MBARI) funds. These data have been used by NASA to develop the SeaWiFS OC2v4 and OC4v4 algorithms.

\section{$\underline{\text { Radiometric data }}$}

The radiometric data were collected using Profiling Reflectance Radiometers (PRR-600) manufactured by Biospherical Instruments Inc. (PRR-600, Profiling Reflectance Radiometer User's Manual). The instruments are composed of two parts:

- A wet sensor that measures downwelling irradiance, $E_{d}$, and upwelling radiance, $L_{u}$, in the water column at fixed channels in the range of the visible light $(400-700 \mathrm{~nm})$. The wavelength channels in which irradiances and radiances were measured by each of the PRR instruments used are listed in Table 4.2. They include the SeaWiFS visible bands at $412,443,490,510,555$ and $665 \mathrm{~nm}$. The PRR wet sensor is lowered from the ship, supported by its own cable, while the output from the sensors $\left(E_{d}\right.$ and $\left.L_{u}\right)$ are displayed in "real time" on a PC monitor.

- A dry sensor radiometrically identical that is kept on the deck during profiling to record the solar irradiance, $E_{d}\left(0^{+}\right)$, at the sea surface.

The wet sensor structure ensures that companion channels (up and downwelling channels) are sampled in a nearly synchronous manner and permits a sampling rate of approximately $2-3 \mathrm{~Hz}$. The irradiance collectors are $2.1 \mathrm{~cm}$ diameter trapezoidal Teflon 
sheets supported by a quartz window. In addition to the optical detectors, the PRR

instrument contains sensors to measure pressure, temperature and battery voltage.

Table 4.2: Wavelength channels in which irradiances and radiances, including PAR (photosynthetic active radiation), were measured by each of the instruments. The instrument serial number is reported in bold at the top of the table: the first number is related to the wet sensor, the second number is related to the dry sensor. The white area is related to the wet sensor: the first eight rows show the downwelling irradiance, $E_{d}$, followed by the wavelengths expressed in $\mathrm{nm}$ and then, the next eight rows show the upwelling irradiance, $L_{u}$, followed by the wavelengths expressed in $\mathrm{nm}$. The gray area refers to the solar irradiance, $E_{s}$, at the surface recorded by the dry sensor. The third column (9612) has only the wet sensor.

\begin{tabular}{|c|c|c|c|c|c|c|c|}
\hline $9612 / 9613$ & $9620 / 9613$ & 9612 & $9600 / 9602$ & $9640 / 9626$ & $9640 / 9662$ & $9640 / 9604$ & $9603 / 9614$ \\
\hline Ed412 & Ed412 & Ed412 & Ed412 & Ed412 & Ed412 & Ed412 & Ed412 \\
\hline Ed443 & Ed443 & Ed443 & Ed443 & Ed443 & Ed443 & Ed443 & Ed443 \\
\hline Ed490 & Ed490 & Ed490 & Ed490 & Ed490 & Ed490 & Ed490 & Ed490 \\
\hline Ed510 & Ed510 & Ed510 & Ed510 & Ed510 & Ed510 & Ed510 & Ed510 \\
\hline Ed555 & Ed555 & Ed555 & Ed555 & Ed555 & Ed555 & Ed555 & Ed555 \\
\hline- & - & $\overline{-}$ & - & - & Ed656 & Ed656 & Ed656 \\
\hline Ed665 & Ed665 & Ed665 & Ed665 & Ed665 & - & - & - \\
\hline PAR & PAR & PAR & PAR & PAR & PAR & - & - \\
\hline Lu412 & Lu412 & $\angle 4412$ & Lu412 & $L u 412$ & Lu412 & Lu4I2 & $L u 412$ \\
\hline$L u 443$ & $L 4443$ & Lu443 & $L u 443$ & $L u 443$ & Lu443 & Lu443 & $L 4443$ \\
\hline$L u 490$ & $L 4490$ & $L u 490$ & $L u 490$ & $L u 490$ & $L 4490$ & $L u 490$ & $L 4490$ \\
\hline Lu510 & $L 4510$ & $L 4510$ & $L 4510$ & 24510 & LuSIO & LuS10 & LuS10 \\
\hline Lu555 & Lu555 & $L u 555$ & $L 4555$ & Lu555 & $L 4555$ & - & - \\
\hline - & - & - & - & - & - & $L 4560$ & $L u 560$ \\
\hline- & - & - & - & - & Lu656 & Lu656 & Lu656 \\
\hline$L 4665$ & Lu665 & Lu665 & Lu665 & Lu665 & - & - & - \\
\hline Lu683 & Lu683 & $L 4683$ & Lu683 & $L 4683$ & - & - & $=$ \\
\hline ES412 & ES412 9 & $P=4 t$ & ES412 & Es412 & Es412 & Es412 & Es412 \\
\hline ES443. & Fs443 mins & Eagy y & 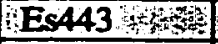 & Es443 HT: & Es443 & Es443 & Es443 \\
\hline AES40 & Es490 of & HOPF & ES490 \% & Es490 Drats & ES490 49 & Es490 & Es490 \\
\hline Es510 & ES510 & $F+1$ & 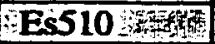 & Es510 n & Es510 & Es510 & ES510 \\
\hline ES555 & ES555 & OAdy & Es555, & Es555 & Es555 & Es555 & Es555 \\
\hline 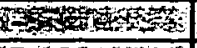 & 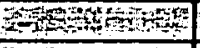 & 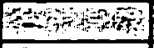 & Andrtust & Es656 & Es656 & Es656 & Es656 \\
\hline 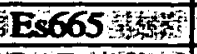 & Es665 & 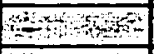 & Es665 tw1 & 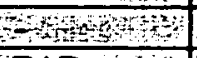 & $-6 \mathrm{~s}$ & $-6 \mathrm{Am}$ & +4, \\
\hline PAR & PAR & 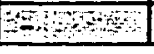 & PAR Fon & PAR & PAR & PAR & $\mathbf{P A R}$ \\
\hline
\end{tabular}


All the instruments were calibrated once a year at the UCMBO calibration facility of the University of California at Santa Barbara. The calibration factors were used in the processing of the data.

\section{CTD/Rosette}

The CTD/Rosette included instruments to measure seawater conductivity, temperature, pressure and dissolved oxygen concentration. Additional chemical and biological parameters were measured from discrete water samples taken with the rosette. These parameters are available in the MBARI database. Chlorophyll concentrations were determined via fluorometric methods using the bottle water samples (Yentsch and Menzel, 1963, Holm-Hansen et al., 1965).

\section{Methods}

\section{Radiometric data processing}

The following processing methods were applied to the raw radiance and irradiance data of the PRR in channels centered at $412,443,490,510,555$ or 560,656 or 665/683 nm (see Table 4.2 for more details on the channels of each instrument).

\section{Processing with $B B O P$}

The program used to process the radiometric PRR data comes from the Bermuda Bio-Optics Project (BBOP) Data Processing software (U.S. JGOFS Planning Report Number 19). This program first flags negative data, averages the data over 1-meter 
intervals and creates separate files for the up and down casts. Then, a 5-point moving average is applied to the up and down cast data to reduce instrumental noise. In order to reduce environmental "noise" caused by surface wave focusing and defocusing, a depth interval between 5-12 $\mathrm{m}$ is chosen to extrapolate the downward irradiance to the surface and to estimate the null depth irradiance, $E_{d}\left(0^{-}\right)$, just below the surface. The vertical attenuation coefficient (slope) and the logarithm of the null depth irradiance (intercept) were obtained through the following linear regression applied over the 5-12 $\mathrm{m}$ depth range (see Fig. 4.4):

$$
\ln E_{d}\left(0^{\circ}\right)=\ln E_{d}(z)+K_{d} z
$$

which corresponds to the logarithmic decrease of $E_{d}$ with depth $z$ with attenuation coefficient $K_{d}$ (see 20). A similar analysis was performed with the upwelling radiance, $L_{u}$, to estimate $K_{u}$ and the null depth radiance $L_{u}\left(0^{-}\right)$.

\section{Special processing}

For a few selected stations with noisy irradiance profiles (especially in the coastal rich waters), the linear regression (34) was performed over a specially selected range of depths in which the profiles appeared to decrease exponentially with depth, thus excluding erroneous data points. This fit was done on the raw irradiances (without moving averaging applied) sampled every meter. The new (and improved) values for the vertical attenuation coefficient $K_{d}$ and for the null depth irradiance $E_{d}\left(0^{-}\right)$were used for subsequent analyses in lieu of the values estimated by BBOP. 




Fig. 4.4. Downward irradiance at $555 \mathrm{~nm}$ versus depth for a station in Monterey Bay (dots) and exponential fit (curve) to the points in depth range 5-12 m (shaded area).

Estimation of chlorophyll-specific absorption coefficients

The chlorophyll-specific absorption of photosynthetic pigment, $a_{p h}{ }^{*}$, and of particulate materials, $a_{d}{ }^{*}$, were estimated following the method described in Kishino et al, 1985 (often referred to as the $a^{*}$ method). Specific volumes were taken from bottle samples and filtered on Whatman GF/F glass-fiber filters. The sample depths, the volumes filtered and the filtration surface areas are shown for each cruise in Table 4.3.

All samples were stored in liquid nitrogen at $-70^{\circ} \mathrm{C}$ until the analysis in laboratory. At the moment of the analysis each sample was allowed to thaw while floating on a $0.2 \mu \mathrm{m}$ filtered seawater to ensure saturation of the filter. Optical density 
Table 4.3: Depths (m), volumes filtered (ml) and surface areas filtered $\left(\mathrm{cm}^{2}\right)$ for each project and cruise.

\begin{tabular}{|l|l|l|l|l|}
\hline Project & Cruise & Depth $(\mathbf{m})$ & Volume filtered $(\mathbf{m l})$ & Surface filtered $\left.\mathbf{c m}^{2}\right)$ \\
\hline $\begin{array}{l}\text { Monterey Bay } \\
\text { Time Series }\end{array}$ & $\begin{array}{l}\text { Point Lobos } \\
1994-1998\end{array}$ & $0,10,20,40$ & 540 & 2.1 \\
\hline CoOP95 & CoOP95 & 0 (more depths) & 540 & 2.1 \\
\hline CoFe96 & CoFe96 & 0 & 552 & 2.1 \\
\hline SECRET & S197 & 0 & 540 & 2.1 \\
\hline SECRET & S497 & 0 & 540 & 2.1 \\
\hline NOAA & N93S & 0 (more depths) & 1050 & 2.1 \\
\hline NOAA & N95F & 0 (more depths) & 1050 & 2.1 \\
\hline NOAA & N96S & 0 & 1074 & 2.1 \\
\hline NOAA & N96E & 0 (more depths) & 1074 & 2.1 \\
\hline NOAA & N97E & 0 & 1050 & 2.1 \\
\hline
\end{tabular}

spectra (350-750 nm) of the filters were measured using a Hewlett Packard 8452A Diode Array Spectrophotometer and a Labsphere integrating sphere RSA-HP-84. Baseline effects were removed by subtracting the spectrum of the blank GF/F filter wetted with filtered water. These baseline-subtracted optical density spectra were then corrected for the path length amplification effect ("beta correction", see Bricaud and Stramski, 1990) and an equation similar to (14) was used to estimate the particulate absorption coefficient spectrum, $a_{p}(\lambda)$. The coefficients for the correction were estimated using a cross calibration with a Uvikon 860 spectrophotometer modified for through-filter measurements for which the beta correction was known. Replicate samples were collected in Monterey Bay at specific stations during the SU93-3 cruise. Each sample was run on both instruments. To determine an empirical calibration factor for all the data, a single linear regression was applied to the combined data set (17 pairs). The best fit for this data set was a third order polynomial (R. Kudela, Personal Communication). 
Detrital particulate absorption was estimated by extracting phytoplankton pigments from the filters used to determine $a_{p}(\lambda)$ with absolute methanol and measuring the absorption spectra of the depigmented particles (Kishino et al., 1985). Pigments were extracted from the filters for a minimum of 4 hours while floating on a small quantity of methanol in a Petri dish. Occasionally, samples from the coastal water or from the subsurface chlorophyll maximum layer resisted extraction, as was apparent from the absorption spectra of the filters, which still exhibited peaks due to phytoplankton pigments. These samples were placed in methanol for up to 20 hours (replacing the methanol a few times during this period) to remove residual peaks. This procedure results

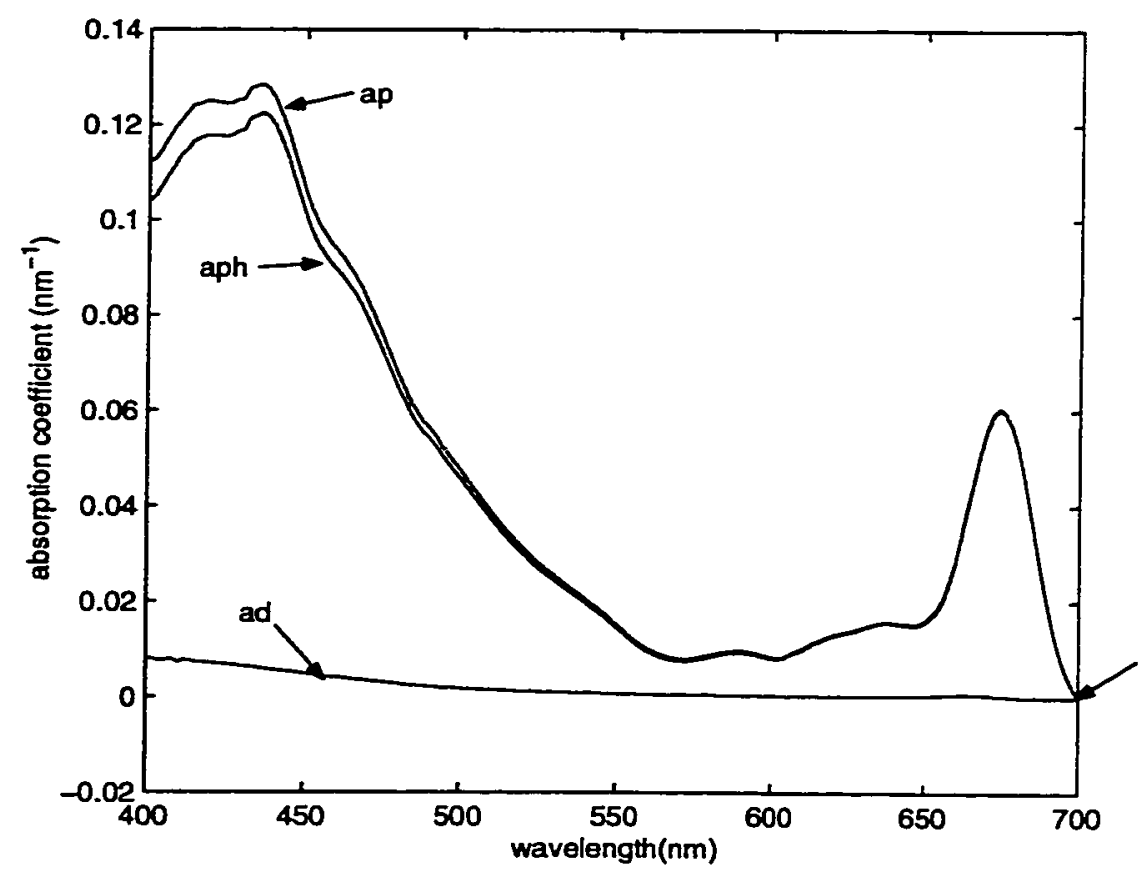

Fig. 4.5. Absorption coefficients for phytoplankton, $a_{p h}$, for detritus $\left(a_{d}\right)$ and for particles $\left(a_{p}\right)$ as a function of wavelength, after adjustment so that they are all equal to zero at 700 nm. 
in an estimate for the detrital particle absorption coefficient spectrum, $a_{d}(\lambda)$, and the phytoplankton absorption coefficient spectrum $a_{p h}(\lambda)$, which can be determined by difference, $a_{p h}(\lambda)=a_{p}(\lambda)-a_{d}(\lambda)$. Before subtraction, $a_{p}$ and $a_{d}$ were adjusted (constant shift) so as to be equal at $700 \mathrm{~nm}$ (Fig. 4.5).

\section{Data adjustments for the application of empirical models}

The empirical models to estimate the chlorophyll concentration from radiance data sensed remotely by satellites use wavelength channels that are different, in some cases, to the in-situ radiometric data considered here. Adjustments were therefore necessary to convert from values measured at one wavelength to values at another nearby wavelength, e.g., from 510 to $520 \mathrm{~nm}$ and from 555 to $565 \mathrm{~nm}$. The reflectance ratios predicted as a function of chlorophyll concentration by the semi-analytical model of Morel (1988), adapted with the Pope and Fry (1997) values for $a_{w}$, were adopted to convert between 555 and $565 \mathrm{~nm}$ and between 510 and $520 \mathrm{~nm}$ (O'Reilly et al., 1998). According to this model, the $R_{r s 55 s} / R_{r s 56 s}$ ratio decreases from 1.13 to 0.97 as $<c h l>$ increases from 0.015 to $7 \mathrm{mg} \mathrm{m}^{-3}$, whereas $R_{\text {rs } 5 I d} / R_{r s 520}$ varies from 1.32 to 0.95 for the same concentration range. Polynomials of the first and third orders were obtained by least squares fit to the reflectance ratio curves shown in O'Reilly et al. (1998).

Some of the empirical algorithms (Table 3.1) involve ratios of normalized waterleaving radiances, $L_{n n}$. When $L_{n n}$ was needed, the remote sensing reflectance was converted to $L_{w n}$ by mutiplying $R_{r s}$ by the mean extraterrestrial solar irradiance (see 28 ). 


\section{Implementation of the semi-Analytical inversion method of Garver and Siegel}

Remote sensing reflectances at five wavelengths $(412,443,490,510$ and $555 \mathrm{~nm})$ instead of eight were used as inputs when applying the Garver and Siegel (1997) inversion model. Note that the above wavelengths are similar but not equal to those used by Garver and Siegel (1997). This discrepancy, however, does not affect substantially the efficiency and the results of the model. One minor practical consequence is that the reference wavelength for $a_{d m}$ was taken at 443 and not at $440 \mathrm{~nm}$.

The remote sensing reflectance model (30) in which the absorption and backscattering coefficients are expressed using $(31,32,33)$ and using a given spectral model for $a_{p h}{ }^{*}$, was inverted to solve for the three unknown parameters, $b_{b p}(412)$, $a_{d m}(443)$, and $\langle c h l>$. This general nonlinear least squares model was solved using a Gauss-Newton algorithm (Bates and Watts, 1988). The method includes a linearization (first order Taylor expansion about first guess values) of the remote sensing reflectance model (30) to iteratively improve an initial parameter guess. At each iteration step the misfit between the model and measured $R_{r s}$ is minimized through regular linear least squares fit to obtain corrections to the parameter values used at the previous step. Derivatives of the model $R_{r s}$ with respect to the three unknowns were estimated analytically and the procedure was implemented in MATLAB. First guess values for the three unknowns were set to zero. Convergence of the algorithm towards the measured remote sensing reflectances was achieved with less than 10 iteration steps.

The parameters estimated from the IOP inversion model, $b_{b p}(412), a_{d m}(443)$, and $\left\langle c h l>\right.$, were then multiplied by their respective spectral shapes $\left(a_{p h}{ }^{*}\right.$ model and equations 
30 and 31 ) to obtain estimates of the three IOPs, $a_{p h}(443), a_{d m}(443)$ and $b_{b p}(443)$. To validate the IOP model, a sensitivity analysis was performed which examines the effects of changing the different modeled spectral shapes $\left(a_{p h} *\right.$ model, $S$, and power for $b_{b p}$; see Fig. 2.6) adopted. In addition to the values used by Garver and Siegel (1997), the $a_{p h}$ * values of S. Maritorena (Personal Communication) were utilized, as well as $a_{p h}{ }^{*}$ spectral shapes and $S$ values determined from the data:

- The spectral shapes of $a_{p h} *$ were taken from the average of the chlorophyll-specific absorption coefficients obtained with the $a^{*}$ method for the open ocean, the coastal stations and regional subsets separately (near-surface samples only).

- $S$ was set to values ranging from 0.015 to $0.025 \mathrm{~nm}^{-1}$, for the different subsets of data considered. These values are slightly larger than those corresponding to the average absorption spectrum shape for detritus (see equation 11) estimated from the data.

The absorption coefficient for pure seawater was taken from the laboratory measurements of Pope and Fry (1997) instead of those of Smith and Baker (1981) (see curve $a_{w 1}$ vice curve $a_{w 2}$ in Fig. 3.1b). For the sensitivity analysis, the minimum value of $S$ was taken as $0.008 \mathrm{~nm}^{-1}$ (instead of $0.006 \mathrm{~nm}^{-1}$ in Garver and Siegel, 1997) because too small values of $S$ cause model inversion problems and produce erroneous results for a significant number of stations.

The retrieved IOPs from each of the model runs were then compared (least squares fit) with the in-situ chlorophyll concentration and with the measured $a_{p h}$ and $a_{d}$ at $443 \mathrm{~nm}$. 
Modification of the semi-Analytical inversion method of Garver and Siegel

In the inversion model of Garver and Siegel (1997), the chlorophyll concentration and the absorption coefficient of phytoplankton are assumed to be linearly related, and the chlorophyll-specific absorption by phytoplankton, $a_{p h}{ }^{*}$, is supposed to be independent of the chlorophyll concentration (see 10). The spectral shape of the phytoplankton absorption is imposed and given to the model through $a_{p h}{ }^{*}$. The modeled chlorophyll concentration is related to the modeled $a_{p h}$ via the same given $a_{p h} *$ spectrum.

It will be seen, however, that the relationship between $\left\langle c h l>\right.$ and $a_{p h}$ is non-linear due to the additional absorption by accessory pigments (mostly important in oligotrophic conditions) and due to packaging effects inhibiting absorption for large values of chlorophyll concentrations. Thus, it is more appropriate to use the power law:

$$
a_{p h}(\lambda)=A(\lambda)<c h l>^{1-B(\lambda)},
$$

derived from (10) and (11), insiead of the linear relation (10) for the absorption by phytoplankton in model (30). The coefficient $A(\lambda)$ contains the spectral shape information, whereas $B(\lambda)$ represents the effects of the accessory pigments and packaging. Note that if $B(\lambda)$ is zero, (35) becomes identical to (10). The inversion model of Garver and Siegel (1997) was modified accordingly. It was run with the remote sensing refectances in five bands (412 to $555 \mathrm{~nm}$ ) using (35) in which the coefficients $A$ and $B$ were estimated from the data via least-squares fit method. 


\section{CHAPTER 5}

\section{RESULTS}

\section{Variability with latitude}

The latitudinal variation of optical properties at the open ocean stations is shown in Fig. 5.1. Parameters that represent the concentration of chlorophyll, such as the ratios of upwelling radiances, $L_{u 443} / L_{u 555}$ and $L_{u 490} / L_{u 555}$, the surface values of the absorption coefficient for phytoplankton at $443 \mathrm{~nm}, a_{p h}(443)$, and the in-situ chlorophyll concentration, $\langle c h l>$, show similar patterns related to major oceanographic regions and fronts. Chlorophyll absorbs more (or equivalently "reflects" less) at shorter wavelengths (443 and $490 \mathrm{~nm}$ ) than at $555 \mathrm{~nm}$ (Fig. 2.5). The ratios $L_{u 443} / L_{u 555}$ and $L_{u 490} / L_{u 555}$ are therefore inversely related to chlorophyll concentration and to $a_{p h}(443)$. The equatorial upwelling region (mostly in the Pacific and Atlantic) shows a maximum in <chl> (reaching $0.3 \mathrm{mg} \mathrm{m}^{-3}$ ) and $a_{p h}(443)$ corresponding to low values for the ratios of radiances. In both hemispheres, the chlorophyll concentration is low in the subtropical gyres (mid-latitudes $20^{\circ}-40^{\circ}$ ). In the North Atlantic, pigment concentration increases with increasing latitudes north of $40^{\circ}$. South of $40^{\circ} \mathrm{S}$ in the Pacific, $\langle\mathrm{chl}\rangle$ increases with increasing south latitudes. In the eastern part (cruise N94S, cyan symbols) the chlorophyll concentration decreases beyond the Antarctic Polar Front (south of $60^{\circ} \mathrm{S}$ ).

A maximum in $a_{d}(412)$ is seen near the equator (Fig. 5.1, right panels) and minima are present at mid-latitudes. The coefficient $a_{d}(412)$ also increases with latitude 
north of $40^{\circ}$ in the North Atlantic. The absorption by detritus in the Indian Ocean departs essentially from the above-mentioned trends (green symbols): The coefficient $a_{d}(412)$ is low $\left(<10^{-2} \mathrm{~m}^{-1}\right)$ and reaches a minimum near the equator.
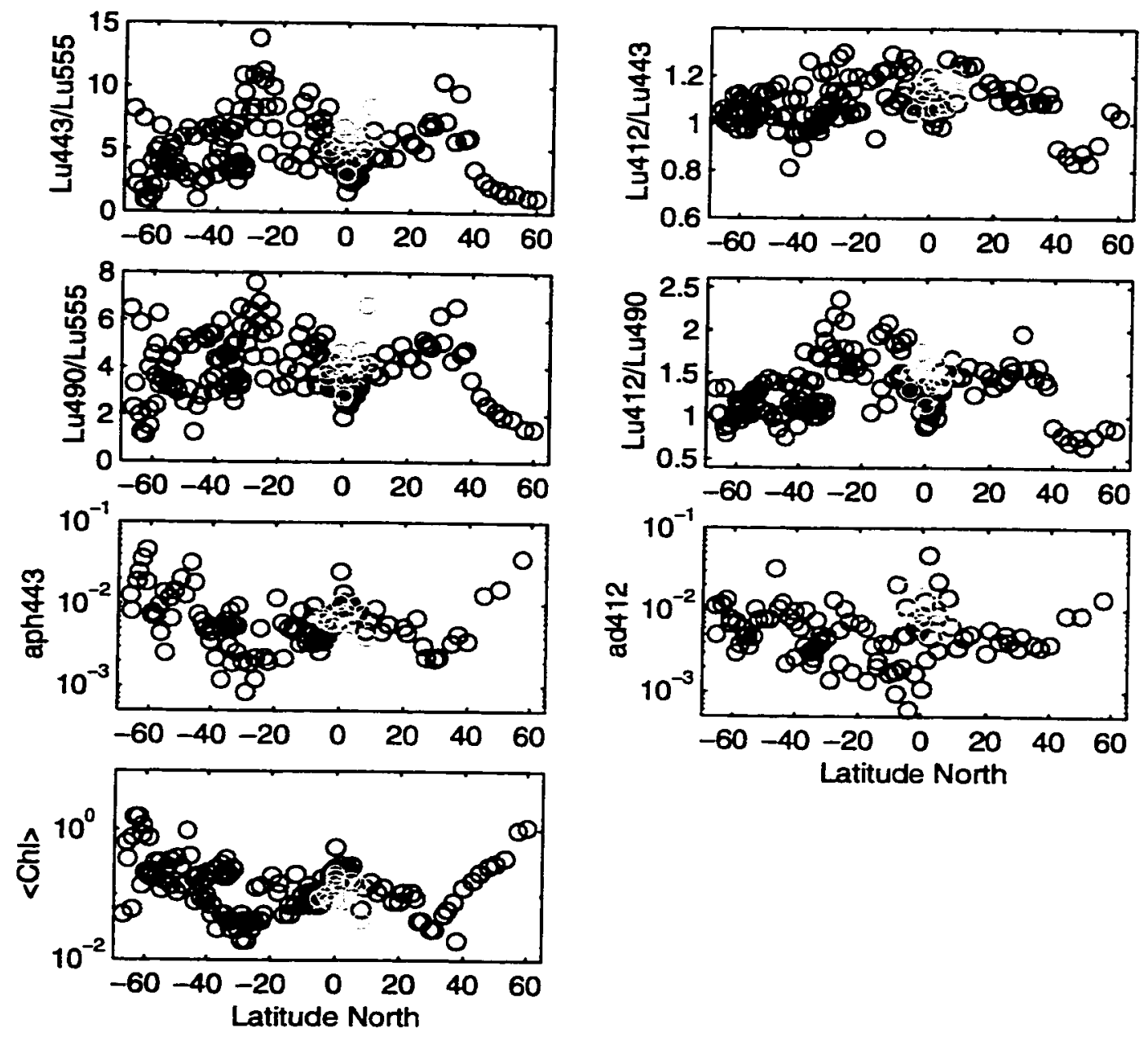

Fig. 5.1. Latitudinal variation of optical properties at the open ocean stations. Left panels: Ratios of upwelling radiances, $L_{u 443} / L_{u 555}$ and $L_{u 490} / L_{u 555}$ and near-surface values of the absorption coefficient for phytoplankton at $443 \mathrm{~nm}, a_{p h}(443)$, and of chlorophyll concentration, <chl>. Right panels: ratios $L_{u 412} / L_{u 443}$ and $L_{u 490} / L_{u 443}$ and near-surface $a_{d}(412)$. Colors represent the different cruises/years considered (see list of symbols). Note that values for $a_{p h}(443)$ and $a_{d}(412)$ were not available for cruise N94S. 



Fig. 5.2. Latitudinal and spectral dependence of the absorption coefficients for phytoplankton, $a_{p h}(\lambda)$, and detritus, $a_{d}(\lambda)$. The parameters are shown for the following wavelengths: $412,443,490,510,555,660$ and $670 \mathrm{~nm}$. Colors correspond to the different cruises/years considered (see list of symbols). The units for the absorption coefficients are $\mathrm{m}^{-1}$. 
The ratios of remote sensing reflectances for the above-mentioned wavelength pair were also inspected. The discussion related to $L_{u}$ applies directly to $R_{r s}$ since these terms covary.

The latitudinal and spectral dependence of the surface values of the absorption coefficients, $a_{p h}$ and $a_{d}$, is shown in Fig. 5.2. The absorption coefficient for phytoplankton is maximal at $443 \mathrm{~nm}\left(\sim 0.1 \mathrm{~m}^{-1}\right)$ and at $670 \mathrm{~nm}\left(\sim 0.03 \mathrm{~m}^{-1}\right)$ at high latitudes. It is in general minimal at $555 \mathrm{~nm}$ (as low as $10^{-4} \mathrm{~m}^{-1}$ in the subtropical gyres at mid-latitudes). The absorption by detritus ranges from large values $\left(-0.05 \mathrm{~m}^{\mathrm{l}}\right)$ at the shortest wavelength $(412 \mathrm{~nm})$ for equatorial latitudes to extremely low values $\left(<10^{-4} \mathrm{~m}^{-1}\right)$ at $670 \mathrm{~nm}$ for southern mid-latitudes.

\section{Dependence of optical properties versus chlorophyll concentration}

\section{Ratios of remote sensing reflectances}

The ratios $R_{r s 443} / R_{r 555}$ and $R_{r s 490} / R_{r 5555}$ show a decreasing trend for increasing chlorophyll concentration when plotted in a log-log plot (Fig. 5.3). The slope is higher for the first ratio, in good agreement with the maximum absorption peak of chlorophyll at $443 \mathrm{~nm}$ (Fig. 2.5). Note that these distributions might be better represented by a curve in "S" shape than with a linear slope (O'Reilly et al., 1998). The "S" shape means that less dependence on $<c h l>$ occurs at extreme values of chlorophyll concentration. For the ratios $R_{r 5412} / R_{r 5490}$ and $R_{r 5412} / R_{r 5443}$, the dependence on chlorophyll is less evident. 



Fig. 5.3. Ratios of remote sensing reflectance versus chlorophyll concentration. The two ratios highly sensitive to $\langle c h l\rangle, R_{r 5443} / R_{r 5555}$ and $R_{r s 490} / R_{r 555}$, are shown in the right panels. Those more related to detritus, $R_{r s 443} / R_{r s 55 s}$ and $R_{r s 490} / R_{r s 555}$, are shown in the left panels. See legend in list of symbols.

\section{Absorption by phytoplankton}

The absorption coefficient for phytoplankton, $a_{p h}(\lambda)$, was plotted versus chlorophyll concentration for $\lambda=412,443,490$ and $670 \mathrm{~nm}$ (Fig. 5.4) for all the stations at all depths (above $120 \mathrm{~m}$ ). For low chlorophyll concentrations (right panels in Fig. 5.4) the linear proportionality is striking with the highest slope occurring for $\lambda=443 \mathrm{~nm}$. The straight 
lines corresponding to the mean $a_{p h}{ }^{*}$ estimated from the data (all stations (green), open ocean (red) and coastal (blue) stations; see next section) fit rather well the scattered points. The $a_{p h} *$ lines (black) provided by S. Maritorena (Personal Communication) are also superimposed in Fig. 5.5. Except at $433 \mathrm{~nm}$, most points are located above Maritorena's lines.

When plotted with all the data and for the full range of chlorophyll concentration (Fig. 5.4, left panels), most of the above straight lines do not represent well the data. For $<c h l>>1 \mathrm{mg} \mathrm{m}^{-3}$, the majority of the points lie below the $a_{p h} *$ lines estimated from the data. The $a_{p h} *$ lines of Maritorena appear to fit better the observations for 490 and 670 nm.

Power laws like (35) can be fit to obtain the numerical values for $A(\lambda)$ and $B(\lambda)$. The first coefficient, $A(\lambda)$, indicates the slope near the origin, while the second, $B(\lambda)$, represents the "bending" of the curve (e.g., $B(\lambda)=0$ for a straight line, $B(\lambda)=0.5$ for a bending like the square root function). This regression was performed for $a_{p h}(\lambda)$ in six bands, $\lambda=412,443,490,510,555$ and $670 \mathrm{~nm}$ (Fig. 5.5 and Table 5.1). The general increase of $a_{p h}$ with increasing <chl> is evident. The highest slope is seen for low chlorophyll concentrations, especially for the wavelengths which are near the absorbing bands of chlorophyll, i.e., 412, 443, 490 and $670 \mathrm{~nm}$ for which $A(\lambda)$ is large. Powers, 1$B(\lambda)$, range between $\sim 0.79$ and $\sim 0.93$. The power closest to unity is obtained for the longest wavelengths (555 and $670 \mathrm{~nm})$, especially for $670 \mathrm{~nm}$ near the secondary maximum of chlorophyll absorption where packaging effects are less important (Stuart et al., 1998). 

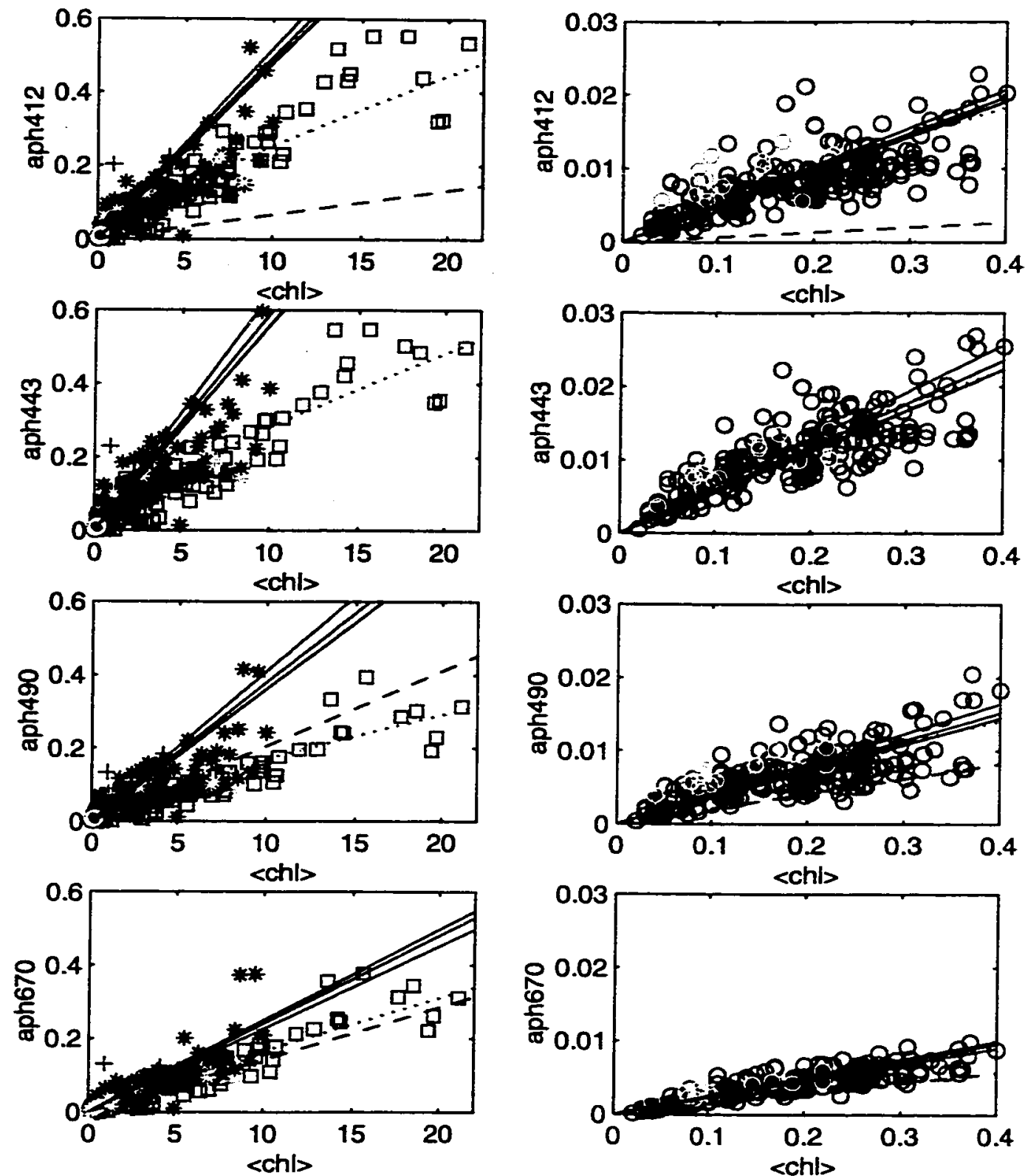

Fig. 5.4. Absorption coefficients for phytoplankton, $a_{p h}(\lambda)$, at $\lambda=412,443,490$ and $670 \mathrm{~nm}$ for all stations (near-surface and deeper samples combined). The values for the whole range of $\langle$ chl $>$ is shown in the left panels, whereas oligotrophic (open ocean) values are displayed in the right panels, with the range of chlorophyll concentrations limited to $0-0.4 \mathrm{mg} \mathrm{m}^{-3}$. The units for the absorption coefficients are $\mathrm{m}^{-1}$. Straight lines are overlaid to show the various $a_{p h}{ }^{*}$ spectra adopted (mean $a_{p h}{ }^{*}$ derived from all data (green), the open ocean stations (red) and the coastal waters (blue). The $a_{p h}{ }^{*}$ of S. Maritorena (Personal Communication) is shown as a dashed black line. The power laws (equation 35) are also depicted with dotted curves. See legend in list of symbols. 

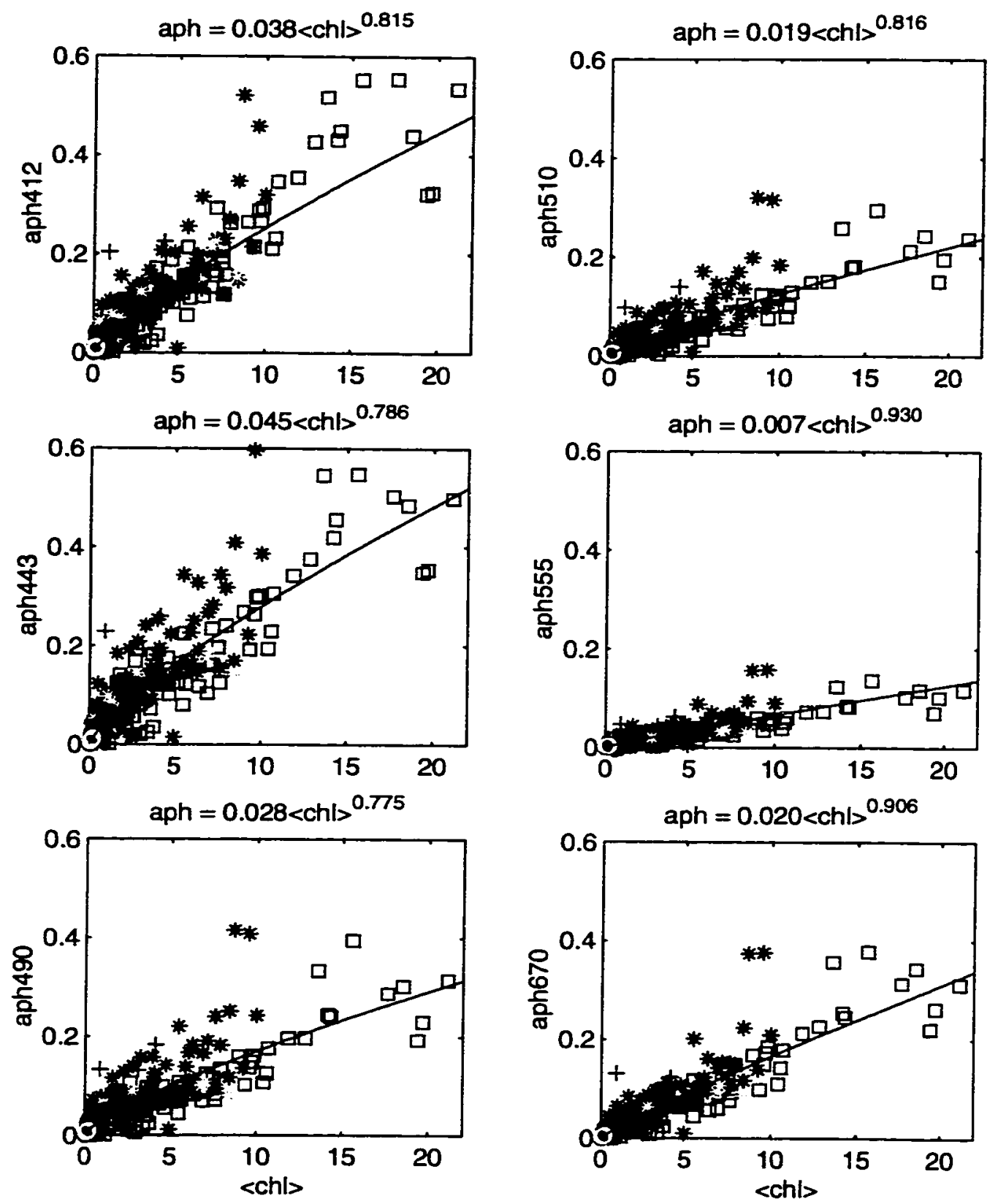

Fig. 5.5. Same as in Fig. 5.4 but for 6 bands: 412, 443, 490, 510, 555 and $670 \mathrm{~nm}$. The power laws $\left.\left(a_{p h}=A<c h l\right\rangle^{1-B}\right)$ obtained through regressions analysis are superimposed (red curves) and are posted on top of each panel. See legend in list of symbols. 


\section{Chlorophyll-specific absorption for phytoplankton}

The chlorophyll-specific absorption coefficient for phytoplankton was calculated by normalizing the absorption coefficients $a_{p h}$ by $<c h l>$ (see equation 10). The results are plotted versus $<c h l>$ in Fig. 5.6. Even after normalization, there is still a relationship between $a_{p h} *$ and chlorophyll. The coefficient $a_{p h} *$ is highest at low chlorophyll, spanning over more than one order of magnitude $\left(0.2\right.$ to $\left.0.01 \mathrm{~m}^{2} \mathrm{mg}^{-1}\right)$, and exhibits large values with ample variations for the shortest wavelengths $(412,443$ and 490$)$ and for the smaller values of $\langle c h l>$. The latter trend is partly due to the division by a small numerical value that amplifies errors but the general decrease of $a_{p h}{ }^{*}$ with increasing $\langle c h l>$ is related to packaging or other effects such as the contribution of accessory pigments to absorption (Bricaud et al., 1995). A power law of the form (11) was fit to the values of $a_{p h}{ }^{*}$ at $443 \mathrm{~nm}$, separating the data set in two parts, measurements at or near the surface and measurements deeper in the euphotic zone, to discriminate between the two kinds of covariation (site to site and along the vertical) affecting the relation between $a_{p h}{ }^{*}$ and $<c h l>$. The values for $A(443)$ and $B(443)$ are similar for the surface and deep observations (Table 5.1) showing the predominance of site to site covariations at both levels. Similar conclusions were obtained by Bricaud et al. (1995). The values of $A$ and $B$ obtained through the fit of (35) at all wavelengths and those given in Bricaud et al. (1995) are also listed in Table 5.1. The A's and B's of Bricaud et al. (1995) appear generally smaller and larger than values estimated in the present study, respectively.

Plotting $a_{p h}{ }^{*}$ versus wavelength (Fig. 5.7) shows two absorption peaks near 443 and $670 \mathrm{~nm}$ and demonstrates the large variations of $a_{p h}{ }^{*}$ for a given wavelength. 

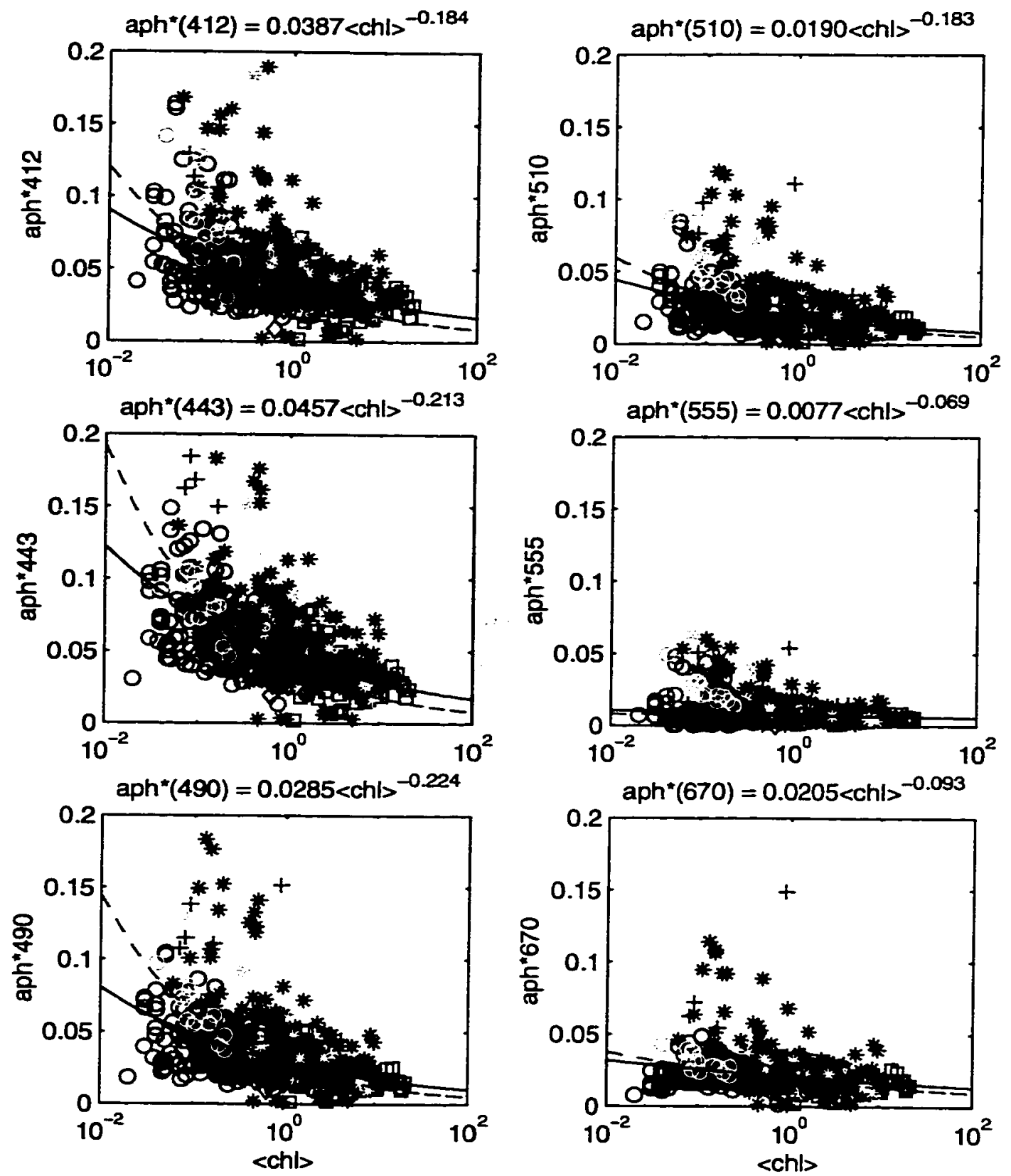

Fig. 5.6. Chlorophyll-specific absorption coefficients for phytoplankton $\left(\mathrm{m}^{2} \mathrm{mg}^{-1}\right)$ at 412 , $-443,490,510,555$ and $670 \mathrm{~nm}$, versus chlorophyll concentration <chl> expressed in $\mathrm{mg}$ $\mathrm{m}^{-3}$, for all stations (surface and deep measurements). Power laws of the form $a_{p h}{ }^{*}=A$ $\langle c h l\rangle^{-B}$ were fitted to the data (solid curves). They are posted on top of each panel. The power laws with the coefficients $A$ and $B$ from Bricaud et al. (1995) (see Table 5.1) are shown with red dashed curves. See legend in list of symbols. 
Table 5.1. Values of $A(\lambda)$ and $B(\lambda)$ obtained when fitting the variations of $a_{p h} *$ versus $<c h l>$ to power laws of the form $a_{p h}{ }^{*}(\lambda)=A(\lambda)\langle c h l\rangle^{-B(\lambda)}$ at wavelengths between 412 and $670 \mathrm{~nm}$. For $443 \mathrm{~nm}$, the data were also separated into near-surface and deep measurements. The values of Bricaud et al. (1995) are listed in the last two columns. Standard errors on $B$ for this study are also listed between parentheses.

\begin{tabular}{|c|c|c|c|c|c|c|}
\hline & \multicolumn{3}{|c|}{ This study, 628 points } & \multicolumn{3}{c|}{ Bricaud et al. (1995), 815 points } \\
\hline Wavelength (nm) & $A$ & $B$ & $r^{2}$ & $A$ & $B$ & $r^{2}$ \\
\hline 412 & 0.0387 & $0.184(0.014)$ & 0.84 & 0.0323 & 0.286 & 0.72 \\
\hline 443 & 0.0458 & $0.213(0.014)$ & 0.84 & 0.0394 & 0.344 & 0.77 \\
\hline 490 & 0.0286 & $0.225(0.015)$ & 0.81 & 0.0274 & 0.361 & 0.77 \\
\hline 510 & 0.0191 & $0.183(0.016)$ & 0.83 & 0.018 & 0.26 & 0.64 \\
\hline 555 & 0.0077 & $0.069(0.022)$ & 0.75 & 0.007 & 0.032 & 0.01 \\
\hline 670 & 0.0206 & $0.094(0.013)$ & 0.88 & 0.0189 & 0.149 & 0.42 \\
\hline Surface(443) & 0.0455 & 0.215 & & & & \\
\hline Deep(443) & 0.0463 & 0.211 & & & & \\
\hline
\end{tabular}

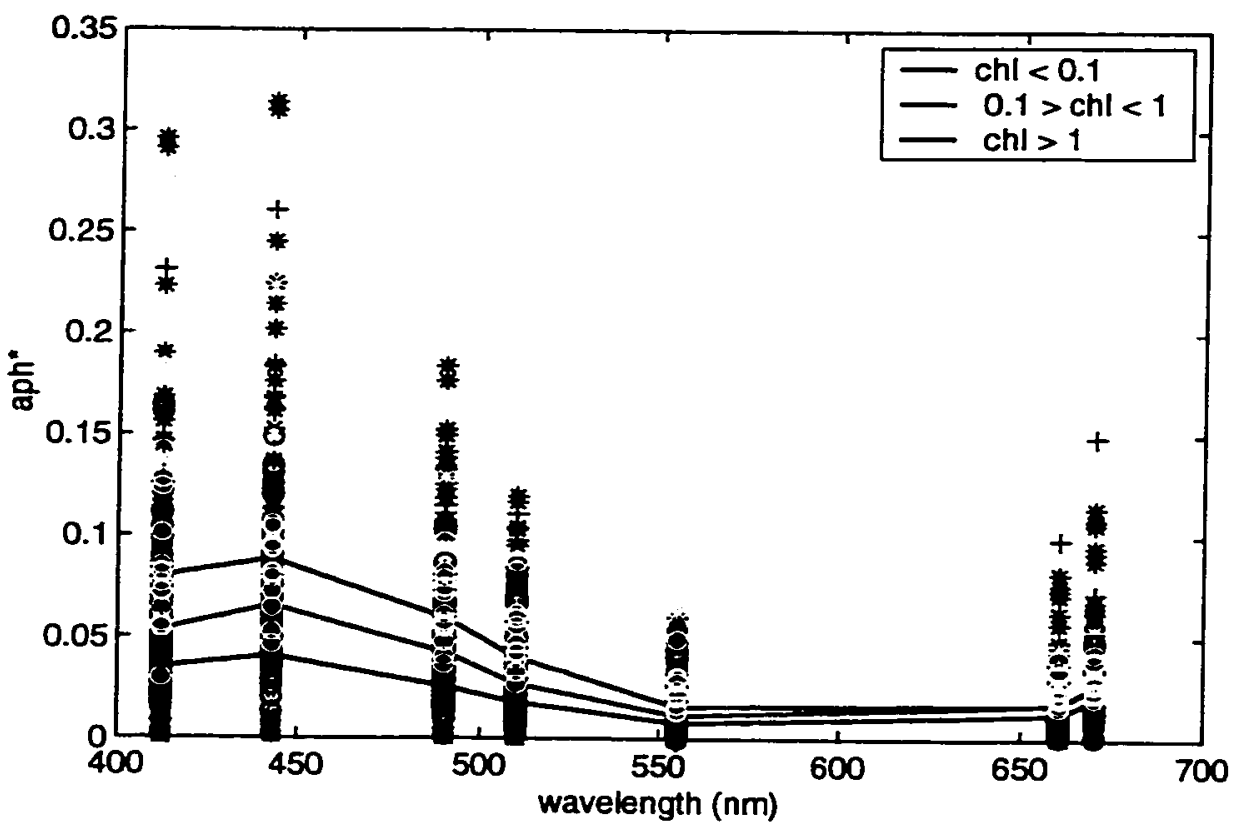

Fig. 5.7. Chlorophyll-specific absorption coefficients for phytoplankton $\left(\mathrm{m}^{2} \mathrm{mg}^{-1}\right)$ versus wavelength for all stations (surface and deep measurements). The curves correspond to the $a_{p h} *$ values averaged in three categories of chlorophyll concentration, $<c h l><0.1 \mathrm{mg}$ $\mathrm{m}^{-3}, 0.1 \mathrm{mg} \mathrm{m}^{-3}<<c h l><1 \mathrm{mg} \mathrm{m}^{-3}$ and $<c h l>>1 \mathrm{mg} \mathrm{m}^{-3}$. See legend in list of symbols. 
When the values are averaged in three intervals of chlorophyll concentration $(<0.1,[0.1-$ 1], >1 $\mathrm{mg} \mathrm{m}^{-3}$ ), the mean $a_{p h} *$ values decrease with increasing $\langle c h l>$, at least for wavelengths less than $555 \mathrm{~nm}$.

Carder et al. (1999) use ratios of remote sensing reflectances to identify waters with low and high packaging effects. A scatter plot of $R_{r 5412} / R_{r 5443}$ versus $R_{r 5443} / R_{r 555}$ for all stations is displayed in Fig. 5.8a, with the line, $R_{r 5412} / R_{r 443}=0.95\left[R_{r 5443} / R_{r 5555}\right]^{0.16}$ of Carder et al. (1999) used to identify "unpackaged" Case I waters (above line). According to this criterion, a large number of stations can be considered as "packaged" (below line) especially for oligotrophic open ocean waters (large values of $R_{r 5443} / R_{r 5555}$, i.e., above 3). For high values of chlorophyll concentration (small values of $R_{r s 443} / R_{r s 555)}$ ), this criterion does not apply. The same line is used to separate high-CDOM (below line) from lowCDOM data points. The stations satisfying the criterion correspond to a wide range of $a_{p h}{ }^{*}$ (points flagged by a black dot in Fig. 5.8b). There is little evidence that their decrease with increasing $\langle c h l\rangle$, due to the inhibiting packaging effects, is more pronounced with respect to the other "non-packaged" values.

\section{Absorption by detritus}

The relationship between the absorption coefficient for detritus and chlorophyll concentration is shown in Fig. 5.9 for $\lambda=412,443$ and $490 \mathrm{~nm}$. Over the entire range of $<c h l>$ (from 0 to $\sim 22 \mathrm{mg} \mathrm{m}^{-3}$ ) there is a positive relationship between $a_{d}$ and $<c h l>$. This trend augments with decreasing wavelengths (slope increases from 0.387 at $490 \mathrm{~nm}$ to 0.453 at $412 \mathrm{~nm}$ using log-transformed variables). This is an indication that chlorophyll 

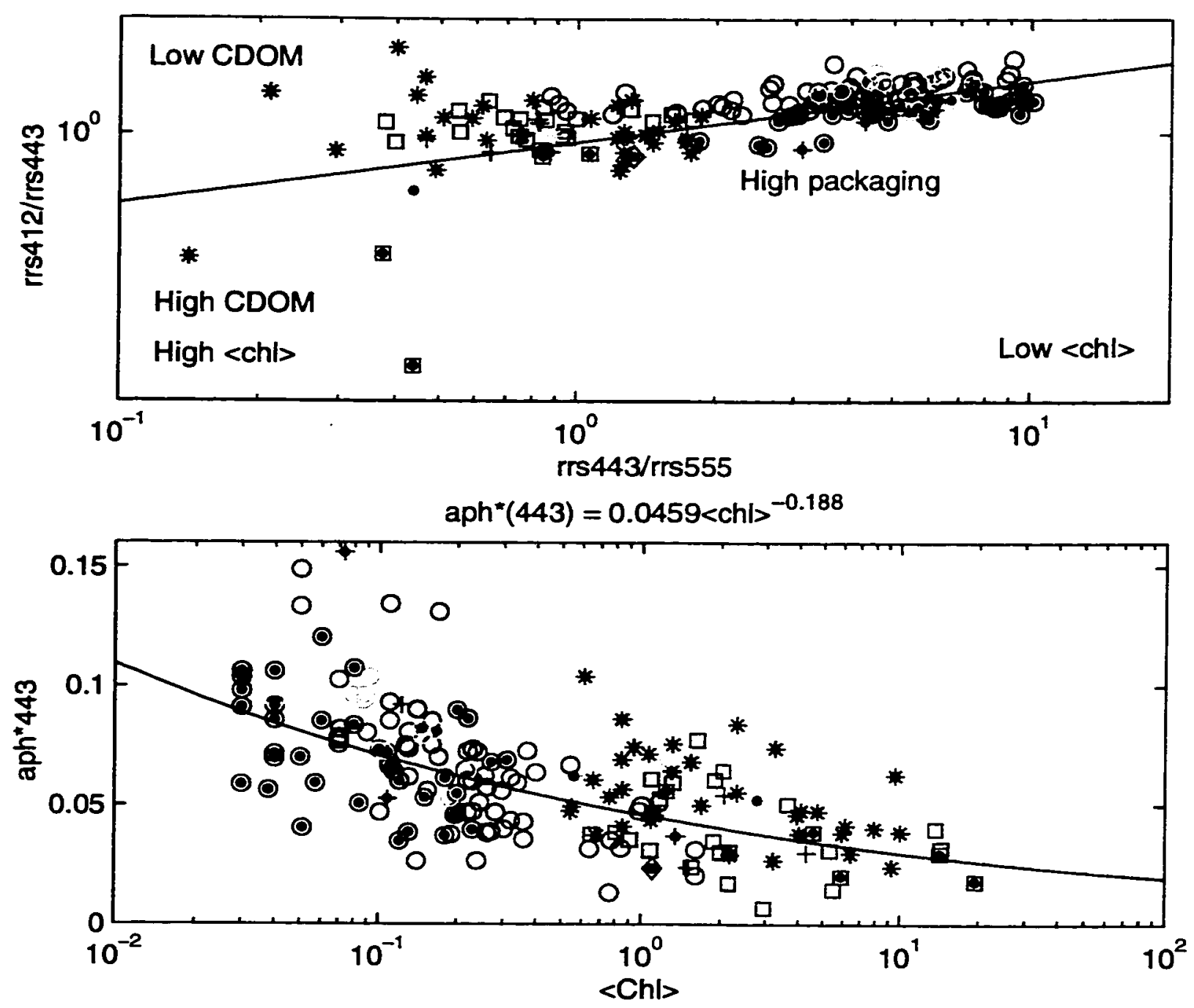

Fig. 5.8. (a) Scatter diagram of $R_{r s 412} / R_{r s 443}$ versus $R_{r 5443} / R_{r 555 s}$ for all stations with line, $R_{r s 412} / R_{r s 443}=0.95\left[R_{r s 443} / R_{r 5555}\right]^{0.16}$ of Carder et al. (1999) used to identify "unpackaged" case 1 data (above line). The points for which packaging effects are important are flagged with solid black dots (b) Chlorophyll-specific absorption for phytoplankton at $\mathbf{4 4 3} \mathbf{n m}$ versus chlorophyll concentration. The points lying below the line in (a) are flagged with solid black dots. The power law obtained by least squares fit is surperimposed with a solid curve and its equation is posted on top of the panel. See legend in list of symbols. 
and detritus tend to co-vary. For low values of $<c h l>$ (less than $1 \mathrm{mg} \mathrm{m}^{-3}$ in most of the open ocean stations) this dependence is weaker. The difference between the low detritus absorption in the South Indian Ocean and the higher values in the equatorial Pacific is responsible for most of the spreading (expanded in this $\log -\log$ plot) at low values of chlorophyll concentration.

The spectral shape of the absorption coefficient for detritus is shown for each station in Fig. 5.10a. The coastal stations exhibit the largest values and all spectra show the expected exponential decay modeled by equation (12). The exponential decay rate, $S$, was estimated from these curves by fitting (12) to the values of $a_{d}$ at 443 and $490 \mathrm{~nm}$. The results are presented versus <chl> in Fig. $5.10 \mathrm{~b}$. The values of $S$ range between 0.003 and $0.036 \mathrm{~nm}^{-1}$, with an average of $0.0141 \mathrm{~nm}^{-1}($ standard deviation $=0.002)$, and have a propensity to increase with increasing chlorophyll concentration. This mean is significantly higher (at the $95 \%$ confidence level, using one-tailed t-student test) than the value of $0.011 \mathrm{~nm}^{-1}$ obtained by Bricaud et al. (1998). When averaged over the following ranges of $<c h l>\left(<0.1,[0.1-1]\right.$ and $\left.>1 \mathrm{mg} \mathrm{m}^{-3}\right)$, mean $S$ values of $0.012( \pm 0.004), 0.014$ $( \pm 0.004)$ and $0.015( \pm 0.003) \mathrm{nm}^{-1}$ were obtained, respectively. The last two values are in contradiction with those reported by Bricaud et al. (1998) that slightly decrease with increasing <chl>: $0.012( \pm 0.002), 0.011( \pm 0.002)$, and $0.010( \pm 0.001) \mathrm{nm}^{-1}$ for the same three <chl> decades. When separated into open ocean and coastal waters, the following values, $0.0121( \pm 0.003)$ and $0.0152( \pm 0.004) \mathrm{nm}^{-1}$, were obtained for $S$, respectively. 

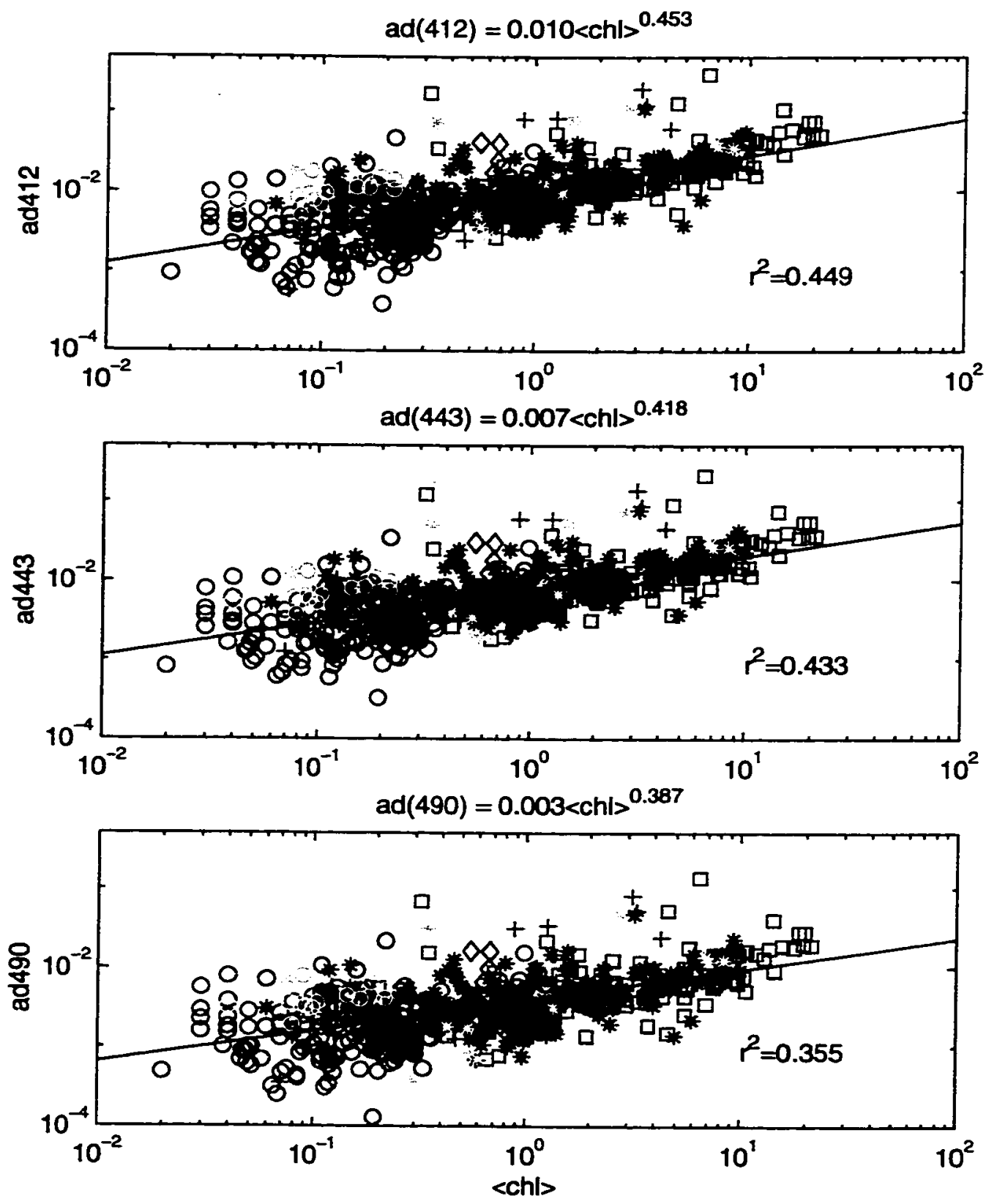

Fig. 5.9. Absorption coefficients for detritus, $a_{d}(\lambda)$, for $\lambda=412,443$ and $490 \mathrm{~nm}$, for all stations (near-surface and deeper samples combined) versus chlorophyll concentration displayed in log-log plots. The units for the absorption coefficients are $\mathrm{m}^{-1}$. The linear regression lines using log-transformed variables are shown. See legend in list of symbols. 

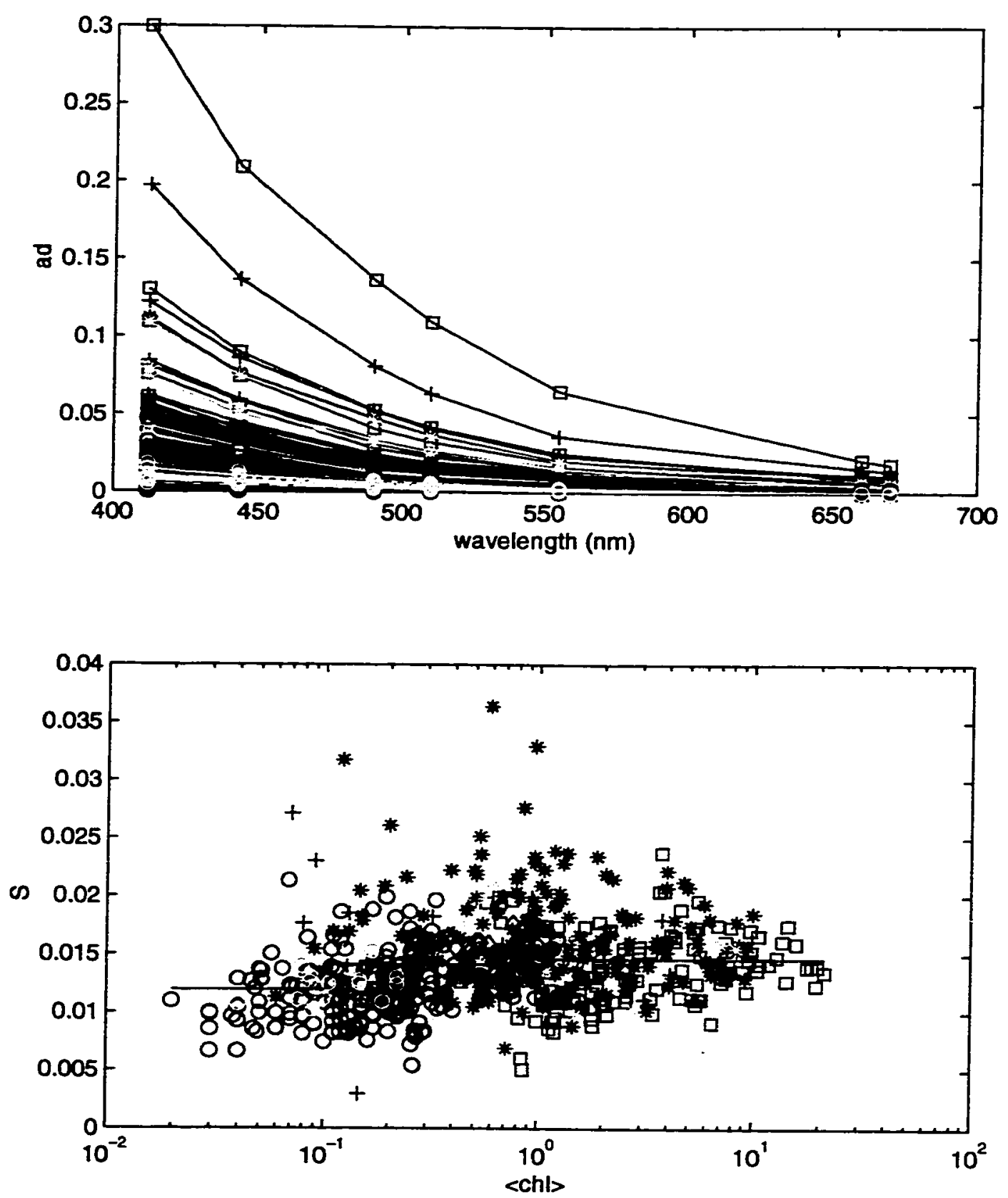

Fig. 5.10. (a) Absorption coefficients for detritus, $a_{d}(\lambda)\left(\mathrm{m}^{-1}\right)$, versus wavelength for all stations (surface and deep measurements). The exponential decrease with increasing wavelength is striking. Larger values correspond to the coastal waters. (b) Exponential decay constant, $S$, estimated from the $a_{d}(\lambda)$ curves shown in (a) and shown versus chlorophyll concentration <chl> $\left(\mathrm{mg} \mathrm{m}^{-3}\right)$. The values of $S$ were determined by fitting equation (11) through the measured $a_{d}$ values at 443 and $490 \mathrm{~nm}$. The average values of $S$ over the three separate ranges of $\langle\mathrm{chl}\rangle(<0.1$, [0.1-1] and $>1 \mathrm{mg} \mathrm{m}^{-3}$ ) are depicted by solid lines. Units for $S$ are $\mathrm{nm}^{-1}$. See legend in list of symbols. 


\section{Total particulate absorption}

Since both $a_{p h}$ and $a_{d}$ generally increase with chlorophyll concentration, it is expected that the absorption coefficient for total particulate matter, $a_{p}$, is related to $<c h l>$ in a similar manner. Empirical relationships linking $a_{p}$ to $<c h l>$ are important because they can be used in bio-optical models (Bricaud et al., 1998). The correlations between $a_{p}(443)$ and $<c h l>$ (Fig. 5.1 la) and between $a_{p h}$ (443) and <chl> (Fig. 5.1 lb) are high ( $r^{2} \sim 0.83$ in both cases). The regression model for total particulate absorption reads: $\left.a_{p}(443)=0.056<c h l\right\rangle^{0.707}$, which is similar to the one of Bricaud et al. (1998). The linear fit is poorer for $a_{d}(443)$ (Fig. 5.11c) with $r^{2} \sim 0.43$. It is also very different from the result of Bricaud et al. (1998).

The relative contribution of non-algal particulate materials (detritus) to the total particulate absorption in seawater can be examined by plotting the ratio $a_{d}(443) / a_{p}(443)$ versus <chl> (Fig. 5.12). There is a trend in the relative detritus absorption, with a decrease from large values $(50-95 \%)$ at low $<c h l>\left(<0.05 \mathrm{mg} \mathrm{m}^{-3}\right)$ to low values $(<10 \%)$ at high $<c h l>\left(>10 \mathrm{mg} \mathrm{m}^{-3}\right)$. Using the models for $a_{p}$ and $a_{d}$ shown in Fig. 5.11 , the dependence of the ratio $a_{d}(443) / a_{p}(443)$ on chlorophyll concentration can be expressed as $0.125<c h l>^{-0.289}$ (straight line in Fig. 5.12). From this relationship, it can be seen that for a fixed chlorophyll concentration, e.g., $1 \mathrm{mg} \mathrm{m}^{-3}$, the relative contribution of detritus to particulate absorption is about $12.5 \%$.

\section{Test of empirical models}

The empirical models listed in Table 3.1, relating chlorophyll concentrations to 



Fig. 5.11. Particulate absorption coefficients, $a_{p}(443)$ (a) and its two components, $a_{p h}(443)$ (b) and $a_{d}(443)(c)$, for all stations (near-surface and deeper samples combined). The values are plotted versus chlorophyll concentration $\left(\mathrm{mg} \mathrm{m}^{-3}\right)$ on a $\log -\log$ plot. Regression lines of the logtransformed values are superimposed as solid lines. The corresponding analytical relation between the absorption coefficient and $\langle c h l\rangle$ is posted. The regression lines of Bricaud et al. (1998) are shown as dotted-dashed lines. The units for the absorption coefficients are $\mathrm{m}^{-1}$. See legend in list of symbols. 


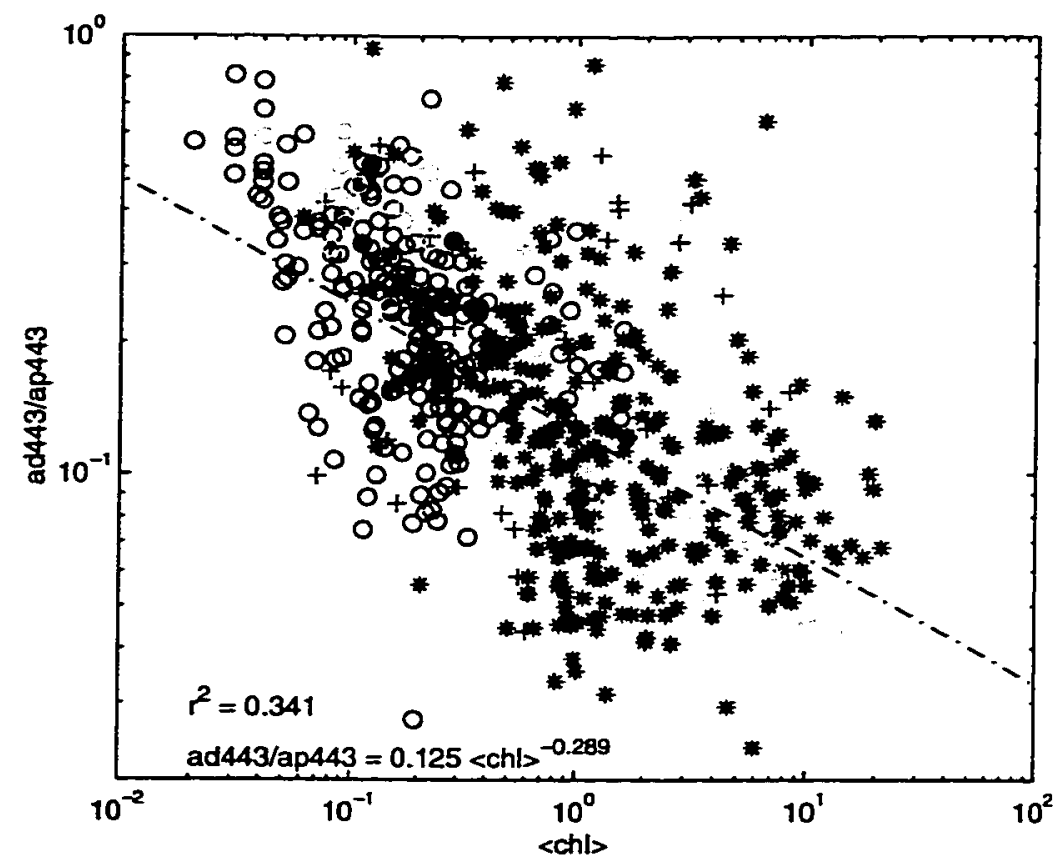

Fig. 5.12. Variations of the ratio of non-algal absorption to total particulate absorption at $443 \mathrm{~nm}$ as a function of $\langle c h l\rangle$. The dotted-dashed line corresponds to the ratio of the linear models shown in Fig. 5.11. Chlorophyll concentration is expressed in $\mathrm{mg} \mathrm{m}^{-3}$. See See legend in list of symbols.

either ratios of remote sensing reflectances, or normalized water leaving radiances or upwelling radiances, were tested with the dataset, including coastal and open ocean measurements. Log-log plots of modeled versus measured chlorophyll concentrations are shown in Fig. 5.13. Straight lines are included to show the $1: 1$ relationship and the power law obtained through linear squares fit of the log-transformed variables. The results of the least squares fits are summarized in Table 5.2. The best model should have the highest correlation, the smallest standard errors, a slope as close as possible to 1 and the smallest intercept. The model of Abbott and Letelier (1997) (Fig. 5.13d) and the CZCS GPs model (Fig. 5.13e), appear the least efficient to represent the data, with a slope very 

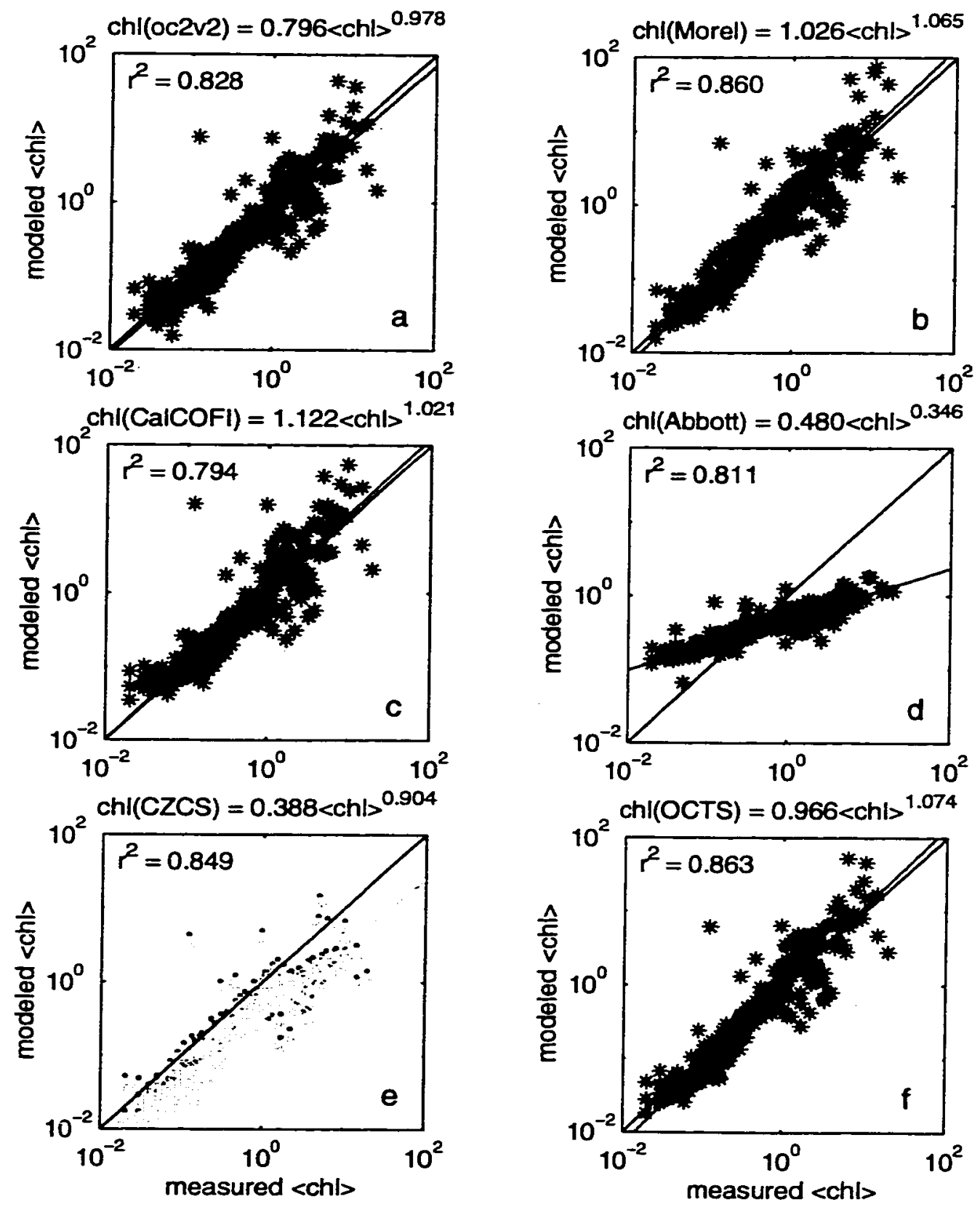

Fig. 5.13. Test of various empirical models for estimating chlorophyll concentration. All panels show the model versus measured $<c h b$ in $\mathrm{mg} \mathrm{m}^{-3}$ (star symbols). Linear least squares fits were used to estimate the power laws posted on top of each plot. The linear regression line is depicted with the same color as the symbols. The blue line represents the one-to-one relationship. The following empirical algorithms are shown: (a) OC2v2 (SeaWiFS; R. Kudela, Personal Communication), (b) Morel (1988), (c) Abbott and Letelier (1997), (d) CalCOFI (Mitchell and Kahru, 1998), (e) CZCS GPs (Evans and Gordon, 1994) and (f) OCTS-C (OCTS-C, 1996). For the CZCS GPs model, the sum of the modeled phaeopigment and chlorophyll concentrations are shown with small black dots. 
Table 5.2. Results of the linear regressions (using log-transformed data) between modeled and measured chlorophyll concentrations (285 pairs) using the empirical models of Table 3.1 and the optimized semi-analytical model of Garver and Siegel (1997). The linear regression model is: $\left.\log (<c h\rangle_{\text {mod }}\right)=$ intercept + slope $\left.\log (<c h l\rangle_{\text {meas. }}\right)$. The standard errors on the slope, intercept and estimate $\left(\log \left(\langle c h l\rangle_{\text {mod }}\right)\right)$ are included, together with the coefficient of determination, $r^{2}$.

\begin{tabular}{|l|cccccc|}
\hline & Intercept & Slope & r2 & S.E. Slope & S.E. Inter. & S.E. Estim. \\
\hline OC2v2 & -0.099 & 0.978 & 0.829 & 0.026 & 0.301 & 0.300 \\
Morel & 0.011 & 1.065 & 0.861 & 0.025 & 0.289 & 0.289 \\
CalCOFI & 0.050 & 1.021 & 0.794 & 0.031 & 0.352 & 0.351 \\
Abbott & -0.318 & 0.347 & 0.812 & 0.010 & 0.113 & 0.113 \\
CZCS & -0.411 & 0.904 & 0.849 & 0.023 & 0.257 & 0.257 \\
OCTS-C & -0.015 & 1.075 & 0.864 & 0.025 & 0.289 & 0.288 \\
\hline
\end{tabular}

different from one and a large intercept, respectively. The data considered in this thesis are best fit by the model of Morel (1988) (Fig. 5.13b) and the OCTS-C model (Fig. $5.13 f)$.

The same analysis was performed and similar tables were produced for subsets of the data for comparison with the results of the semi-analytical model of Garver and Siegel (1997) (see section 5.7). The oligotrophic open ocean data (Table 5.3), the Pacific stations between $10^{\circ} \mathrm{N}$ and $40^{\circ} \mathrm{S}$ (Table 5.4), and the coastal data (Table 5.5) were considered separately. Again the model of Morel (1988) and the OCTS-C model generally outperform all the other models since they have maximum correlation and slope (intercept) nearest to one (zero). For the Pacific and the California coastal waters, the correlations between the log-transformed measured and modeled chlorophyll concentrations are typically lower than those for the global data: $r^{2} \sim 0.42-0.74$ compared to $r^{2}-0.79-0.87$. 
The standard error about the estimate $\left.\log (<c h l\rangle_{\text {mod }}\right)$ ranges between 0.113 and 0.351 when considering all stations (Table 5.2). This corresponds to an uncertainty on the estimated $<c h l>$ of 1.3 and $2.2 \mathrm{mg} \mathrm{m}^{-3}$, respectively. For the coastal data only, this error can be as large as 0.535 (Table 5.5) or $3.4 \mathrm{mg} \mathrm{m}^{-3}$ in chlorophyll concentration.

Table 5.3. Same as in Table 5.2 but for 147 oligotrophic open ocean stations only.

\begin{tabular}{|l|cccccc|}
\hline & Intercept & Slope & $r^{2}$ & S.E. Slope & S.E. Inter. & S.E. Estim. \\
\hline OC2v2 & -0.219 & 0.890 & 0.793 & 0.038 & 0.182 & 0.178 \\
Morel & -0.118 & 0.981 & 0.851 & 0.034 & 0.164 & 0.161 \\
CalCOFI & -0.212 & 0.773 & 0.774 & 0.035 & 0.166 & 0.163 \\
Abbott & -0.362 & 0.314 & 0.724 & 0.016 & 0.077 & 0.076 \\
CZCS & -0.438 & 0.941 & 0.852 & 0.032 & 0.156 & 0.153 \\
OCTS-C & -0.162 & 0.957 & 0.845 & 0.034 & 0.164 & 0.161 \\
Semi-Anal. & -0.035 & 0.844 & 0.722 & 0.050 & 0.207 & 0.202 \\
\hline
\end{tabular}

Table 5.4. Same as in Table 5.2 but for 47 Pacific (north of $40^{\circ} \mathrm{S}$ ) open ocean stations only.

\begin{tabular}{|l|cccccc|}
\hline & Intercept & Slope & $r^{2}$ & S.E. Slope & S.E. Inter. & S.E. Estim. \\
\hline OC2v2 & -0.390 & 0.725 & 0.538 & 0.101 & 0.240 & 0.213 \\
Morel & -0.311 & 0.814 & 0.735 & 0.074 & 0.175 & 0.155 \\
CalCOFI & -0.491 & 0.503 & 0.514 & 0.074 & 0.175 & 0.155 \\
Abbott & -0.398 & 0.282 & 0.710 & 0.027 & 0.065 & 0.057 \\
CZCS & -0.614 & 0.790 & 0.736 & 0.071 & 0.169 & 0.150 \\
OCTS-C & -0.428 & 0.700 & 0.622 & 0.082 & 0.195 & 0.173 \\
Semi-Anal. & -0.183 & 0.806 & 0.809 & 0.058 & 0.137 & 0.121 \\
\hline
\end{tabular}


Table 5.5. Same as in Table 5.2 but for 72 coastal stations for which a* measurements are available.

\begin{tabular}{|l|cccccc|}
\hline & Intercept & Slope & $r^{2}$ & S.E. Slope & S.E. Inter. & S.E. Estim. \\
\hline OC2v2 & 0.033 & 0.826 & 0.464 & 0.106 & 0.428 & 0.424 \\
Morel & 0.175 & 0.913 & 0.493 & 0.111 & 0.447 & 0.443 \\
CalCOFI & 0.173 & 1.004 & 0.446 & 0.134 & 0.539 & 0.535 \\
Abbott & -0.268 & 0.356 & 0.573 & 0.037 & 0.148 & 0.147 \\
CZCS & -0.228 & 0.522 & 0.419 & 0.074 & 0.297 & 0.294 \\
OCTS-C & 0.119 & 0.914 & 0.533 & 0.102 & 0.412 & 0.409 \\
Semi-Anal. & 0.099 & 0.773 & 0.761 & 0.052 & 0.199 & 0.197 \\
\hline
\end{tabular}

\section{Application of the semi-analytical model of Garver and Siegel}

The inversion model of Garver and Siegel (1997) was first applied (see implementation details in section 4.2.4) to all data with the following spectral shapes: mean $a_{p h} *$ obtained from all the data (general $a_{p h} *$ in Fig. $3.1 c$ ), $S=0.02 \mathrm{~nm}^{-1}$ and with a power of -1 for $b_{b p}(\lambda) / b_{b p}(412)$. The retrieved IOPs and the modeled/measured chlorophyll concentrations are displayed in Fig. 5.14. Except for a few coastal stations for which the inversion model was singular and for which no results were obtained, the modeled $<c h l>$ is reasonably similar to the measured values. The agreement between the modeled and measured <chl> is better for the open ocean stations where the chlorophyll concentration is less than $1 \mathrm{mg} \mathrm{m}^{-3}$. In general the correlation between the logtransformed measured/modeled values is high $\left(r^{2} \sim 0.77\right)$ but this value is slightly lower than the ones obtained using empirical models (Table 5.2). However, the correlation of the non log-transformed concentrations $\left(r_{l}^{2} \sim 0.12\right)$ is low and the relationship is far from a one-to-one correspondence (slope 0.7 ). The model tends to overestimate the chlorophyll 

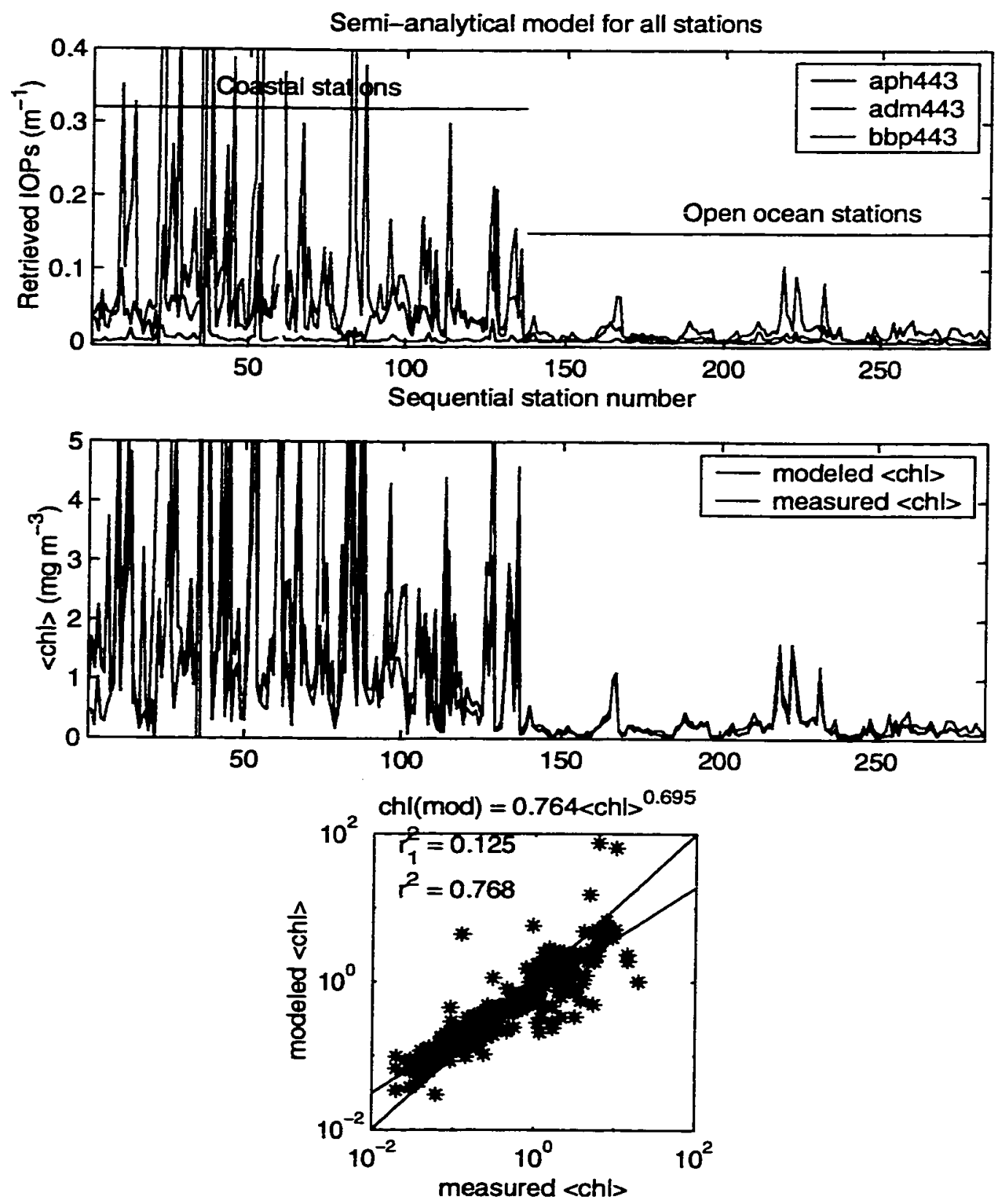

Fig. 5.14. Results of the semi-analytical inversion model using an averaged $a_{p h}{ }^{*}$ estimated from all the data. $S=0.02 \mathrm{~nm}^{-1}$ and $b_{l p} \sim \lambda^{-1}$. The three IOPs retrieved by the model are shown in the top panel. Units are $\mathrm{m}^{-1}$. The modeled and measured chlorophyll concentrations $\left(\mathrm{mg} \mathrm{m}^{-3}\right)$ are compared in the middle panel. A scatter diagram of the modeled versus measured chlorophyll concentrations $\left(\mathrm{mg} \mathrm{m}^{-3}\right)$ is displayed in the lower panel. Log-transformed variables were used to fit the best power model for the chlorophyll concentrations. The resulting relationship is posted. The coefficient of determination between the logtransformed (non log-transformed) modeled and measured values is also indicated, $r^{2}\left(r_{1}^{2}\right)$. These statistics are based on $\mathbf{2 8 5}$ stations for which the model was successfully inverted. 
concentration for oligotrophic conditions and it generally underestimates $<c h l>$ for coastal waters.

The semi-analytical model was then applied to subsets of the data with parameters optimized for the individual sets considered. First the open ocean stations were considered and an extensive sensitivity analysis was carried out. These data were selected because the semi-analytical model performed well in oligotrophic waters (Fig. 5.14). Second, the open ocean stations in the Pacific (north of $40^{\circ} \mathrm{S}$ ) were used separately because the model (with the above parameters for the spectral shapes) overestimates chlorophyll concentration. Finally the semi-analytical model was applied to the California coastal data only, with spectral shapes optimized for these waters, to see if it could be improved relative to the empirical models.

\section{Open ocean stations and sensitivity analysis}

The model of Garver and Siegel (1997) was applied to 129 open ocean stations, referred to as stations 73 to 202 in the following discussion and plots. A sensitivity analysis was conducted to determine the best set of IOPs for the data considered here.

- Sensitivity to changes in $S$ : The model was run with $a_{p h} *$ (mean value from open ocean data) and $b_{b p}(\lambda) / / b_{b p}(412)$ (-1 power) spectral shapes (see Fig. 3.1) and with several values of the exponential decay rate, $S$, of the absorption by dissolved/detrital materials found in the literature or obtained from the data (Figs. 3.1 and 5.11b). The results of the sensitivity test with respect to $S\left(0.008,0.011,0.014\right.$ and $\left.0.02 \mathrm{~nm}^{-1}\right)$ are displayed in Fig. 5.16 where the three retrieved IOPs, $a_{p h}(443), a_{d m}(443)$ and $b_{b p}(443)$ are plotted versus 
station number. Changes in the value for $S$ have a significant effect on the magnitude of the modeled $a_{p h}(443)$ and $a_{d m}(443)$ and less of an effect on the $b_{b p}(443)$ retrievals. The absorption coefficients for phytoplankton (detritaldissolved substances) increase (decrease) with increasing $S$. The top panel of Fig. 5.15 shows that $a_{p h}(443)$ can become negative for a few stations, especially when $S$ is small. The correlation between the modeled $a_{p h}(443)$ and the chlorophyll concentration measured in the surface waters (Table 5.6) is maximum for $S=0.02 \mathrm{~nm}^{-1}\left(r_{1}^{2} \sim 91 \%\right)$. This case also yields the best correlation, although quite low, between the modeled $a_{d m}(443)$ and the measured $a_{d}(443)$ and $K_{d}(412) / K_{d}(490)$. The latter ratio is used by Garver and Siegel (1997) as an indicator of absorption by detritaldissolved materials. The $a_{d m}$ spectrum calculated using $S=$ $0.02 \mathrm{~nm}^{-1}$ was chosen for further sensitivity analysis. It is the same value obtained through sensitivity analysis by Garver and Siegel (1997) for the Sargasso Sea waters. However, the mean values for $S$ obtained here are much less than $0.02 \mathrm{~nm}^{-1}$ (Fig. 5.10) because the exponential decay constant for $a_{d m}$ is larger than the one for $a_{d}$.

Note that for values of $S$ larger than $0.02 \mathrm{~nm}^{-1}$ (results not shown), the correlations between measured and modeled $\left\langle c h l>, a_{p h}\right.$ and $a_{d}$, are even higher. High correlation, however, does not mean accurate prediction. The larger values of $S$ result in slopes that are significantly different than $l$ (less than 0.8 ) producing an overestimation of $\langle c h l\rangle$ in oligotrophic waters and an underestimation of high chlorophyll concentrations.

- Sensitivity to changes in the power of $b_{b p}$ : For the second set of model runs, three $b_{b p}$ spectra $\left(\lambda^{0}, \lambda^{-1}\right.$ and $\left.\lambda^{-2}\right)$ were used while holding the $a_{p h}{ }^{*}$ and $a_{d m}$ spectra constant (our open ocean estimate and an exponential shape with $S=0.02 \mathrm{~nm}^{-1}$, respectively). The 

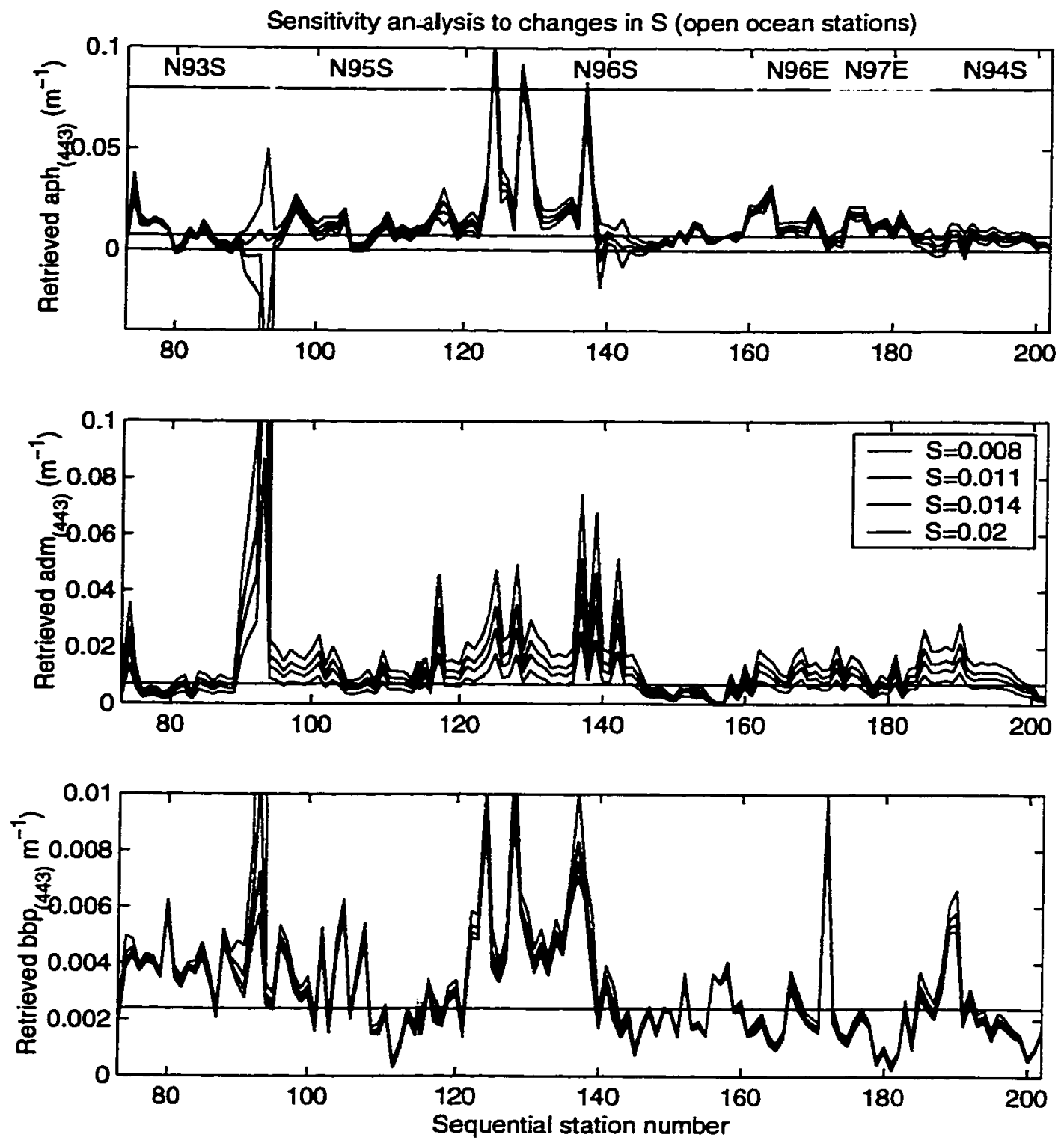

Fig. 5.15. The three IOPs, $a_{p h}(443), a_{d m}(443)$ and $b_{b p}(443)$, retrieved by the semianalytical model of Garver and Siegel (1997) at the open ocean stations (sequential number 73 to 202) for several values of $S\left(0.008,0.011,0.014\right.$ and $\left.0.02 \mathrm{~nm}^{-1}\right)$. The constant values for pure seawater are also depicted (horizontal solid lines). Units are $\mathrm{m}^{-1}$. 
Table 5.6. Results of linear regressions (percent variance explained: $r_{l}^{2}$ ) between retrieved IOP's $\left(a_{p h}(443), a_{d m}(443)\right.$ and $\left.b_{b p}(443)\right)$ and measured bio-optical variables for sensitivity analysis varying $a_{d m} *$ spectra using open ocean data. Best correlations for $a_{p h}$ and $a_{d m}$ are obtained for $S=0.02 \mathrm{~nm}^{-1}$ (gray areas).

\begin{tabular}{|c|ccc|ccc|cc|cc|cc|}
\hline & \multicolumn{3}{|c|}{$S=\mathbf{0 . 0 0 8}$} & \multicolumn{3}{c|}{$S=\mathbf{0 . 0 1 1}$} & \multicolumn{3}{c|}{$S=\mathbf{0 . 0 1 4}$} & \multicolumn{3}{c|}{$S=0.02$} \\
& $a_{p h}$ & $a_{d m}$ & $b_{b p}$ & $a_{p h}$ & $a_{d m}$ & $b_{b p}$ & $a_{p h}$ & $a_{d m}$ & $b_{b p}$ & $a_{p h}$ & $a_{d m}$ & $b_{b p}$ \\
\cline { 2 - 13 } & 0 & 11 & 30 & 49 & 18 & 45 & 80 & 22 & 42 & 91 & 24 & 39 \\
$a_{p h}$ (meas) & 1 & 17 & 33 & 32 & 26 & 37 & 61 & 29 & 33 & 76 & 31 & 30 \\
$a_{d}$ (meas) & 0 & 2 & 2 & 8 & 5 & 1 & 13 & 6 & 1 & 16 & 7 & 0 \\
$K(412) / K(490)$ & 1 & 7 & 13 & 2 & 21 & 17 & 10 & 29 & 14 & 19 & 34 & 12 \\
\hline
\end{tabular}

results of the linear regressions for this set of model runs are essentially identical (Table 5.7), as are the retrieved values for the three IOPs (Fig. 5.16). Since the choice of the $b_{b p}$ spectrum has little effect on the results of the IOP inversion for the dataset considered, the power $\lambda^{-1}$ was adopted because it is a common representation from the literature for particulate backscatter (Morel, 1987).

Table 5.7: Same as Table 5.6 but for sensitivity analysis varying $b_{b p}{ }^{*}(\lambda)$ spectra as $\left(\lambda \lambda_{0}\right)^{-n}(n=0,1,2)$.

\begin{tabular}{|c|c|c|c|c|c|c|c|c|c|}
\hline & & wer & & & wer & & & wer $=$ & \\
\hline & $a_{p h}$ & $a_{d m}$ & $b_{b_{p}}$ & $a_{p h}$ & $a_{d m}$ & $b_{b p}$ & $a_{p h}$ & $a_{d m}$ & $b_{b p}$ \\
\hline$<c h l\rangle$ & 90 & 16 & 34 & 891 & 24 & 39 & 91 & 33 & 45 \\
\hline$a_{p h}$ (meas) & 76 & 24 & 25 & 16 & 31 & 30 & 75 & 39 & 34 \\
\hline$a_{d}$ (meas) & 17 & 6 & 0 & 16 & . & $\mathbf{0}$ & 15 & 8 & 1 \\
\hline$K(412) / K(490)$ & 20 & 34 & 11 & 19 & 34 & 12 & 18 & 32 & 13 \\
\hline
\end{tabular}

- Sensitivity to changes in $a_{p h} *$ : The third model sensitivity analysis compared five $a_{p h} *$ spectra (see Fig. 3.1), for a fixed value of $S\left(0.02 \mathrm{~nm}^{-1}\right)$ and for $b_{b p} \sim \lambda^{-1}$ (Fig. 5.17). The 
results of the linear regressions are again quite similar (Table 5.8), with the highest correlation between $a_{p h} *$ and the measured $<c h l>$ for the general and open ocean averaged $a_{p h} *$ spectra. The $a_{p h} *$ of S. Maritorena (Personal Communication, 2000) appears to have the maximum correlation between modeled $a_{d m}$ and measured $a_{d}$ $\left(r_{l}^{2}=13 \%\right)$. No $a_{p h}{ }^{*}$ spectra produce negative values for $a_{d m}(443)$ (Fig. 5.17). The $a_{p h} *$ spectrum estimated from the open ocean stations was chosen as the optimum model because of its generally high correlations between modeled and measured parameters.

Table 5.8: Same as Table 5.6 but for sensitivity analysis varying $a_{p h} *(\lambda)$ spectra.

\begin{tabular}{|c|ccc|ccc|ccc|}
\hline & \multicolumn{3}{|c|}{$a_{p h}{ }^{*}=$ general } & \multicolumn{3}{c|}{$a_{p h} *=$ open water } & \multicolumn{3}{c|}{$a_{p h} *=$ Morel } \\
& $a_{p h}$ & $a_{d m}$ & $b_{b p}$ & $a_{p h}$ & $a_{d m}$ & $b_{b p}$ & $a_{p h}$ & $a_{d m}$ & $b_{b p}$ \\
\cline { 2 - 10 } & 91 & 23 & 40 & 911 & 24 & 39 & 90 & 42 & 47 \\
$a_{p h}$ (meas) & 76 & 30 & 30 & $7 \sigma_{1}$ & 31 & 30 & 75 & 47 & 35 \\
$a_{d}$ (meas) & 16 & 7 & 0 & 16 & -5 & 0 & 16 & 10 & 1 \\
$K(412) / K(490)$ & 19 & 33 & 12 & 19 & 34 & 12 & 19 & 35 & 13 \\
\hline
\end{tabular}

\begin{tabular}{|c|ccc|ccc|}
\hline & \multicolumn{3}{|c|}{$a_{p h} *=$ Bricaud } & \multicolumn{3}{c|}{$a_{p h}^{*}=$ Maritorena } \\
& $a_{p h}$ & $a_{d m}$ & $b_{b p}$ & $a_{p h}$ & $a_{d m}$ & $b_{b p}$ \\
\cline { 2 - 7 } & 89 & 31 & 43 & 86 & 60 & 40 \\
$a_{p h}$ (meas) & 75 & 37 & 33 & 64 & 61 & 28 \\
$a_{d}$ (meas) & 16 & 8 & 1 & 15 & 13 & 1 \\
$K(412) / K(490)$ & 18 & 34 & 12 & 12 & 32 & 9 \\
\hline
\end{tabular}

The results of the optimized semi-analytical inversion model using an average $a_{p h}{ }^{*}$ from the open ocean stations, $S=0.02 \mathrm{~nm}^{-1}$ and $b_{b p} \sim \lambda^{-1}$ are presented in Fig. 5.18. The modeled and measured chlorophyll concentrations agree, except for a overestimation of as much as $0.2 \mathrm{mg} \mathrm{m}^{-3}$ for stations 144-184 and 197-202 in the Pacific. The relative 



Fig. 5.16. Same as Figure 5.15 with $S=0.02 \mathrm{~nm}^{-1}$ and for different spectral shapes for the backscattering coefficient: $\lambda^{0}, \lambda^{-1}, \lambda^{-2}$ (see equation 33 ). 

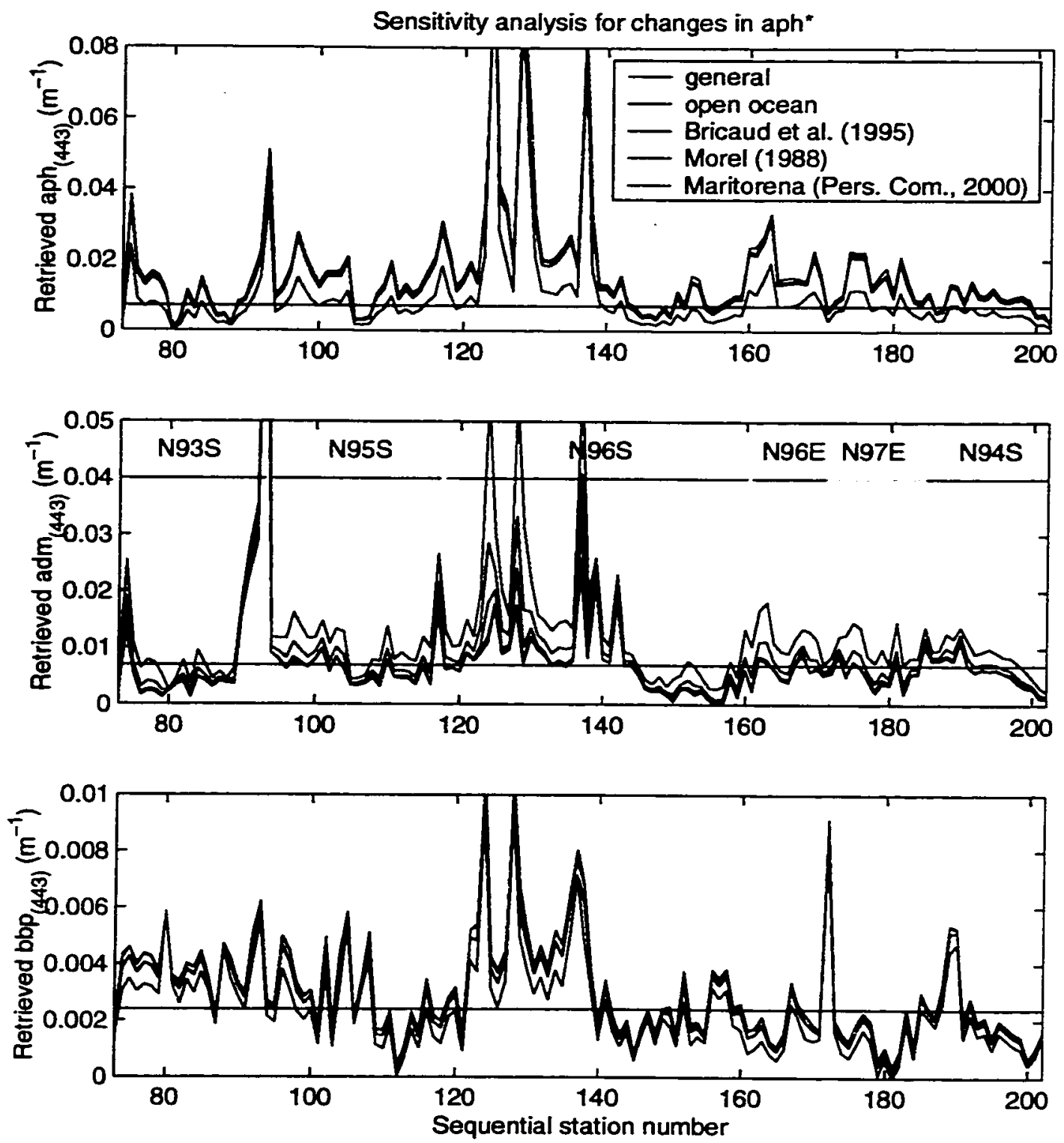

Fig. 5.17. Same as Figure 5.15 with $S=0.02 \mathrm{~nm}^{-1}$ and with power law $\lambda^{-1}$ for backscattering, but for the following $a_{p h}{ }^{*}$ spectral models: (general) averaged $a_{p h}{ }^{*}$ obtained from all surface measurements; (open) averaged $a_{p h}{ }^{*}$ for the open ocean only; the models of Bricaud et al. (1995), of Morel (1988), and of S. Maritorena (Personal Communication, 2000). 
absorption by detrital/dissolved substances as given by the model, $a_{d m}(443)$, and the relative absorption by detritus (measured $a_{d}(443)$ ) are also compared. Both absorption coefficients have been normalized by the modeled $a_{p h}(443)+a_{d m}(443)$. If the model correctly simulates $a_{d m}(443)$, this parameter would always exceed $a_{d}(443)$ and the difference would be a signature of absorption by dissolved susbtances. This is mostly the case for stations at high latitudes (sequential station numbers $90-140$ in Fig. 5.18) where the relative absorption contribution by CDOM can approach 50\% (difference between the two curves in percent). However, for other stations in the Pacific (between $10^{\circ} \mathrm{N}$ and $40^{\circ} \mathrm{S}$; around 150 and $160-180$ in Fig. 5.18), the measured $a_{d}(443)$ can be significantly larger than the modeled $a_{d m}(443)$, even exceeding $100 \%$ of the entire modeled absorption. They are considered separately below as means to improve the inversion model by changing the input parameters are explored.

Scatter diagrams of modeled versus measured variables for the optimized semianalytical inversion model are shown in Fig. 5.19. Log-transformed variables were also used to fit the best power model for the chlorophyll concentrations. The correlation between the log-transformed chlorophyll concentrations is $r^{2} \sim 0.72$, which is still lower than the values obtained with the empirical models (see Table 5.3). The slope and intercept are close to 1 and 0 , respectively (see values and associated standard errors in Table 5.3). The corresponding $a_{p h}(443)$ are also well correlated $\left(r_{l}^{2}=0.76\right)$. In contrast the correlation between the measured $a_{d}(443)$ and modeled $a_{d m}(443)$ is low $\left(r_{l}^{2}=0.07\right)$. The modeled $a_{d m}(443)$ and its relative importance with respect to the total absorption 

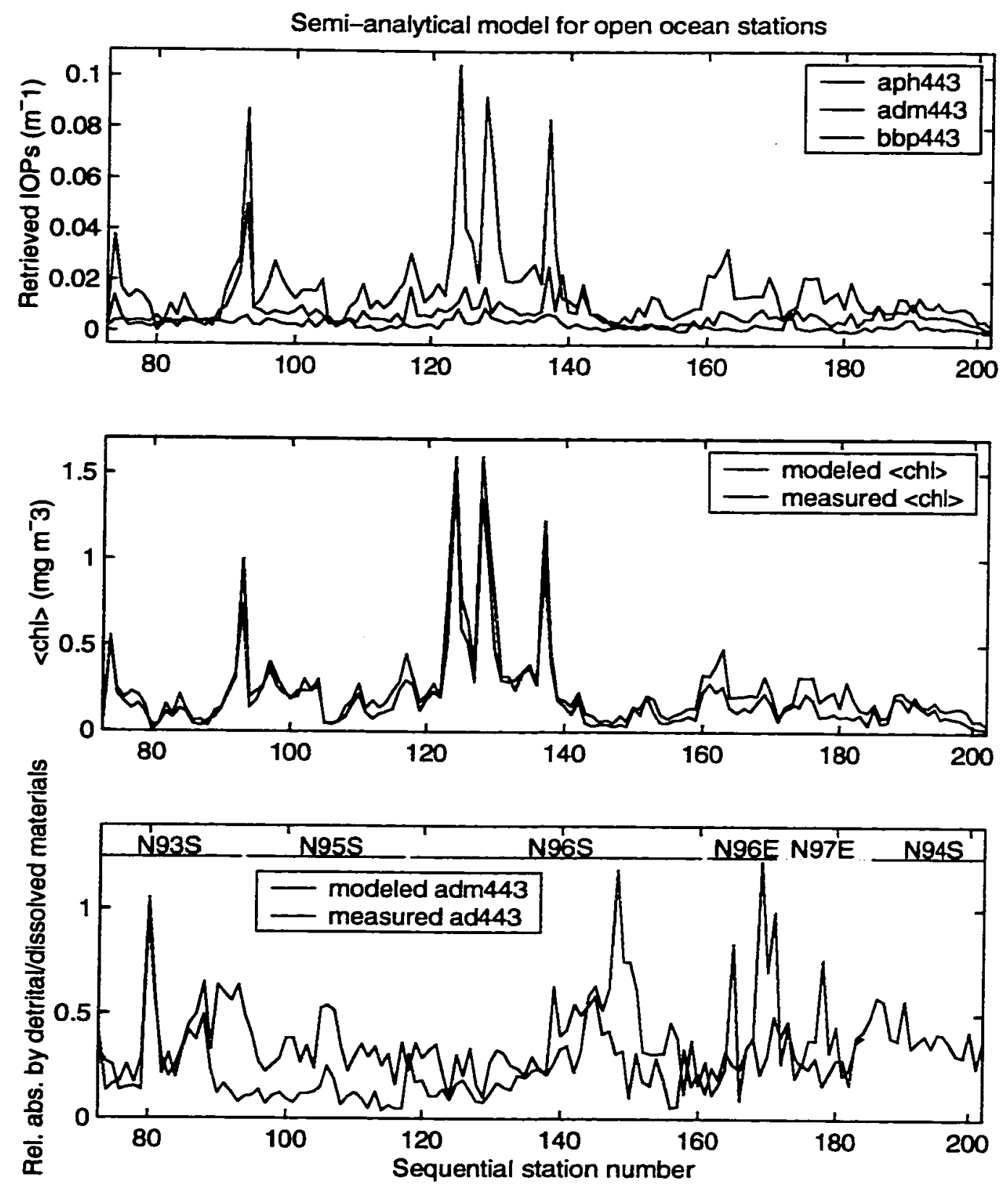

Fig. 5.18. Results of the optimized semi-analytical inversion model using an averaged $a_{p h} *$ from the open ocean stations, $S=0.02 \mathrm{~nm}^{-1}$ and $b_{b p} \sim \lambda^{-1}$. The three IOPs retrieved by the model are shown in the top panel. Units are $\mathrm{m}^{-1}$. The modeled and measured chlorophyll concentrations $\left(\mathrm{mg} \mathrm{m}^{-3}\right)$ are compared in the middle panel. In the lower panel, the relative absorption by detrital/dissolved substances as given by the model, $a_{d m}(443)$, and the relative absorption by detritus (measured $a_{d}(443)$ ) are confronted. The absorption coefficients have been normalized by the modeled $a_{p h}(443)+a_{d m}(443)$. All results are shown versus station sequence number (from 73 to 202). Measured $a_{d}(443)$ are not available for stations beyond number 184 . 

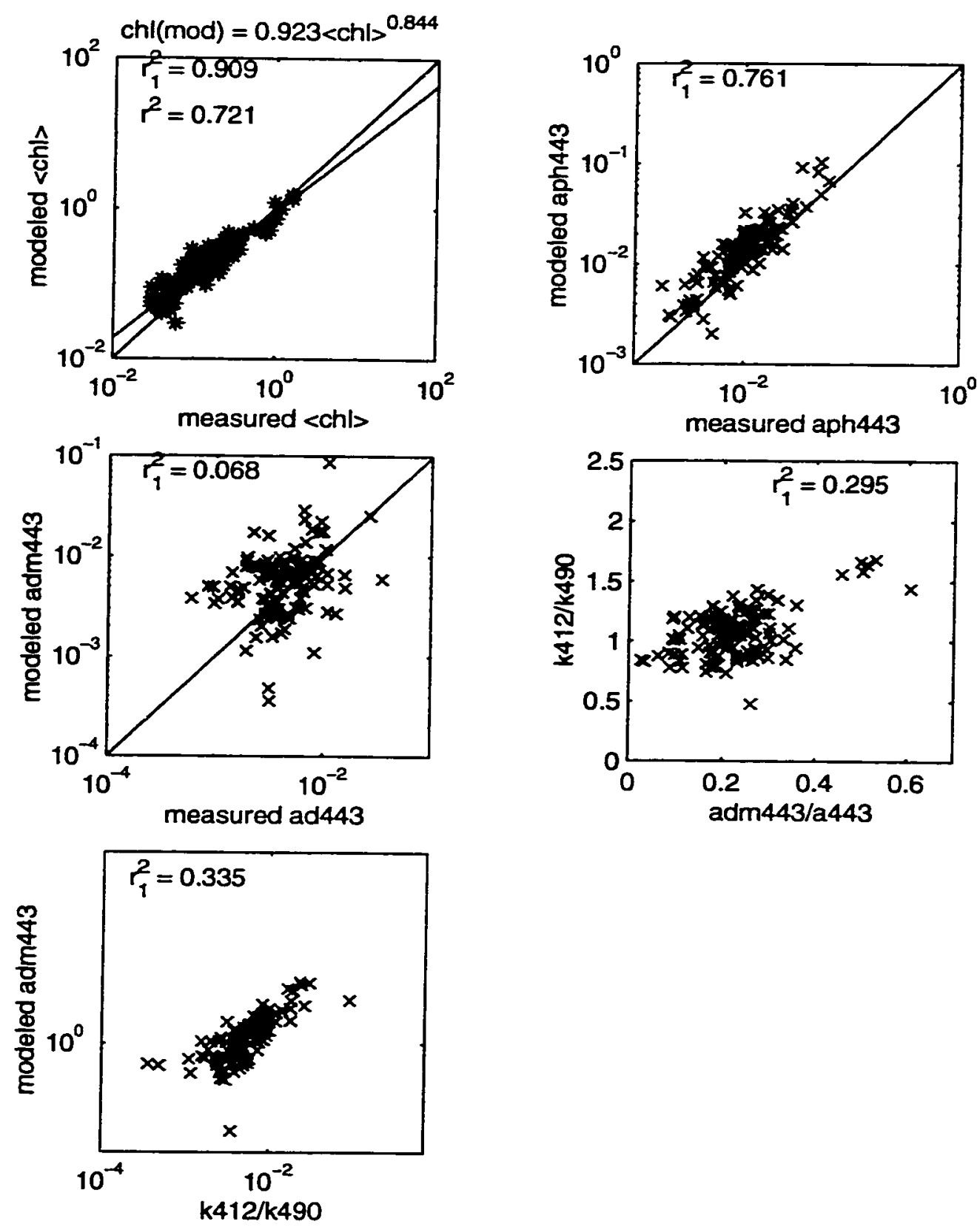

Fig. 5.19. Scatter diagrams of modeled versus measured variables for the optimized semianalytical inversion model. Units are $\mathrm{mg} \mathrm{m}^{-3}$ for chlorophyll concentrations and $\mathrm{m}^{-1}$ for the absorption coefficients. The coefficient of determination, $r_{l}{ }^{2}$, is shown for each scatter plot. Log-transformed variables were also used to fit the best power model for the chlorophyll concentrations. The resulting relationship is posted. For $\langle\operatorname{chl}\rangle$, the coefficient of determination between the log-transformed modeled and measured values is also indicated, $r^{2}$. 
retrieved by the model, $a_{d m}(443) / a(443)$, are also compared to the ratio $K_{d}(412) / K_{d}(490)$. Although the correlation is rather low $\left(r_{I}^{2}-0.30-0.34\right)$, the normalized absorption coefficient for dissolved/detrital substances tend to increase with increasing values of the ratio of attenuation coefficients.

\section{Pacific Ocean stations}

The open ocean stations in the Pacific between $10^{\circ} \mathrm{N}$ and $40^{\circ} \mathrm{S}$ were considered separately. The semi-analytical model with the $a_{p h} *$ of S. Maritorena (Personal Communication), with $S=0.02 \mathrm{~nm}^{-1}$ and with $b_{b p} \sim \lambda^{-1}$ yields the best results (Fig. 5.20). The chlorophyll concentration is no longer overestimated by the model and the modeled absorption by detrital/dissolved materials generally exceeds the measured absorption by detritus. The correlation between the log-transformed modeled and measured $<c h l>$ approaches $r^{2}=0.81$ (Fig. 5.21). This value surpasses the correlation obtained with the empirical models (Table 5.4). The intercept and slope of the regression line are respectively close to zero and one. Hence, it can be concluded that the optimized semianalytical model outperforms the empirical models for the chlorophyll concentrations. The absorption coefficient for phytoplankton, $a_{p h}(443)$, is underestimated by the model because the $a_{p h} *$ of Maritorena underestimates the real relationship between $a_{p h}(443)$ and $<c h l>$ for the range of chlorophyll concentration considered $\left(<c h l><0.3 \mathrm{mg} \mathrm{m}^{-3}\right.$, see Fig. 5.4). With regards to the absorption by detrital/dissolved substances, both $a_{d m}(443)$ and $\left.a_{d m}(443) / a(443)\right)$ tend to increase with the ratio of attenuation coefficients $K_{d}(412) / K_{d}(490)$. The modeled $a_{d m}(443)$ and measured $a_{d}(443)$ are still poorly correlated 

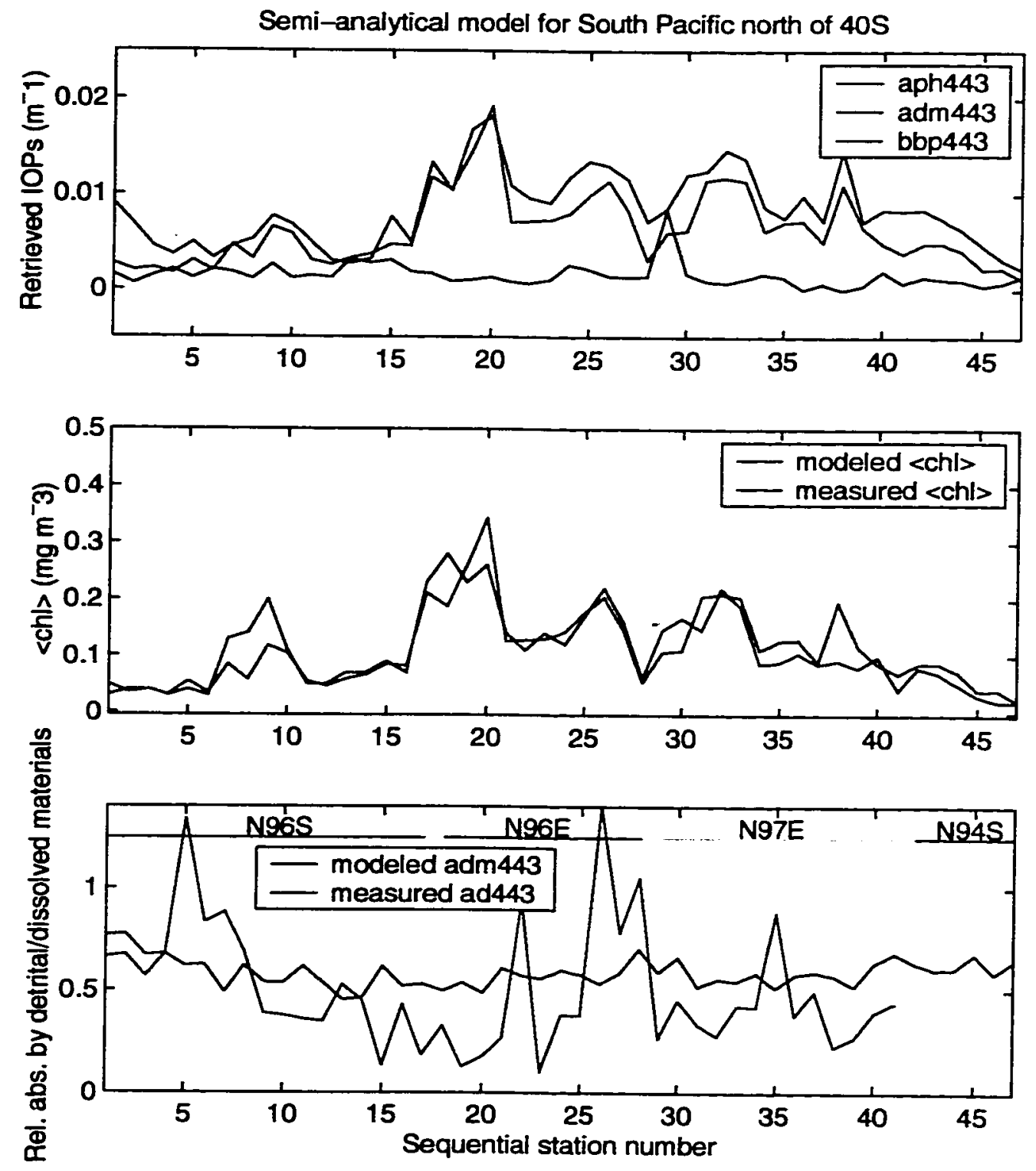

Fig. 5.20. Same as Fig. 5.18 but for the open ocean stations in the Pacific north of $40^{\circ} \mathrm{S}$ and using the following parameters: $a_{p h}{ }^{*}$ of Maritorena, $S=0.02 \mathrm{~nm}^{-1}$ and $b_{b p} \sim \lambda^{-1}$. All results are shown versus station sequence number ( 1 to 47$)$ which do not necessarily correspond to the ones used in Fig. 5.18. 



Fig. 5.21. Same as Fig. 5.19 but for the open ocean stations in the Pacific north of $40^{\circ} \mathrm{S}$. 
while the former generally exceeds the latter (Fig. 5.21).

\section{California coastal stations}

The last subset of data considered consists of the coastal stations off the California coast (mostly in Monterey Bay) where $\mathrm{a}^{*}$ measurements were available. The results of the inversion model with the following optimized parameters are depicted in Fig. 5.22: average $a_{p h}{ }^{*}$ spectrum estimated from the coastal stations, $S=0.025 \mathrm{~nm}^{-1}$ and $b_{b p} \sim \lambda^{-1}$

The scatter diagrams and the regression lines of the modeled versus measured parameters show that the semi-analytical model performs well in these coastal waters (Fig. 5.23). The retrieval of $\langle c h l\rangle$ is significantly better compared to the empirical models (Table 5.5). The correlation between modeled and measured values is high $\left(r^{2} \sim 0.76\right)$, the intercept is close to zero but the slope is less than one (0.761). The model

$a_{d m}(443)$ surpasses the measured $a_{d}(443)$ except for two stations, leaving "space" for the non-measured absorption by dissolved substances. Poor correlation exists between the modeled $a_{d m}(443)$ and the ratio of attenuation coefficients $K_{d}(412) / K_{d}(490)$.

\section{Comparison between measured and modeled IOPs}

A summary of the measured and modeled IOPs is presented in Table 5.9. Mean ratios of various combinations of parameters (measured $a_{p}$ and $a_{d,}$ modeled $a_{p h}$ and $a_{d m}$ ) are listed for different water types and geographical locations. First, the mean ratio of two measured quantities, $a_{d} / a_{p}$, is shown to represent the relative contribution of detritus 

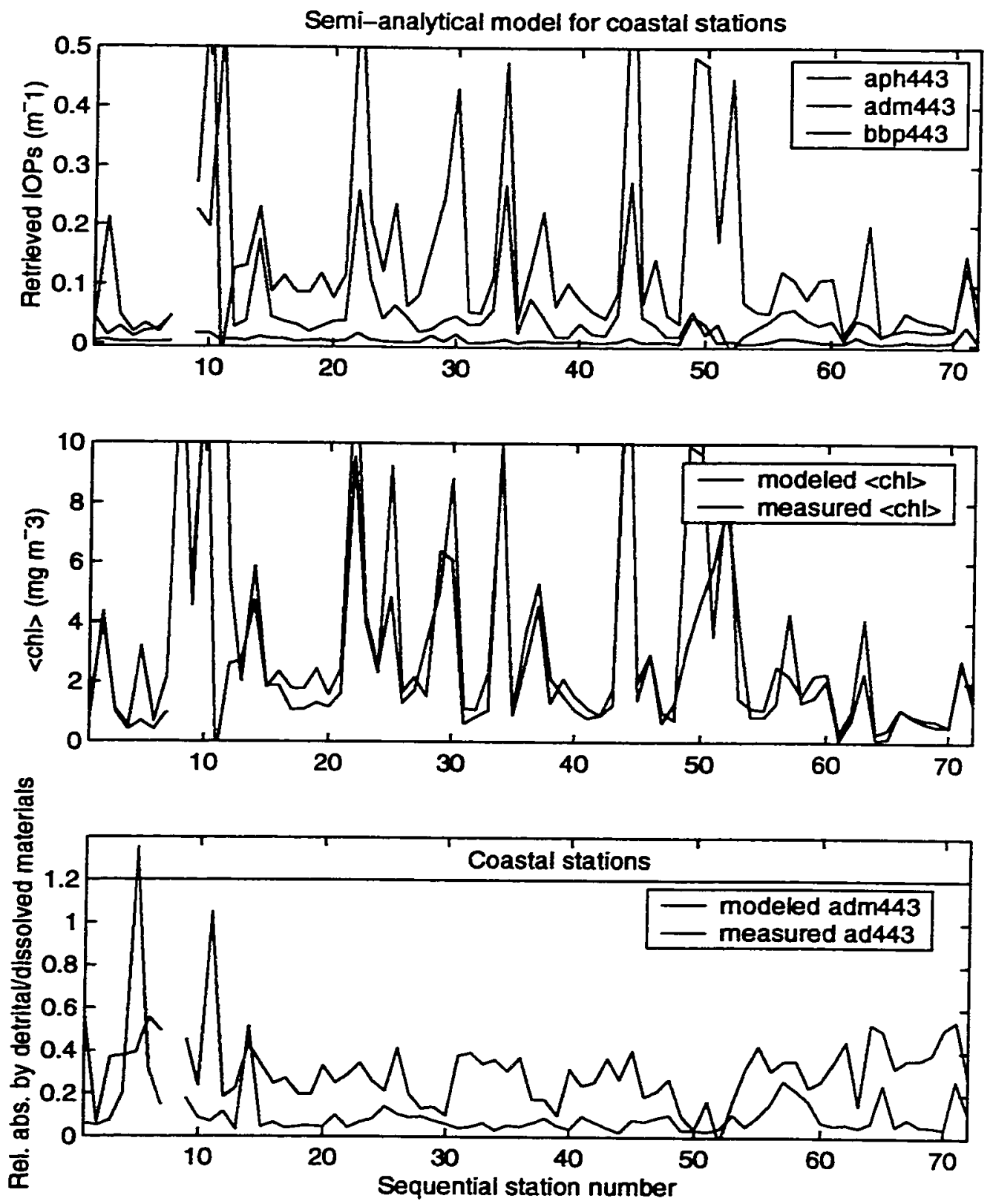

Fig. 5.22. Same as Fig. 5.18 but for selected coastal stations (where $a^{*}$ measurements were available) and using the following parameters: $a_{p h}{ }^{*}$ extimated from the coastal stations, $S=0.025 \mathrm{~nm}^{-1}$ and $b_{b p}-\lambda^{-1}$. All results are shown versus station sequence number (1 to 73). 

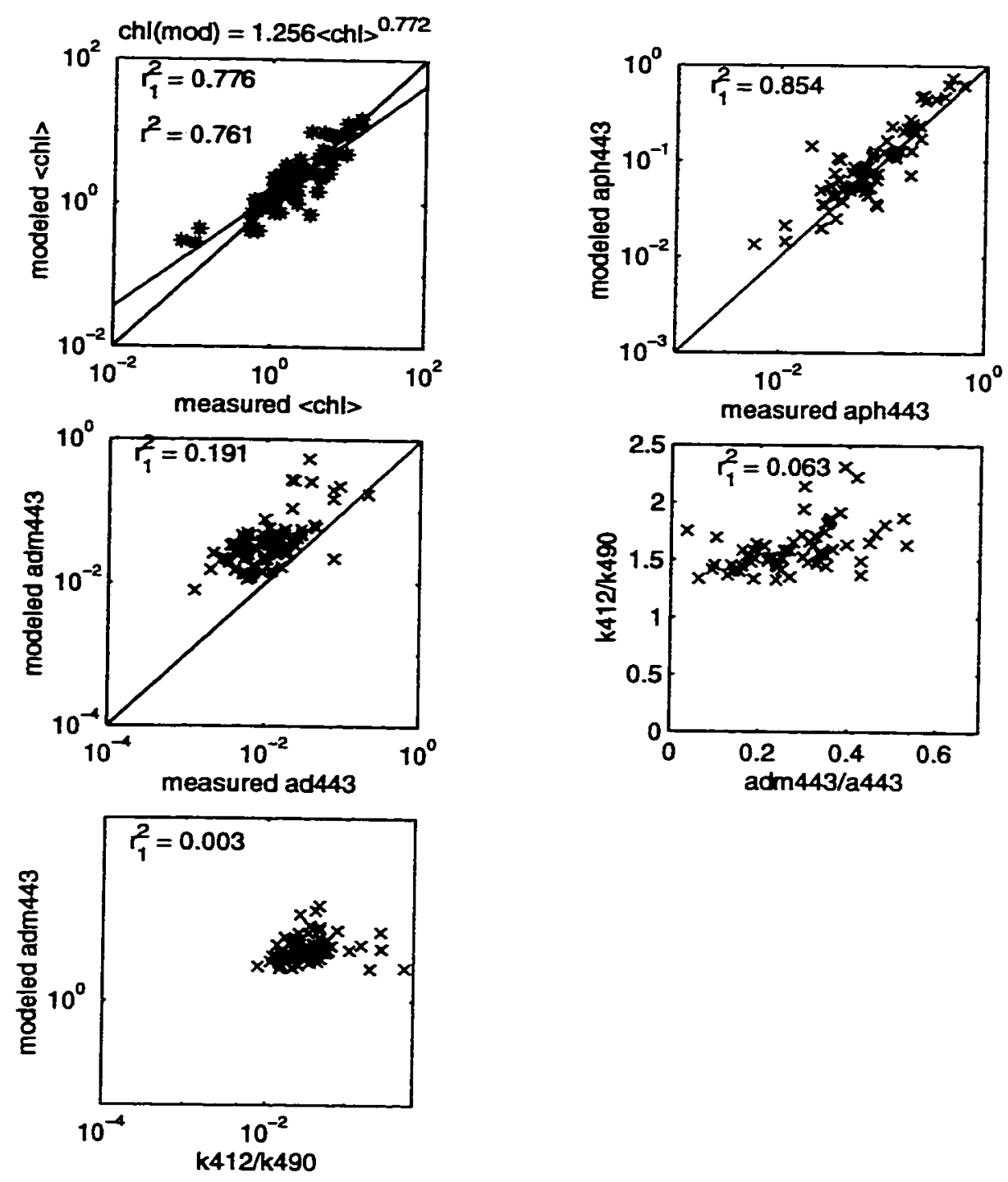

Fig. 5.23. Same as Fig. 5.19 but for Californian coastal stations. 
absorption with respect to the total absorption by particulates. The ratio is large for the Pacific north of $40^{\circ} \mathrm{S}$ and is small for the California coast and in the Indian Ocean. Then, one model and two hybrid (modeled and measured) ratios are considered to show the relative importance of the absorption by phytoplankton, by particles and by dissolved substances. These do not necessarily sum up to $100 \%$ because (1) they are means of ratios and not ratios of means, and (2) the measured $a_{d}$ and $a_{p h}$ (used in the numerators) are not always equal to their modeled counterparts. The modeled parameters were obtained with the semi-analytical model of Garver and Siegel (1997) optimized for the respective regions.

The relative contribution of phytoplankton to light absorption, represented by the mean of $a_{p h} /\left(a_{p h}+a_{d m}\right)$, ranges from $\sim 52 \%$ in the Indian Ocean to $\sim 63 \%$ in the coastal waters and in the Pacific between $10^{\circ} \mathrm{N}$ and $40^{\circ} \mathrm{S}$. The mean $a_{d} /\left(a_{p h}+a_{d m}\right)$, that indicates the relative importance of absorption by detrital substances, follows the same trend as $a_{d} / a_{p}$, with a pronounced maximum for the Pacific between $10^{\circ} \mathrm{N}$ and $40^{\circ} \mathrm{S}(\sim 51 \%)$ and a weak contribution $(\sim 11 \%)$ for the coastal waters and the Indian ocean. An estimate of the relative contribution of absorption by dissolved substances is obtained by subtracting the measured $a_{d}$ from the modeled $a_{d m}$, followed by a normalization with the modeled absorption by particulate and dissolved substances. This mean ratio indicates that CDOM is more important in the Indian Ocean $(-38 \%)$ and in the coastal areas (20\%). In contrast, the absorption by CDOM is relatively small $(\sim 8 \%)$ for the Pacific between $10^{\circ} \mathrm{N}$ and $40^{\circ} \mathrm{S}$

In conclusion, dissolved substances in the California coastal waters and the Indian 
Ocean waters absorb light much more than the detrital particulate materials (twice and four times as much, respectively). These two regions are different with respect to the absorption by phytoplankton, which is more important in the coastal waters. For the open ocean, Atlantic and Pacific, absorption by detritus dominates the effects of CDOM. The predominant effect of detritus is mostly seen in the Pacific between $10^{\circ} \mathrm{N}$ and $40^{\circ} \mathrm{S}$ (reaching $~-51 \%$ ) where it can be as important as the absorption by phytoplankton.

Table 5.9: Comparison between measured and modeled IOPs using the optimized semianalytical model of Garver and Siegel (1997) applied to four regions: coastal waters off California, the Pacific Ocean between $10^{\circ} \mathrm{N}$ and $40^{\circ} \mathrm{S}$, the Indian Ocean and the Atlantic and Pacific Oceans (south of $40^{\circ} \mathrm{S}$ ). Hybrid measured/modeled parameters are considered in the last three columns: $a_{p}$ and $a_{d}$ are measured quantities whereas $a_{d m}$ and $a_{p h}$ are model outputs.

\begin{tabular}{|c|c|c|c|c|c|c|}
\hline & $a_{p h} *$ & $\begin{array}{c}S \\
n^{-1}\end{array}$ & $\begin{array}{c}\text { meas. } \\
a_{d} / a_{p}\end{array}$ & $\begin{array}{c}\text { modeled } \\
a_{p h} /\left(a_{p h}+a_{d m}\right)\end{array}$ & $\begin{array}{c}\text { hybrid } \\
a_{d} /\left(a_{p h}+a_{d m}\right)\end{array}$ & $\begin{array}{c}\text { hybrid } \\
\left(a_{d m}-a_{d}\right) /\left(a_{p h}+a_{d m}\right)\end{array}$ \\
\hline coastal & own data & 0.025 & $14.50 \%$ & $62.73 \%$ & $11.06 \%$ & $19.78 \%$ \\
Pacific 10N-40S & Maritorena & 0.02 & $42.90 \%$ & $62.61 \%$ & $50.54 \%$ & $7.68 \%$ \\
Indian & own data & 0.015 & $19.71 \%$ & $51.66 \%$ & $10.56 \%$ & $37.78 \%$ \\
Atlantic \& Pacific & open data & 0.02 & $30.17 \%$ & $54.17 \%$ & $23.76 \%$ & $10.69 \%$ \\
\hline
\end{tabular}

\section{Application of the modified model of Garver and Siegel}

The inversion model of Garver and Siegel (1997) was modified so that the absorption by phytoplankton is modeled by the power law (35) instead of the linear relation (10). The modified model was run for all the stations with the following spectral shapes: $A(\lambda)$ obtained from all the data (see Fig. 5.4 and Table 5.1), $S=0.02 \mathrm{~nm}^{-1}$ and with a power of -1 for $b_{b p}(\lambda) / b_{b p}(412)$. The power, $1-B(\lambda)$, was either set to constant 
values $(0.9,0.8,0.7$ and 0.6$)$ or was taken from the fit to the data (Fig. 5.4 and Table 5.1). The retrieved IOPs and the modeled/measured chlorophyll concentrations are displayed in Figs. 5.24 and 5.25 for the variable and constant $B(\lambda)(=0.25)$, respectively. Note that the correlation between the modeled and measured chlorophyll concentrations are identical for all the constant values adopted for $B$, only the intercept and slope of the regression line vary.

The model cannot be inverted for 23 stations (mostly in coastal water) when the $B(\lambda)$ values obtained from the data are utilized (Fig. 5.5 and Table 5.1). Discarding these stations, the coefficient of determination between the log-transformed concentrations is $r^{2}-0.81$. The relationship is close to a one-to-one correspondence with a slope $\sim 0.92$ (standard error $=0.03$ ) (Fig. 5.24). Using a constant value for $B(=0.25)$, the results are similar to those presented above (slope $\sim 0.91$ and $r^{2} \sim 0.79$, excluding 10 stations for which the IOPs were not retrieved; see Fig. 5.25).

In order to compare quantitatively the performances of the regular and modified semi-analytical inodels, regression statistics were computed using a common set of stations for which the inversion was possible in all cases (261 stations out of 284 , see Table 5.10). The slope of the regression lines using the modified models is $\sim 0.9 \pm 0.03$. This represents a significant improvement over the semi-analytical model using $a_{p h} *$ for which the slope is only $-0.64 \pm 0.02$ (see Table 5.2 ). The correlation coefficients for the modified semi-analytical model are similar to those of the regular model of Garver and Siegel (1997) and those of the empirical models. 
Table 5.10: Results of the linear regressions (using log-transformed data) between modeled and measured chlorophyll concentrations for the semi-analytical model of Garver and Siegel (regular and modified versions) using all data. The linear regression model is: $\log \left(\langle c h l\rangle_{\text {mod }}\right)=$ intercept + slope $\log \left(\langle c h l\rangle_{\text {meas. }}\right)$. The standard errors on the slope, intercept and estimate $\left(\log \left(\langle c h l\rangle_{\text {mod }}\right)\right)$ are included, together with the coefficient of determination, $r^{2}$. These statistics are based on 261 stations for which all versions of the model were successfully applied.

\begin{tabular}{|l|cccccc|}
\hline & Intercept & Slope & $r^{2}$ & S.E. Slope & S.E. Inter. & S.E. Estim. \\
\hline Regular & -0.163 & 0.638 & 0.815 & 0.019 & 0.187 & 0.187 \\
\hline Modified & & & & & & \\
Variable $B$ & 0.086 & 0.915 & 0.809 & 0.028 & 0.274 & 0.273 \\
$B=0.25$ & 0.542 & 0.881 & 0.820 & 0.026 & 0.253 & 0.253 \\
\hline
\end{tabular}

Although the correlations of the log-transformed measured and modeled concentrations are similar to those obtained with the non-modified model, the modified model tends to overestimate the chlorophyll concentration in rich waters (e.,g., $<$ chl $>>1$ $\mathrm{mg} \mathrm{m}^{-3}$ ). For example, the four peaks of high $<c h l>$ for stations above sequential number 150 in Figs. 5.24 and 5.25, are largely overestimated by the model. This causes the correlation of the non log-transformed concentrations to decrease to values of $r_{I}{ }^{2}$ as low as 0.15. Despite this problem with the large chlorophyll values, the modified semianalytical model has an improved efficiency for the retrieval of low chlorophyll concentration, say less than $1 \mathrm{mg} \mathrm{m}^{-3}$. The $A$ and $B$ values of Bricaud et al. (1995) (Table 5.1) were also used but did not produce good results because the $B$ values are too large. 

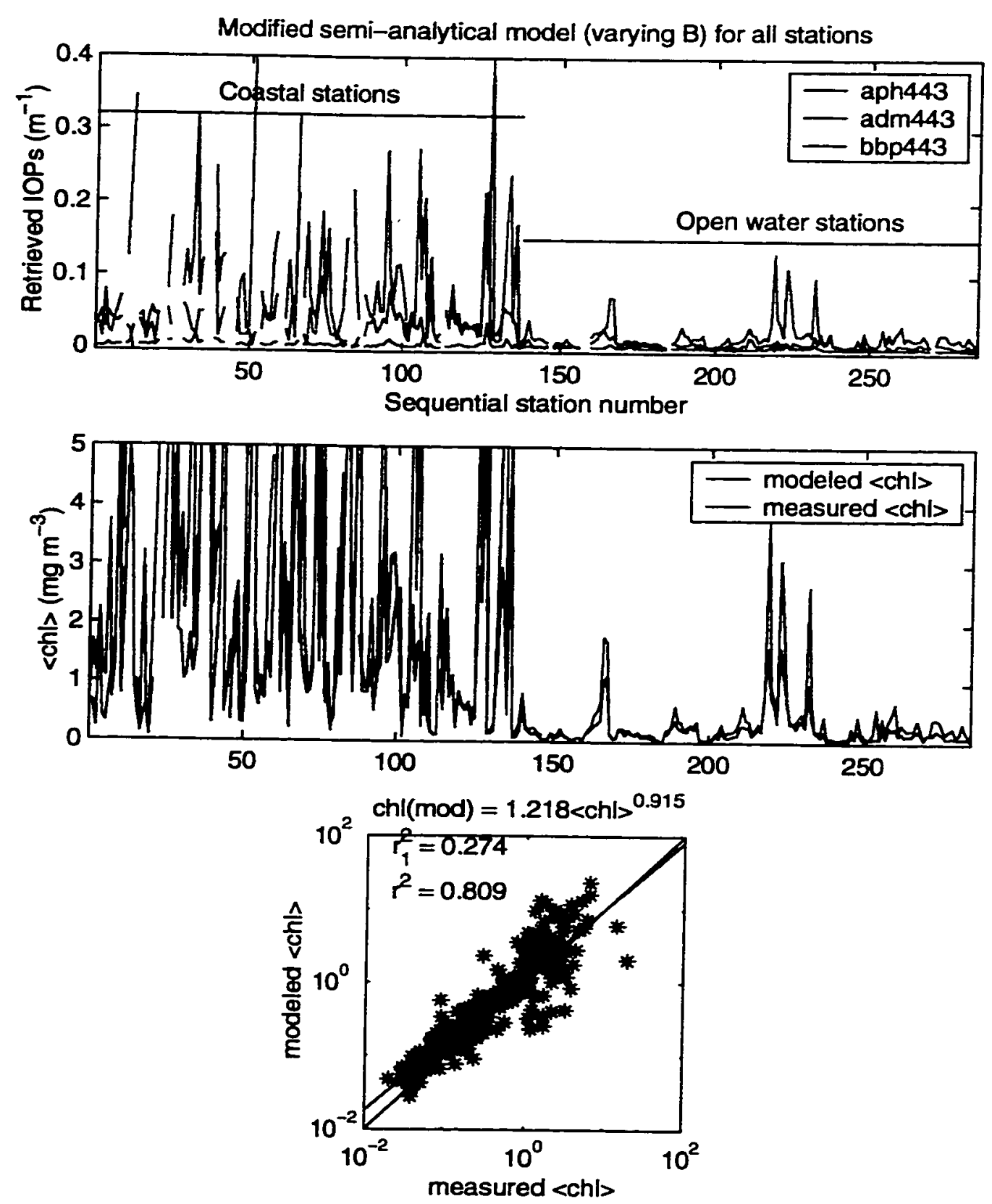

Fig. 5.24. Same as Fig. 5.15 but using the modified model of Garver and Siegel (1997) with $A(\lambda)$ and $B(\lambda)$ obtained from the regression analysis with the data (Table 5.1), $S=$ $0.02 \mathrm{~nm}^{-1}$ and $b_{b p} \sim \lambda^{-1}$. 

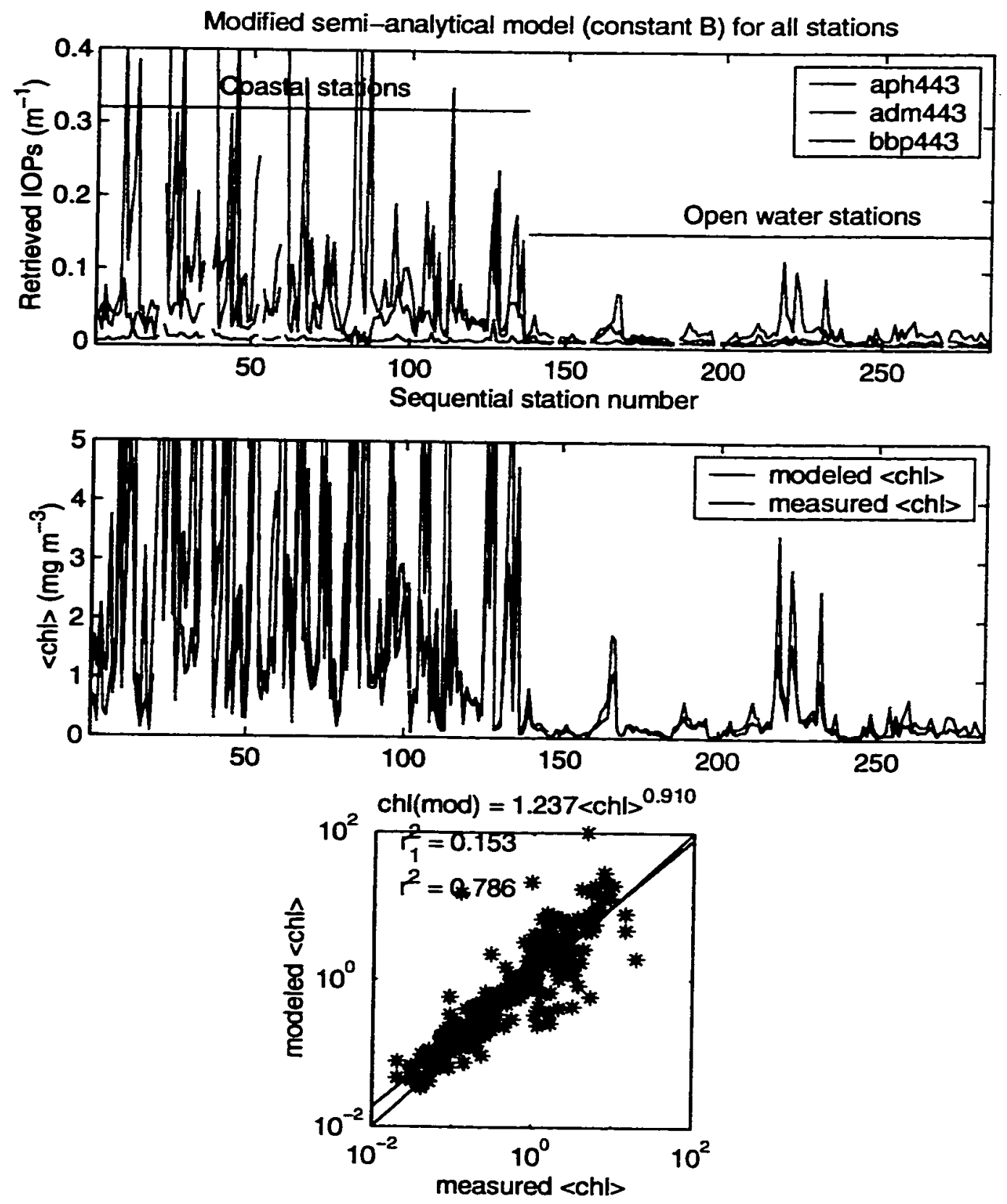

Fig. 5.25. Same as Fig. 5.24 but with $B(\lambda)=0.25$. 


\section{CHAPTER 6}

\section{DISCUSSION}

The reflectance of the ocean is inversely related to absorption (equations 29 and 30). Semi-analytical models use this inverse relationship to estimate absorption and backscattering from remotely sensed reflectance. Chlorophyll can then be estimated from the decomposed absorption spectrum. It is therefore paramount to know the spectral and chlorophyll dependence of the absorption coefficient for phytoplankton. It is also important to know the same for the absorption by detrital and dissolved materials. Current semi-analytical models (Garver and Siegel, 1997; Carder et al, 1999) combine the latter two parameters essentially because of the paucity of data on CDOM.

The data collected allow for the study of the spectral relationship between the absorption coefficient for phytoplankton and chlorophyll (Figs. 5.4 and 5.5). For most wavelengths the relationship is best described by a power law function (equation 35 and Fig. 6.1). At high chlorophyll concentration, there is a lower absorption per unit chlorophyll (Fig. 5.5). This is thought to be related to packaging or self-shading effects (Bricaud et al, 1995; Carder et al., 1999). For the coastal stations the increase absorption is probably due to pigments like chlorophyll-c and carotenoids (Bidigare et al., 1990; Hoepffner and Sathyendranath, 1993). It is suggested that the enhanced absorption at lower chlorophyll concentration is related to increased effects of photoprotective/accessory pigments. It is further proposed that at low chlorophyll concentration this effect should vary as a function of the health of the photosynthetic 
reaction system. In the next several paragraphs the data will be analyzed with this hypothesis in mind.

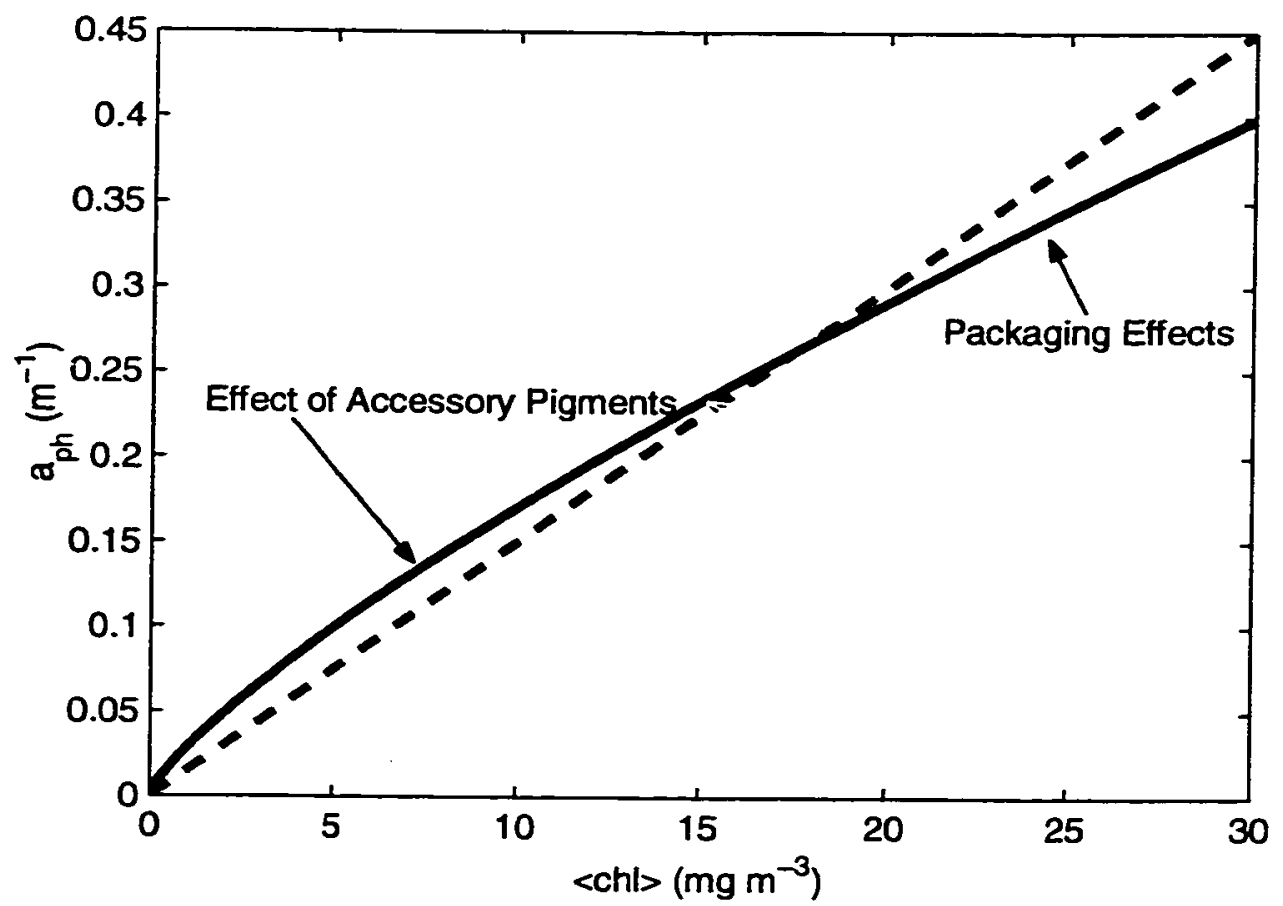

Fig. 6.1. Linear $\left(a_{p h}{ }^{*}\right)$ and power law $\left(A<c h l>^{1-B}\right)$ models for $a_{p h}$ versus $<c h l>$ using coefficients similar to those estimated for the data at $490 \mathrm{~nm}$ (Table 5.1). The effects of accessory pigments and of packaging are indicated.

Examining the low chlorophyll data, mostly at low latitudes, it can be seen that there are several different bio-optical provinces (see $a_{p l 2}{ }^{*}, S$ or $a_{d}$ versus $\langle c h l>$ in Figs. 5.6, 5.10 and 5.11). The Indian Ocean partitions out as a lower absorption per unit chlorophyll system (Figs. 5.6 and 6.2). At the other end of the range is the Pacific north of $40^{\circ} \mathrm{S}$ that exhibits high absorption per unit chlorophyll. In between these two is the tropical Atlantic. What would make these specific absorptions fall out in the above 
described manner? Other authors have reported high concentration of photo-protective pigments in the equatorial Pacific (Allali et al, 1997). Lindley et al. (1995) removed the photo-protective signal from the total pigment absorption and showed how iron limited the quantum yield of photosynthesis. Indeed, it has been demonstrated repeatedly that iron limits the phytoplankton in this region. The loading of photo-protective pigments may therefore be a response of the phytoplankton in this region to this limitation and their fragile photosystems (Behrenfeld and Falkowski, 1997). The Atlantic and Indian Oceans, in contrast, are known to have higher supplies of iron (Chavez and Smith, 1995). If this hypothesis is correct and the level of photo-protective pigments is related to iron, than the Indian Ocean appears to be the most iron replete.

Let us focus on the relationship between $a_{p h}$ and $<c h l>$ (Fig. 5.5), which was best represented by a power law (35) and compare the values for $A$ and $B$ to those reported by Bricaud et al. (1995). Comparing the numerical values in Table 5.1, it is seen that the values found in this work indicate more contribution of accessory pigments (larger $A^{\prime} s$ ) and less packaging effects (smaller $B$ 's). The differences in slopes for low chlorophyll (essentially the $A$ 's) are mostly due to the inclusion of the equatorial Pacific in the dataset, for which the phytoplankton absorption per unit chlorophyll is larger than in other regions due to the contribution of photo-protective/accessory pigments. The geographical variations of $a_{p h} *$ are also clearly evident in Fig. 6.2, where the chlorophyllspecific absorption by phytoplankton was averaged for the Indian (green), the South Pacific (magenta), the Atlantic (blue), equatorial Pacific (yellow) and the coastal stations (dashed). The South and the equatorial Pacific show higher $a_{p h}$ * values, together with the 
Atlantic that presents a slightly different spectral shape. The Indian Ocean, on the other hand, presents a spectral shape more similar to the coastal stations.

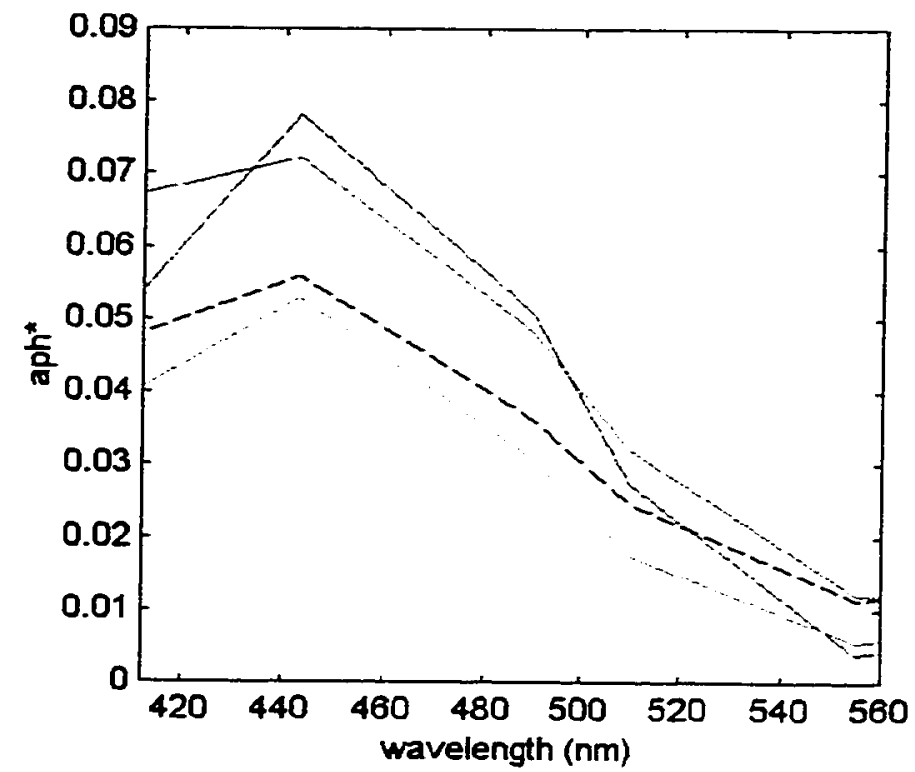

Fig. 6.2: Specific absorption of phytoplankton versus wavelength estimated from several subsets of our data: Indian (green), California coastal (black dashed), Atlantic (blue), South and Equatorial Pacific (purple and yellow).

The absorption by detritus (Figs. 5.9 and 5.10) generally increases with increasing chlorophyll concentration. In oligotrophic waters minimal values were measured for the Indian Ocean and maximal in the equatorial Pacific, while in the meso/eutrophic waters spring values in California coastal waters are the highest and summer values are the lowest. It is interesting to note that these trends are reversed for the exponential shape of the absorption spectrum: the lower (higher) $S$ is seen for the equatorial Pacific (Indian Ocean) for low <chl>; for the waters off California, $S$ is smaller in spring than in summer. 
An inverse relationship is evident between the ratio $\operatorname{ad}(443) / a p(443)$ and chlorophyll (Fig. 5.12), , meaning that the relative percentage of the absorption due to detritus is more important for low chlorophyll ecosystems. Within the same geographical regions of the open ocean (e.g., in the Indian and the equatorial Pacific), there is a large scatter spanning almost $10-80 \%$. These results contrast with those of Bricaud et al. (1998) in which the ratio of nonalgal absorption to total particulate absorption at $440 \mathrm{~nm}$ does not show a decreasing trend with increasing $\langle c h l\rangle$. The dataset considered in this work does not include waters with high sediments and high chlorophyll, like those of estuarine regions considered by Bricaud et al. (1998). High chlorophyll areas are often referred to as Case 2 waters for which the contribution of other constituents is as important as, or even more important than, the absorption by chlorophyll. The relative absorption by detrital materials in the California coastal waters is mostly low.

Similar conclusions can be drawn from Fig. 5.11 where the dependences of $a_{p h}, a_{d}$ and $a_{p}$ on $<c h l>$ at $443 \mathrm{~nm}$ are analyzed. The results are again compared to those of Bricaud et al. (1995). The regression line for $a_{p h}$, which corresponds to $1-B(\lambda)=0.785$, is larger than the estimates obtained by Bricaud et al. $(1995 ; 1998): 0.656$ and 0.627 , respectively. For $a_{d}$, the opposite is true with the estimate for the slope reaching $\sim 0.42$ compared to 0.724 (Bricaud et al., 1998). When combined in $a_{p}$, the above trends tend to compensate and the slope is $\sim 0.71$ which is closer to 0.635 of Bricaud et al. (1998). In other words, the total absorption by particles is similar, but for low chlorophyll the relative contribution of phytoplankton (detritus) is lower (higher) for the dataset considered in this thesis while for high $<$ chl $>$ it is the opposite. 
Several empirical algorithms were evaluated to assess their accuracy in retrieving the chlorophyll measurements and to compare their performance to the one of a semianalytical model. The models selected include those of Morel (1988), CZCS, OCTS-C and SeaWiFS (OC2v2) which yield high correlation between measured/modeled chlorophyll concentrations $\left(r^{2}>0.83\right)$. The algorithm of Abbott and Letelier (1997) also shows high correlation between the measured and modeled values but this relationship is far from the 1:1 line. This means that the coefficients in their algorithm (Table 3.1) could easily be changed to better represent the data considered here with the same high correlation and a better one-to-one correspondence. The reason for the non ideal slope (far from 1) of the Abbott and Letelier (1997) algorithm is probably due to the limited, and non-representative (even for the California Current) observations from which the coefficients were estimated.

The performance of the semi-analytical model of Garver and Siegel (1997), using $a_{p h}{ }^{*}$ and $S$ values obtained from literature or from the data, is lower than the one of empirical models both in terms of correlation and slope/intercept of the regression between measured and modeled chlorophyll concentrations. The reason for this result originates from the fact that the data considered here are heterogeneous, as shown before in terms of large geographical variations of optical properties. A better estimation of chlorophyll, in terms of slope and intercept, was obtained using a power law (35) to relate $a_{p h}$ and $\langle c h l\rangle$, as suggested by the data. The correlation, however, was not significantly improved.

In order to obtain information on other constituents (detritus and CDOM) in 
addition to $<c h l>$ from remote sensing reflectance measurements, the semi-analytical model was applied to four different subsets of data: Coastal, Indian, Pacific $\left(10^{\circ} \mathrm{N}-40^{\circ} \mathrm{S}\right)$ and combined South Pacific and Atlantic. This partition was based on the distribution of optical properties, e.g., $a_{p h}{ }^{*}$ and $S$, versus chlorophyll. Coastal and Indian stations have low $a_{p h}{ }^{*}$ and high $S$, but they were separated due to their difference in $\langle c h l\rangle$ and relative detritus absorption. When the model was applied to the South Pacific and Atlantic data, a group of stations could be identified in the Pacific between $10^{\circ} \mathrm{N}$ and $40^{\circ} \mathrm{S}$ for which the modeled $\langle$ chl $>$ exceed largely the measurements. Hence, they were treated separately. Note that the $a_{p h}{ }^{*}$ spectra and $S$ values adopted for the four regions were chosen to optimize the agreement between modeled parameters (e.g., $\left.\langle c h l\rangle, a_{d m}(443)\right)$ and corresponding measured quantities.

Another quantitative way to estimate the efficiency of the empirical and semianlytical models in retrieving chlorophyll concentration is to compute the relative difference between measured and modeled concentrations:

$$
\text { Relative difference }=\left(\langle c h l\rangle_{\text {meas. }}-\langle c h l\rangle_{\text {mod. }}\right) /\langle c h l\rangle_{\text {meas. }} .
$$

The mean and standard deviation of this relative difference are listed in Table 6.1. Notice first that the CZCS algorithm (Table 3.1) underestimates <chl> significantly by more than $49 \pm 32 \%$ in all the regions. Better results could be obtained without subtracting the effects of phaepigments as shown with black dots in Fig. 5.13e. The empirical model of Abbott and Letelier (1997) underestimates (62 $\pm 19 \%)$ and overestimates $(-76 \pm 51 \%)$ chlorophyll for the coastal and Pacific $\left(10^{\circ} \mathrm{N}-40^{\circ} \mathrm{S}\right)$ stations, respectively. All the other 
models, including the semi-analytical one, do not show a significant mean relative difference, except for the Indian Ocean where the empirical algorithms (OC2v2 and Morel) underestimate chlorophyll by more than $30 \%$ and the semi-analytical model overestimates chlorophyll by $64 \%$. For the best models (e.g, OC2v2 for coastal and Pacific stations, and the semi-analytical model for all stations except in the Indian Ocean), the relative difference between measured and modeled $<c h l>$ is bounded by about $\pm 50 \%$.

Table 6.1: Relative difference between measured and modeled chlorophyll concentrations (in percent) for several empirical and semi-analytical models applied to the same number of common stations.

\begin{tabular}{|l|cc|cc|cc|cc|}
\hline & \multicolumn{2}{|c|}{ Coastal } & \multicolumn{2}{c|}{ Pacific (10N-40S) } & \multicolumn{2}{c|}{ Indian } & \multicolumn{2}{c|}{ Atlantic and S. Pacific } \\
& mean & std & mean & std & mean & std & mean & std \\
\hline OC2V2 & $-1 \%$ & $62 \%$ & $9 \%$ & $53 \%$ & $34 \%$ & $24 \%$ & $16 \%$ & $36 \%$ \\
Morel & $-29 \%$ & $61 \%$ & $18 \%$ & $34 \%$ & $32 \%$ & $22 \%$ & $-18 \%$ & $58 \%$ \\
CalCOFI & $-24 \%$ & $67 \%$ & $-17 \%$ & $59 \%$ & $18 \%$ & $29 \%$ & $-8 \%$ & $49 \%$ \\
Abbott & $62 \%$ & $19 \%$ & $-76 \%$ & $51 \%$ & $-39 \%$ & $52 \%$ & $26 \%$ & $64 \%$ \\
CZCS & $49 \%$ & $32 \%$ & $57 \%$ & $18 \%$ & $65 \%$ & $11 \%$ & $50 \%$ & $25 \%$ \\
OCTS-C & $-19 \%$ & $61 \%$ & $14 \%$ & $45 \%$ & $34 \%$ & $17 \%$ & $-3 \%$ & $59 \%$ \\
Semi-Anal & $11 \%$ & $45 \%$ & $-10 \%$ & $34 \%$ & $-64 \%$ & $37 \%$ & $-16 \%$ & $45 \%$ \\
\hline
\end{tabular}

The application of the regular and modified inversion models of Garver and Siegel (1997) to the data provided interesting information about the absorption by dissolved substances (CDOM) which was not directly measured with the spectrophotometric a* method. Dissolved substances in the California coastal waters and the Indian Ocean waters absorb more light than the particulate materials (twice and four times as much, respectively). For the Atlantic and South Pacific open waters absorption by detritus dominates the effects of CDOM. The predominant effect of detritus is mostly 
seen in the Pacific between $10^{\circ} \mathrm{N}$ and $40^{\circ} \mathrm{S}$ (reaching $-51 \%$ ) where it becomes as important as the absorption by phytoplankton. CDOM has little effect is this area. 


\section{CHAPTER 7}

\section{CONCLUSIONS}

Optical data and chlorophyll measurements obtained from most of the word's ocean basins and in California coastal waters between 1993 and 1998 were analyzed to assess the efficiency of empirical algorithms and semi-analytical models in retrieving chlorophyll concentration (and the concentration of detritaldissolved materials for the case of semi-analytical models) from optical measurements.

The major conclusions are as follows:

1) The global dataset considered can be divided in distinct bio-provinces characterized by different optical properties.

2) Semi-analytical models are closed to the empirical ones in terms of accuracy to estimate chlorophyll concentration from optical measurements.

3) Current semi-analytical models are not as effective as empirical models mainly because of geographical variations in the parameters used, $a_{p h}{ }^{*}$ and $S$.

- For $a_{p h}{ }^{*}$, a better understanding is needed on what are the factors affecting the absorption characteristics by phytoplankton, including those related to physiological changes of the cells.

- For $S$, combining absorption by detritus and CDOM into one single exponential decay constant might not be a good approximation. More data are needed to understand the spectral absorption characteristics of detritus and CDOM separately.

4) Nevertheless, the semi-analytical models provide important information about 
relative absorption by other constituents that contribute to remote sensing reflectances. 


\section{LITERATURE CITED}

Abbott, M. R., and R. M. Letelier. 1997. Bio-Optical drifters - Scales of variability of chlorophyll and fluorescence. Proceedings of the Society of Photo-optical Instrumentation Engineers, Ocean Optics XIII 2963: 216-221.

Allali, K, A. Bricaud and H. Claustre. 1997. Spatial variations in the chlorophyllspecific absorption coefficients of phytoplankton and photosynthetically active pigments in the equatorial Pacific. Journal of Geophysical Research 102: $12,413-12,423$.

Austin, R. W. 1974. Inherent spectral radiance signals of the ocean surface. Ocean Color Analysis, SIO ref. 74-10, 2.1-2.20.

Baker, K. S., and R. C. Smith. 1979. Quasi-inherent characteristics of the diffuse attenuation coefficient for irradiance. Proceedings of the Society of Photooptical Instrumentation Engineers, Ocean Optics VI 208: 60-63.

Bates, D. M., and D. G. Watts. 1988. Non-Linear Regration Analysis and Its Applications. New York, John Wiley.

Behrenfeld, M. J., and P. G. Falkowski. 1997. Photosynthetic rates derived from satellite-based chlorophyll concentration. Limnology and Oceanography 42: 120.

Bidigare, R. R., M. E. Ondrusek, J. H. Morrow and D. A. Kiefer. 1990. In vivo absorption properties of algal pigments. Proceedings of the Society of Photooptical Instrumentation Engineers, Ocean Optics X, 1302: 290-302.

Blizard, M. A. 1986. Ocean Optics: Introduction and overview. Proceedings of the Society of Photo-Optical Instrumentation Engineers, Ocean Optics VIII, 637: 2-17.

Bricaud, A., A. Morel and L. Prieur. 1981. Absorption by dissolved organic matter of the sea (yellow substances) in the UV and visible domains. Limnology and Oceanography 26: 43-53.

Bricaud, A., and D. Stramsky. 1990. Spectral absorption coefficients of living phytoplankton and non-algal biogenous matter: A comparison between the Peru upwelling area and Sargasso Sea. Limnology and Oceanography 35: 562-582. 
Bricaud, A., M. Babin, A. Morel and H. Claustre. 1995. Variability in the chlorophyllspecific absorption coefficients of natural phytoplankton: Analysis and parameterization. Journal of Geophysical Research 100(C7): 13,321-13,332.

Bricaud, A., A. Morel, M. Babin, K. Allali and H. Claustre. 1998. Variations of light absorption by suspended particles with chlorophyll-a concentration in oceanic (case 1) waters: Analysis and implications for bio-optical models. Journal of Geophysical Research 103(C13): 31,033-31,044.

Carder, K. L., R. G. Steward, G. R. Harvey and P. B. Ortner. 1989. Marine humic and fulvic acids: Their effects on remote sensing of ocean chlorophyll. Limnology and Oceanography 34(1): 68-81.

Carder, K. L., S. K. Hawes, K. A. Baker, R. C. Smith, R. G. Steward and B. G. Mitchell. 1991. Reflectance model for quantifying chlorophyll-a in the presence of productivity degradation products. Journal of Geophysical Research 96: 20,599-20,611.

Carder, K. L., F. R. Chen, Z. P. Lee, S. K. Hawes and D. Kamykowsky. 1999. Semianalytic Moderate-Resolution Imaging Spectrometer algorithms for chlorophyll-a and absorption with bio-optical domains based on nitratedepletion temperatures. Journal of Geophysical Research 104(C3): 5403-5421.

Chavez, F. P., and S. L. Smith. 1995. Biological and chemical consequences of ocean ocean upwelling. In 'Upwelling in the Ocean: Modern Processes and Ancient Records", C. P. Summerhayes et al. (Eds.), John Wiley \& Sons, 149-169.

Clarke, G. K., G. C. Ewing and C. J. Lorenzen. 1970. Spectra of back scattered light from the sea obtained from aircraft as a measure of chlorophyll concentration. Science 167: 1119-1121.

Evans, R. H., and H. R. Gordon. 1994. Color zone color scanner "system calibration": A retrospective examination. Journal Geophysiscal Research 99: 7293-7307.

Garver, S. A., and D. A. Siegel. 1994. Variability in the near surface particulate absorption spectra: What can a satellite ocean color imager sea? Limnology and Oceanography 39(6): 1349-1367.

Garver, S. A., and D. A. Siegel. 1997. Inherent optical property inversion of ocean color spectra and its biogeochemical interpretation. 1. Time series from the Sargasso Sea. Journal of Geophysical Research 102(C8): 18,607-18,625.

Gordon, H. R. 1989. Can the Lambert-Beer law be applied to the attenuation coefficient of the ocean water? Limnology and Oceanography 34: 1389-1409. 
Gordon, H. R., and A. Morel. 1983. Remote assessment of ocean color for interpretation of satellite visible imagery, a review; Lecture Notes on Coastal and Estuarine Studies. New York, Springer Verlag.

Gordon, H. R., D. K. Clark, J. W. Brown, O. B. Brown, R. H. Evans and W. W. Broenkow. 1983. Phytoplnakton pigment concentration in the Middle Atlantic Bight: comparison between ship determinations and Coastal Zone Color Scanner estimates, Applied Optics 22: 20-36.

Gordon, H. R., O. B. Brown, R. H. Evans, J. W. Brown, R. C. Smith, K. S. Baker and D. K. Clark. 1988. A semianalytic radiance model of ocean color. Journal of Geophysical Research 93: 10,909-10,924.

Hoepffner, N., and S. Sathyendranath. 1993. Determination of the major groups of phytoplankton pigments form the absorption of total particulate matter. Journal of Geophysical Research, 98: 22,789-22,803.

Holm-Hansen, O., C. J. Lorenzen, R. W. Holmes and J. D. H. Strickland. 1965. Fluorometric determination of chlorophyll. J. Cons. Int. Explor. Mer 30: 3-15.

Iturriaga, R. R., and D. Siegel, 1989. Microphotometric characterization of phytoplankton and detrital absorption properties in the Sargasso Sea, Limnology and Oceanography 34(8): 1706.

Kirk, J. T. O. 1976. Yellow substance (gelbstoff) and its contribution to the attenuation of photosynthetically active radiation in some inland and coastal southeastern Australian waters. Australian Journal Marine and Freshwater Research 27: 6171.

Kirk, J. T. O. 1981. Monte Carlo study of the underwater light field in, and the relationships between optical properties of turbid yellow waters. Australian. Journal of Marine and Freshwater Research 32: 517-532.

Kirk, J. T. O. 1994. Light and Photosynthesis in Aquatic Ecosystems. Cambridge, Great Britain, Cambridge University Press, pp. 509.

Kishino, M., M. Takahashi, N. Okami and S. Ichimura. 1985. Estimation of spectra absorption coefficient of phytoplankton in the Sea. Bulletin of Marine Science 37: 634-642.

Lindley, S. T., R. R. Bidigare and R. T. Barber. 1995. Phytoplankton photosynthesis parameters along $140^{\circ} \mathrm{W}$ in the equatorial Pacific. Deep-Sea Research II, 42(23): 441-463. 
Michell, B. G., and M. Kahru. 1998. Algorithms for SeaWiFS developed with the CalCOFI data set. CalCOFI Rep. 39, 26pp.,Calif. Coop. Oceanic Fish. Invest. Rep., La Jolla, California.

Mobley, C. D. 1994. Light and Water: Radiactive Transfer in Natural Waters, Academic, San Diego, California, Academic Press, pp. 592.

Morel, A. 1973. Diffusion de la lumiere par les eaux de mer. Resultats experimentaux et approache theorique, in NATO AGARD lecture series No 61. Optics of the Sea, Chap 3.1, 76pp.

Morel A. 1987. Chlorophyll-specific scattering coefficient of phytoplankton: A simplified theoretical approach. Deep-Sea Research, part A, 34, 1093-1105.

Morel, A. 1988. Optical Modeling of the upper ocean in relation to its biogenous matter content (case I waters). Journal of Geophysical Research 93: 10,74910,768 .

Morel, A. 1991. Optics of marine particles and marine optics, in Particles Analysis in Oceanography, NATO ASI Series, G27, S. Demers, Editor, Springer Verlag, Berlin.

Morel, A., and L. Prieur. 1977. Analysis of variation in ocean color. Limnology and Oceanography 22: 709-722.

OCTS-C. 1996. Science on the GLI mission, Ocean Optics XIII, Halifax, Canada, p. 16.

OReilly, J. E., S. Maritorena, B. G. Michell, D. A. Siegel, K. L. Carder, S. A. Garver, M. Kahru and C. McClain 1998. Ocean color chlorophyll algorithms for SeaWIFS. Journal of Geophysical Research 103(CL1): 24, 937-24,953.

Pope, R. M., and E. S. Fry 1997. Absorption spectrum (380-700 nm) of pure water. II. Integrating cavity measurements. Applied Optics 36(33): 8710-8723.

Preisendorfer, R., W. 1961. Application of radiative transfer theory to light measurements in the sea. Union Geod. Geophys. Inst. monogr., 10: 11-30.

Prieur, L., and S. Sathyendranath , 1981. An optical classification of coastal and oceanic waters based on the specific spectral absorption curves of phytoplankton pigments, dissolved organic matter, and other particulate materials. Limnology and Oceanography 26(4): 671-689. 
Siegel, D. A., and T. D. Dickey 1987. Observations of the vertical structure of the diffuse attenuation coefficient spectrum. Deep-Sea Research 34(4): 547.

Smith, R. C., and K. S. Baker. 1981. Optical properties of the clearest natural water (200-800 nm). Applied Optics 20: 177-184.

Smith, R. C., and K. S. Baker 1986. Analysis of ocean optical data II. Ocean Optics VIII, SPIE 637: 95-100.

Smith, R. C., B. Prezelin, R. R. Bidigare and K. S. Baker. 1989. Bio-optical modelling of photosynthetic production in coastal waters. Limnology and Oceanography 34: 1524-1544.

Stuart, V., S. Sathyendranath, T. Platt, H. Maass and B. D. Irwin. 1998. Pigments and species composition of natural phytoplankton populations: effect on the absorption spectra. Journal of Plankton Research, 20(2): 187-217.

Truper, H. G., and Yentsch. 1967. Use of glass-fibers filters for the rapid preparation of in vivo absorption spectra of photosyntethic bacteria. Journal of Bact. 94 : 1255-1256.

Yentsch, C. S., and D. W. Menzel 1963. A method for the determination of phytoplankton, chlorophyll, and phaeophytin by fluorescence. Deep-Sea Research 10: 221-231. 